Simulação numérica direta de escoamentos sobre superfícies côncavas com transferência de calor 



\title{
Simulação numérica direta de escoamentos sobre superfícies côncavas com transferência de calor
}

\author{
Vinicius Malatesta
}

Orientador: Prof. Dr. Leandro Franco de Souza

Tese apresentada ao Instituto de Ciências Matemáticas e de Computação - ICMC-USP, como parte dos requisitos para obtenção do título de Doutor em Ciências - Ciências de Computação e Matemática Computacional. VERSÃO REVISADA 
Ficha catalográfica elaborada pela Biblioteca Prof. Achille Bassi e Seção Técnica de Informática, ICMC/USP, com os dados fornecidos pelo(a) autor(a)

\begin{tabular}{|c|c|}
\hline \multirow[t]{3}{*}{ M239s } & $\begin{array}{l}\text { Malatesta, Vinicius } \\
\text { Simulação numérica direta de escoamentos sobre } \\
\text { superfícies côncavas com transferência de calor / } \\
\text { Vinicius Malatesta; orientador Leandro Franco de } \\
\text { Souza.-- São Carlos, } 2014 . \\
\quad 86 \text { p. }\end{array}$ \\
\hline & $\begin{array}{l}\text { Tese (Doutorado - Programa de Pós-Graduação em } \\
\text { Ciências de Computação e Matemática Computacional) -- } \\
\text { Instituto de Ciências Matemáticas e de Computação, } \\
\text { Universidade de São Paulo, } 2014 \text {. }\end{array}$ \\
\hline & $\begin{array}{l}\text { 1. Mecânica dos fluidos. 2. Instabilidade } \\
\text { centrífuga. 3. Vórtices de Görtler. 4. Transferência } \\
\text { de calor. 5. Simulação numérica direta. I. Franco de } \\
\text { Souza, Leandro, orient. II. Título. }\end{array}$ \\
\hline
\end{tabular}


À minha esposa Laura, e aos meus filhos gêmeos, Arthur e Murilo com amor 



\section{Agradecimentos}

À FAPESP, pelo apoio financeiro concedido por quadro anos na forma de bolsa de estudo com o processo 2010/00495-1.

À minha querida esposa Laura, que deixou de se dedicar a sua vida acadêmica para me apoiar no meu sonho e cuidar dos nossos filhos, sou imensamente agradecido.

Aos meus pais Líder e Maria, pelos ensinamentos e o amor desprendido sem reservas.

Ao Professor Leandro Franco de Souza, que me recebeu de braços abertos, pela grande orientação, e incentivos essenciais e necessários para a realização desta tese, sem o qual não seria possível. Além de sua amizade e carinho, o qual levarei por todo vida como sendo o meu maior mentor.

Ao Professor Joseph T. C. Liu, que foi meu supervisor durante o estágio de 6 meses de doutorado na Brown University, pela amizade, pelas reuniões semanais seguidas de um bom expresso, e por me dar uma outra visão mundo, além de providenciar que eu tivessse uma confortável estadia.

Aos meus irmãos Fernando, Evandro e Priscila, pela amizade e carinho sempre presente na minha vida.

Ao grande amigo Wallace, que esteve ao meu lado num dos momentos mais difícieis.

Aos amigos do LMAC, pela amizade e o apoio neste desafio.

Ao Instituto de Ciências Matemáticas e de Computação, pela infra-estrutura concedida para a realiza deste trabalho. 



\section{Sumário}

1 Introdução 1

2 Revisão Bibliográfica $\quad 7$

2.1 Instabilidade Hidrodinâmica . . . . . . . . . . . . . . . . . . . 8

2.2 Instabilidade Centrífuga . . . . . . . . . . . . . . . . . . . . . . . . 9

2.3 Instabilidade Secundária . . . . . . . . . . . . . . . . . . . 15

2.4 Vórtices e Transferência de Calor . . . . . . . . . . . . . . . . 18

3 Formulação $\quad 21$

3.1 Sistemas de Coordenadas e Decomposição do Escoamento . . . . . . . . . . 22

3.2 Coordenadas Curvilíneas Ortogonais . . . . . . . . . . . . . 23

3.2.1 Equações de Navier-Stokes em um Sistema de Coordenadas Ortogonais . . . . . . . . . . . . . . . . . . 25

3.3 Formulação Perturbação . . . . . . . . . . . . . . . . . 30

4 Método Numérico 33

4.1 Método Espectral . . . . . . . . . . . . . . . . . . . . . . . 33

4.2 Derivadas Temporais . . . . . . . . . . . . . . . . . . 35

4.3 Derivadas Espaciais . . . . . . . . . . . . . . . . . . . 35

4.3.1 Cálculo da Primeira Derivada . . . . . . . . . . . . . . . . 36

4.3 .2 Cálculo da Segunda Derivada . . . . . . . . . . . . . . . 37

4.4 Equação de Poisson . . . . . . . . . . . . . . . . . . . . . 38

4.5 Condições de Contorno . . . . . . . . . . . . . . . . . . . . 43

5 Verificação e Validação $\quad 45$

6 Resultados 53

6.1 Vórtices de Görtler e transferência de calor . . . . . . . . . . . . . . . 53

6.1.1 Análise da transfêrencia de calor adotando os parâmetros experimentais de Swearingen e Blackwelder [1987] . . . . . . . . . . . 53 
6.1.2 Análise da transferência de calor adotando os parâmetros numéricos de Li e Malik [1995a] . . . . . . . . . . . . . . . . . 55

6.1.3 Análise da transferência de calor adotando os parâmetros experimentais de Momayez et al. [2004a,b] . . . . . . . . . . . 57

6.1.4 Análise da transferência de calor adotando os parâmetros experimentais de Mitsudharmadi et al. [2004, 2005a,b] . . . . . . . . . 66

6.2 Instabilidade secundária e transferência de calor em escoamentos contendo vórtices de Görtler . . . . . . . . . . . . . . . . . . . . . . . . 67

6.2 .1 Modo varicoso . . . . . . . . . . . . . . . . . . 68

6.2 .2 Modo sinuoso . . . . . . . . . . . . . . . 70

$\begin{array}{lll}7 & \text { Conclusões e Trabalhos Futuros } & 77\end{array}$

$\begin{array}{ll}\text { Referências } & 81\end{array}$ 


\section{Lista de Figuras}

1.1 Ilustração do experimento de Reyndols. . . . . . . . . . . . . . . . . . . 2

1.2 Instabilidade de Kelvin-Helmholtz. . . . . . . . . . . . . . . . . . . 4

1.3 Ilustração do experimento de Taylor. . . . . . . . . . . . . . . . . . . 4

1.4 Ilustração dos vórtices de Görtler - Floryan [1982]. . . . . . . . . . . . . 5

1.5 Distribuição da componente de velocidade $u$ em diversas posições $x$. . . . 6

2.1 (a) Escoamento de Taylor-Couette. (b) Escoamento em um canal com curvatura. (c) Escoamento de uma camada limite sobre uma superfície concava - - Drazin e Reid [1981] . . . . . . . . . . . . . . . . . . . . . . . . 10

2.2 Comprimento de onda transversal - $\beta$ em função do número de Görtler - Floryan [1982]. . . . . . . . . . . . . . . . . . . . . . . . . . . 12

2.3 Número de onda característico - $\Lambda$ em função do número de Görtler - Floryan [1982]. . . . . . . . . . . . . . . . . . . . . . . . . . . . . . . . 13

2.4 Ilustração das regiões ascendente e descendente geradas pelos vórtices de Görtler - - Girgis e Liu [2002]. . . . . . . . . . . . . . . . . . . . . . . . . 14

2.5 Transporte do momento para a estrutura vortical desenvolvido experimentalmente - - Peerhossaini [1987] . . . . . . . . . . . . . . . . . . . . . . 14

2.6 Contorno de velocidade realizado numericamente - - Benmalek e Saric [1994]. 14

2.7 Distorção do perfil de velocidade para diferentes locais na coordenada $x$ - Benmalek e Saric [1994]. . . . . . . . . . . . . . . . . . . . . . . . 15

2.8 estruturas do tipo varicoso - - Swearingen e Blackwelder [1987]. . . . . . . 17

2.9 estruturas do tipo sinuoso - - Swearingen e Blackwelder [1987]. . . . . . . . 17

3.1 Domínio de integração. . . . . . . . . . . . . . . . . . . . . . 22

3.2 Coordenadas Curvilíneas . . . . . . . . . . . . . . . . . . . 23

4.1 Ilustração do número de pontos utilizado para comunicação. . . . . . . . . 42 
5.1 Comparação da média do coeficiente de atrito na direção transversal. Linha sólida - Presente código. Linha Tracejada - Resuldados numéricos Liu e Lee [1995]. . . . . . . . . . . . . . . . . . . . . . . . . . 46

5.2 Comparação da variação em $x$ da média do de $N u$ na direção $z$ para $\operatorname{Pr}=0,72$. Linha sólida - Presente código. Linha Tracejada - Resuldados numéricos Liu e Lee [1995]. . . . . . . . . . . . . . . . . . 47

5.3 Comparação da variação em $x$ da média do de $N u$ na direção $z$ para $\operatorname{Pr}=7,07$. Linha sólida - Presente código. Linha Tracejada - Resuldados numéricos Liu e Lee [1995]. . . . . . . . . . . . . . . . . . . . 47

5.4 Distruibuição transversal do número de Nusselt, normalizado pelos valores correspondentes a placa plana de Blasius-Pohlhausen com o número de Prandtl $\operatorname{Pr}=0,72$ em três posições. $(x=40--80--120 \mathrm{~cm})$ Linha sólida - Presente código. Linha pontilhada - Resuldados numéricos Liu e Lee $[1995] \ldots \ldots \ldots \ldots$. . . . . . . . . . . . . . . . . . . 48

5.5 Distruibuição transversal do número de Nusselt, normalizado pelos valores correspondentes a placa plana de Blasius-Pohlhausen com o número de Prandtl $\operatorname{Pr}=7,07 . \quad(x=40--80--120 \mathrm{~cm})$ Linha sólida - Presente código. Linha pontilhada - Resuldados numéricos Liu e Lee [1995]. ... . 48

5.6 Distruibuição máxima da amplitude de perturbação. Linha sólida - Presente código. Símbolos - Resuldados experimentais Mitsudharmadi et al. [2004]. . . . . . . . . . . . . . . . . . . . . . . . . . 49

5.7 Contornos de velocidade, $x=350 \mathrm{~mm}$ - - Mitsudharmadi et al. [2004]. . . . 50

5.8 Contornos de velocidade, $x=350 \mathrm{~mm}$. . . . . . . . . . . . . 50

5.9 Contornos de velocidade, $x=500 \mathrm{~mm}$ - - Mitsudharmadi et al. [2004]. . . . 50

5.10 Contornos de velocidade, $x=500 \mathrm{~mm} . \ldots \ldots \ldots$. . . . . . 50

5.11 Contornos de velocidade, $x=600 \mathrm{~mm}$ - - Mitsudharmadi et al. [2004]. . . . 50

5.12 Contornos de velocidade, $x=600 \mathrm{~mm} . \ldots \ldots \ldots$

5.13 Contornos de velocidade, $x=700 \mathrm{~mm}$ - - Mitsudharmadi et al. [2004]. . . . 50

5.14 Contornos de velocidade, $x=700 \mathrm{~mm}$. . . . . . . . . . . . 50

5.15 Contornos de velocidade, $x=745 \mathrm{~mm}$ - - Mitsudharmadi et al. [2004]. . . . 51

5.16 Contornos de velocidade, $x=745 \mathrm{~mm} . \ldots \ldots \ldots 1$

5.17 Contornos de velocidade, $x=805 \mathrm{~mm}$ - - Mitsudharmadi et al. [2004]. . . . 51

5.18 Contornos de velocidade, $x=805 \mathrm{~mm} \ldots \ldots \ldots \ldots$. . . . . 51

5.19 Contornos de velocidade, $x=852 \mathrm{~mm}$ - - Mitsudharmadi et al. [2004]. . . . 51

5.20 Contornos de velocidade, $x=852 \mathrm{~mm} \ldots \ldots \ldots \ldots$. . . . . 51

5.21 Contornos de velocidade, $x=904 \mathrm{~mm}$ - - Mitsudharmadi et al. [2004] . . . 51

5.22 Contornos de velocidade, $x=904 \mathrm{~mm} . \ldots \ldots \ldots$. . . . . 51 
6.1 Distribuição de energia na direção longitudinal para cada modo de Fourier transversal. Comprimento de onda transversal fundamental de $\lambda_{z}=0,18$. . 54

6.2 Contornos de isovelocidade (linhas tracejadas) e isotemperatura (linhas sólidas) no plano $z y$ em $R e_{x}=3,2 \times 10^{5}$ para $\lambda_{z}=0,18$. . . . . . . . . . 55

6.3 Evolução na direção longitudinal da média do número de Stanton na direção transversal para $\lambda_{z}=0,18 \ldots \ldots \ldots \ldots \ldots \ldots$. . . . . . . . . . 55

6.4 Distribuição de energia na direção longitudinal para cada modo de Fourier transversal. Comprimento de onda transversal fundamental de $\lambda_{z}=0,09$. $\quad 56$

6.5 Contornos de isovelocidade (linhas tracejadas) e isotemperatura (linhas sólidas) no plano $z y$ em $R e_{x}=3,2 \times 10^{5}$ para $\lambda_{z}=0,09$. . . . . . . . . . 57

6.6 Evolução na direção longitudinal da média do número de Stanton na direção transversal para $\lambda_{z}=0,09 \ldots \ldots \ldots \ldots$. . . . . . . . . 57

6.7 Distribuição de energia na direção longitudinal para cada modo de Fourier transversal. Comprimento de onda transversal fundamental de $\lambda_{z}=0,36$. $\quad 58$

6.8 Contornos de isovelocidade (linhas tracejadas) e isotemperatura (linhas sólidas) no plano $z y$ em $R e_{x}=3,2 \times 10^{5}$ para $\lambda_{z}=0,36$. . . . . . . . 58

6.9 Evolução na direção longitudinal da média do número de Stanton na direção transversal para $\lambda_{z}=0,36 \ldots \ldots \ldots \ldots \ldots$

6.10 Distribuição de energia na direção longitudinal para cada modo de Fourier transversal. Comprimento de onda transversal fundamental de $\lambda_{z}=0,05 . \quad$. 59

6.11 Contornos de isovelocidade (linhas tracejadas) e isotemperatura (linhas sólidas) no plano $z y$ em em $R e_{x}=3,32 \times 10^{5}$ para $\lambda_{z}=0,05$. . . . . . . 60

6.12 Evolução na direção longitudinal da média do número de Stanton na direção transversal para $\lambda_{z}=0,05 \ldots \ldots \ldots \ldots$. . . . . . . . . . 6 60

6.13 Distribuição de energia na direção longitudinal para cada modo de Fourier transversal. Comprimento de onda transversal fundamental de $\lambda_{z}=0,10$. .

6.14 Contornos de isovelocidade (linhas tracejadas) e isotemperatura (linhas sólidas) no plano $z y$ em $R e_{x}=3,32 \times 10^{5}$ para $\lambda_{z}=0,10$. . . . . . . . 61

6.15 Evolução na direção longitudinal da média do número de Stanton na direção transversal para $\lambda_{z}=0,10 \ldots \ldots \ldots \ldots \ldots$. . . . . . . . . . . .

6.16 Distribuição de energia na direção longitudinal para cada modo de Fourier transversal. Comprimento de onda transversal fundamental de $\lambda_{z}=0,15$. .

6.17 Contornos de isovelocidade (linhas tracejadas) e isotemperatura (linhas sólidas) no plano $z y$ em $R e_{x}=3,32 \times 10^{5}$ para $\lambda_{z}=0,15$. . . . . . . . .

6.18 Evolução na direção longitudinal da média do número de Stanton na direção transversal para $\lambda_{z}=0,15 \ldots \ldots \ldots \ldots \ldots$

6.19 Distribuição de energia na direção longitudinal para cada modo de Fourier transversal. Comprimento de onda transversal fundamental de $\lambda_{z}=0,20$. . 
6.20 Contornos de isovelocidade (linhas tracejadas) e isotemperatura (linhas sólidas) no plano $z y$ em $R e_{x}=3,32 \times 10^{5}$ para $\lambda_{z}=0,20$. . . . . . . . 64

6.21 Evolução na direção longitudinal da média do número de Stanton na direção transversal para $\lambda_{z}=0,20 \ldots \ldots \ldots \ldots$. . . . . . . . . . 64

6.22 Distribuição de energia na direção longitudinal para cada modo de Fourier transversal. Comprimento de onda transversal fundamental de $\lambda_{z}=0,25$. . 65

6.23 Contornos de isovelocidade (linhas tracejadas) e isotemperatura (linhas sólidas) no plano $z y$ em $R e_{x}=3,32 \times 10^{5}$ para $\lambda_{z}=0,25$. . . . . . . . 65

6.24 Evolução na direção longitudinal da média do número de Stanton na direção transversal para $\lambda_{z}=0,25 \ldots \ldots \ldots \ldots \ldots$. . . . . . . . . 65

6.25 Distribuição de energia na direção longitudinal para cada modo de Fourier transversal. Comprimento de onda transversal fundamental de $\lambda_{z}=0,30$. 66

6.26 Contornos de isovelocidade (linhas tracejadas) e isotemperatura (linhas sólidas) no plano $z y$ em $R e_{x}=3,32 \times 10^{5}$ para $\lambda_{z}=0,30$. . . . . . . 66

6.27 Evolução na direção longitudinal da média do número de Stanton na direção transversal para $\lambda_{z}=0,30 \ldots \ldots \ldots$. . . . . . . . . . 67

6.28 Evolução na direção longitudinal da média do número de Stanton na direção transversal para o número de onda $\lambda_{z}=0,02 . . . . .67$

6.29 Amplitude máxima de cada velocidade $u$ na direção longitudinal para cada frequência sobre o plano $(x, y) \ldots \ldots \ldots$. . . . . . . . . . 69

6.30 Isocontorno da perturbação da velocidade longitudinal não estacionária e as isolinhas do escoamento de Görtler no plano $z y$ em $R e_{x}=1,4 \times 10^{5}$. . . 69

6.31 Isocontornos obtidos com $Q=0.5$ colorida pela temperatura $(\theta)$ e a distribuição de temperatura no corte $z \times y \ldots \ldots \ldots$. . . . . . . 70

6.32 Isocontornos obtidos com $Q=0.5$ colorida pela temperatura $(\theta)$ e a distribuição de temperatura no corte $z \times y$. . . . . . . . . . . . 71

6.33 Evolução na direção longitudinal da média do número de Stanton na direção transversal. . . . . . . . . . . . . . . . . . . . 72

6.34 Amplitude máxima de cada velocidade $u$ na direção longitudinal para cada frequência sobre o plano $(x, y) \ldots \ldots . \ldots$. . . . . . . . . 72

6.35 Isocontorno da perturbação da velocidade longitudinal não estacionária e as isolinhas do escoamento de Görtler no plano $z y$ em $R e_{x}=1,5 \times 10^{5}$. . . 73

6.36 Isocontornos obtidos com $Q=0.5$ colorida pela temperatura $(\theta)$ e a distribuição de temperatura no corte $z \times y \ldots \ldots \ldots$. . . . . . 74

6.37 Isocontornos obtidos com $Q=0.5$ colorida pela temperatura $(\theta)$ e a distribuição de temperatura no corte $z \times y \ldots \ldots \ldots \ldots$. . . . . . . 75 


\section{Resumo}

Escoamentos sobre superfícies côncavas estão sujeitos à instabilidade centrífuga, dando origem a vórtices longitudinais, conhecidos como vórtices de Görtler. Esses vórtices são responsáveis por gerar distorções fortes nos perfis de velocidade. Como os vórtices são contra-rotativos, duas regiões surgem entre os mesmos: uma região de upwash e uma região de downwash. Na região de upwash o fluido próximo à parede é jogado para longe da mesma. Na região de downwash acontece o contrário, o fluido que se desloca a uma velocidade maior é jogado em direção à parede. Os vórtices se amplificam inicialmente de forma linear. À jusante, na região não linear de desenvolvimento dos vórtices, a amplitude dos mesmos já é elevada, e há a formação de uma estrutura do tipo cogumelo com a distribuição da componente de velocidade na direção principal do escoamento. Essa nova distribuição de velocidade é tridimensional e difere em muito da camada limite obtida com a solução das equações de Blasius. Levando-se em consideração a camada limite térmica, já foi observado que, na média, há um aumento de transferência de calor na direção da parede. No presente trabalho, é verificado numericamente a transferência de calor na presença de vórtices de Görtler. Para tal, foi desenvolvido e implementado um código de simulação numérica direta espacial (DNS - do inglês Direct Numerical Simulation). Os resultados deste trabalho mostram a intensificação da transferência de calor através dos vórtices de Görtler, tanto no regime não-linear como na instabilidade secundária.

Palavras-chave: vórtices de Görtler, tranferência de calor, transição laminarturbulento, simulação numérica direta, método de diferenças finitas compactas, método espectral, computação paralela. 



\section{Abstract}

Flows over concave surfaces are subject to centrifugal instability. It gives rise to streamwise vortices known as Görtler vortices. These vortices are responsible for generating strong distortions in the velocity profiles. As the vortices are counterrotating, two regions arise between them: a region of upwash and a region of downwash. In the upwash region, the fluid near the wall is convected away from it. In the downwash region the opposite happens, the fluid moving at a faster speed is moved towards the wall. The vortices initially amplify linearly in the downstream. When their amplitude is already high, in the non-linear development region, a mushroomtype structure, with the velocity distribution in the main flow direction, is formed. This new three-dimensional velocity distribution is different from the boundary layer obtained with the solution of Blasius equations. Taking into account a thermal boundary layer, on average, an increase in the heat transfer in the wall direction has been observed. In the present work, it is verified numerically the heat transfer in the presence of Görtler vortices. A simulation code was developed and implemented using Direct Numerical Simulation (DNS). The results of this work show the intensification of heat transfer through the Gortler vortices both in the non-linear regime and in the secondary instability.

Keywords: Görtler vortices, heat transfer, laminar-turbulent transition, direct numerical simulation, compact finite difference schemes, spectral method, parallel computing. 



\section{Capítulo 1 \\ Introdução}

A distinção entre um sólido e um fluido é baseada na capacidade da substância resistir a uma tensão de cisalhamento (ou tangencial) aplicada. Quando uma pequena força de cisalhamento constante é aplicada, o sólido eventualmente para de deformar-se num certo ângulo de deformação fixo, enquanto o fluido se deforma continuamente, e a taxa de deformação tende para uma certo valor. A mecânica dos fluidos é definida como a ciência que trata do comportamento dos fluidos em repouso (estática dos fluidos) e em movimento (dinâmica dos fluidos) e da interação entre fluidos e sólidos ou entre fluidos.

O estudo de mecânica dos fluidos é amplamente usado tanto em atividades do cotidiano como em modernos projetos de engenharia, de mangueiras para irrigar um jardim a aeronaves complexas. A mecânica dos fluidos desempenha um papel fundamental no corpo humano, como no coração que está bombeando sangue para todas as partes do corpo humano através das artérias e veias. Ela também pode ser aplicada a projetos de engenharia como: embarcações, aeronaves e espaçonaves, usinas termelétricas, automóveis, turbinas eólicas e inúmeras outras aplicações industriais, além de estar ligada a fenômenos naturais, como ciclo de chuvas, padrões de clima, ondas no oceano e etc.

Um dos primeiros problemas em engenharia, que a humanidade enfrentou, foi o suprimento de água para uso nas cidades que foram se desenvolvendo. Os aquedutos romanos, alguns dos quais ainda estão em uso, são os melhores exemplos conhecidos. A contribuição mais antiga nesta área foi feita pelo matemático grego Arquimedes (285-212 A.C.), o qual, formulou e aplicou o princípio do empuxo para determinar o teor de ouro da coroa do Rei Hiero I.

Durante a idade média a aplicação da hidráulica expandiu-se vagarosamente, porém foram criadas bombas e pistões para remover água das minas e moinhos movidos a água e a vento sendo aperfeiçoados para moer grãos. Tais invenções possibilitaram assim poste- 
riormente a revolução industrial, onde a maioria dos criadores do progresso permanecem desconhecidos.

Durante o período da renacença, com a introdução e aplicação do método científico, Simon Stevin (1548-1617), Galileo Galilei (1564-1642) e Evangelista Torricelli (1608-1647) aplicaram o método científico aos fluidos ao investigarem as distribuições de pressão e vácuo, o qual foi integrado e refinado pelo matemático e físico Blaise Pascal (1623-1662). O grande físico Sir Isaac Newton (1643-1727), aplicou suas leis aos fluidos e explorou a inércia e resistência dos fluidos, viscosidade e jatos livres. Tal esforço, foi ampliado pelo grande matemático Daniel Bernoulli (1700-1782) e pelo brilhante matemático e físico Leornard Euler (1707-1783). Juntos, o trabalho deles definiu as equações de energia e momento. Bernoulli, em 1738, publicou um trabalho intitulado Hydrodynamic, este pode ser considerado o primeiro texto sobre mecânica dos fluidos.

No século XIX, avanços fundamentais eclodiram. Jean Poiseuille (1799-1869) mediu com precisão escoamentos em tubos capilares de fluidos múltiplos, já Gotthilf Hagen (17971884) definiu a diferença entre escoamento laminar e turbulento em tubulações. Osborne Reynolds (1842-1919) continuou esse trabalho e desenvolveu o número adimensional que leva seu nome. Enfim, de modo similar, em paralelo a Louis Navier (1785-1836), George Stokes (1819-1903) completaram as equações gerais do movimento dos fluidos com atrito.

O estudo da instabilidade tem início com o artigo clássico de 1883 de Osborne Reynolds, ele estudou o escoamento em tubos e investigou o fenômeno da transição de escoamento laminar para escoamento turbulento. Na figura 1.1 é mostrado o desenho de fluxo do experimento, onde temos: $(a)$ - fluxo laminar em um tubo; $(b)$ - transição para o fluxo turbulento em um tubo; $(c)$ - transição para o fluxo turbulento sendo iluminado por uma centelha. Reynolds utilizou um traçador no centro de dutos de vidro para visualização do escoamento. Verificou-se que, de acordo com um parâmetro adimensional, que levou seu próprio nome (o número de Reynolds) existe um valor crítico no qual, um fluxo laminar se torna turbulento.

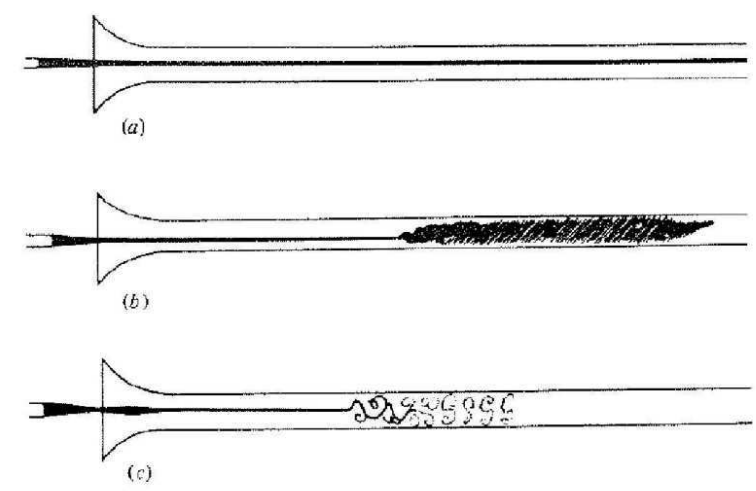

Figura 1.1: Ilustração do experimento de Reyndols.

Em 1880, Lord Rayleigh (1842-1919) estudou as equações para escoamento invíscido 
em um canal, onde deduziu um teorema que mostra que para um escoamento invíscido incompressível, um ponto de inflexão no perfil de velocidade médio do escoamento paralelo é condição necessária de instabilidade.

O estudo teórico da propagação de pertubações numa camada limite foi realizado independentemente por Willian MacFadden Orr (1866-1934) em 1907 e por Arnold Johannes Sommerfeld (1868-1951), em 1908, dando origem a hoje conhecida equação de Orr-Sommerfeld. Os primeiros pesquisadores que demostraram que a equação de OrrSommerfeld tem pertubações instáveis para escoamentos sem pontos de inflexão foram Water Tollmien (1900-1968) e Hermann Schlichting em 1933. Em homenagem a estes dois pesquisadores, as ondas não estacionárias que se propagam sobre a camada limite são denominadas ondas de Tollmien-Schlichting.

Sob a orientação de Arnold Johannes Sommerfeld, Werner Karl Heisenberg (19011976), com apenas 23 anos, publicou sua tese de doutorado em soluções estáveis e turbulentas para equação viscosa. Ele conclui que a equação de Orr-Sommerfeld permite soluções instáveis, estabelecendo, também, a ordem de grandeza do número de Reynolds crítico para o perfil de um escoamento de Poiseuille usando um método assintótico.

Um outro problema de instabilidade hidrodinâmica importante ocorre em camadas cisalhantes livres, o qual é um processo de fundamental importância em escoamentos geofísicos e de engenharia. O estudo acadêmico deste problema é feito através de um problema padrão: a camada de mistura. A camada de mistura desenvolve-se na interface de duas correntes paralelas de fluidos que se movem horizontalmente em velocidade diferentes. O perfil de velocidade do escoamento é instável a pequenas pertubações devido a presença de um ponto de inflexão. Esta instabilidade primária, caracterizada pela formação de vórtices e que se denomina instabilidade de Kelvin-Helmholtz $(K-H)$ em homenagem aos seus criadores Herman Ludwig Ferdinand von Helmholtz (1821-1894), que postulou este estudo sobre escoamento invícido em 1868 e resolvido por William Thomson (1824-1907)- Lord Kelvin em 1871. A instabilidade $(K-H)$ é encontrada frequentemente acima da troposfera e abaixo da estratosfera, como ilustrado na figura 1.2, e no encontro dos rio Negro e Solimões.

A primeira teoria sobre instabilidade em dinâmica de fluidos onde estão presentes forças de curvatura foi elaborada por Lord Rayleigh em 1916. Em 1923, Geoggrey Ingham Taylor (1886-1975) estudou teoricamente e experimentalmente o comportamento de escoamentos entre cilindros concêntricos rotativos e mostrou a existência de instabilidades causadas pelo efeito centrífugo que acarretavam na transição do escoamento inicial para um regime laminar caracterizado pelo movimento secundário transversal ao escoamento inicial. Este escoamento é composto por vórtices toroidais contra-rotativos, conforme ilustrado na figura 1.3.

Cinco anos mais tarde, W. R. Dean estudou o escoamento em um duto curvo, e demonstrou a existêcia de vórtices contra-rotativos, semelhantes aos vórtices de Taylor. 

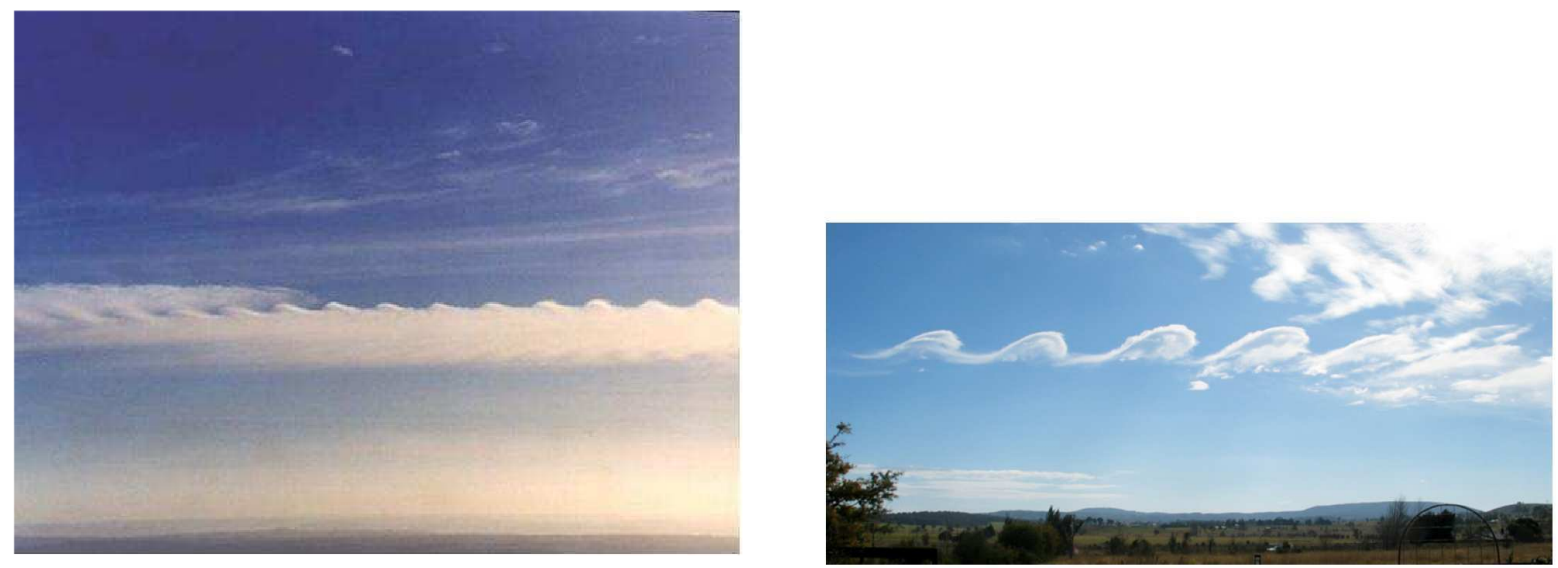

Figura 1.2: Instabilidade de Kelvin-Helmholtz.

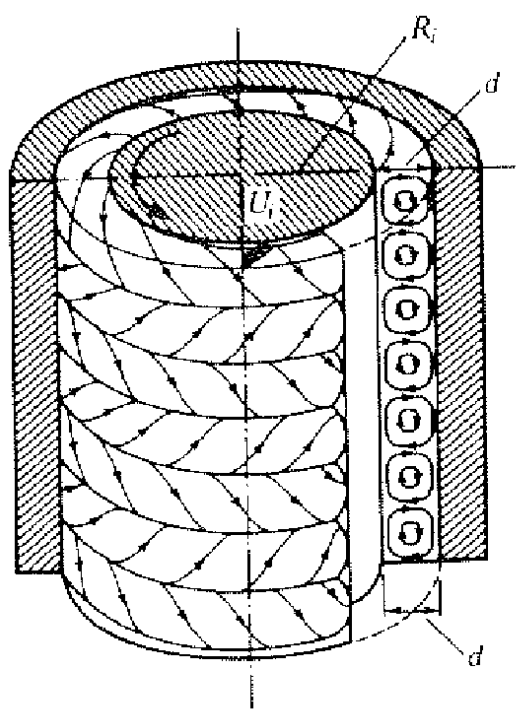

Figura 1.3: Ilustração do experimento de Taylor.

Em 1940, Görtler fez um estudo teórico de camada limite sobre superfícies concavas e mostrou que as forças centrífugas podem levar a um tipo de instabilidade que culmina no aparecimento de vórtices longitudinais contra-rotativos. Estes vórtices são conhecidos atualmente como vórtices de Görtler [1940] e são ilustrados na figura 1.4.

Os vórtices de Görtler são contra-rotativos, e com isto duas regiões são formadas entre os mesmos: uma região de downwash, onde fluido de alta velocidade é impelido na direção perpendicular à parede; e uma região de upwash, onde ocorre o contrário, fluido de baixa velocidade é impelido para fora da camada limite. Este efeito dos vórtices modifica a estrutura da camada limite, fazendo com que a distribuição da componente da velocidade na direção principal do escoamento - $u$, se modifique na direção principal do escoamento $x$ e tenha, na região onde a amplitude dos vórtices já é grande, o formato de cogumelo em um plano normal ao escoamento principal. Diversos perfis do componente 


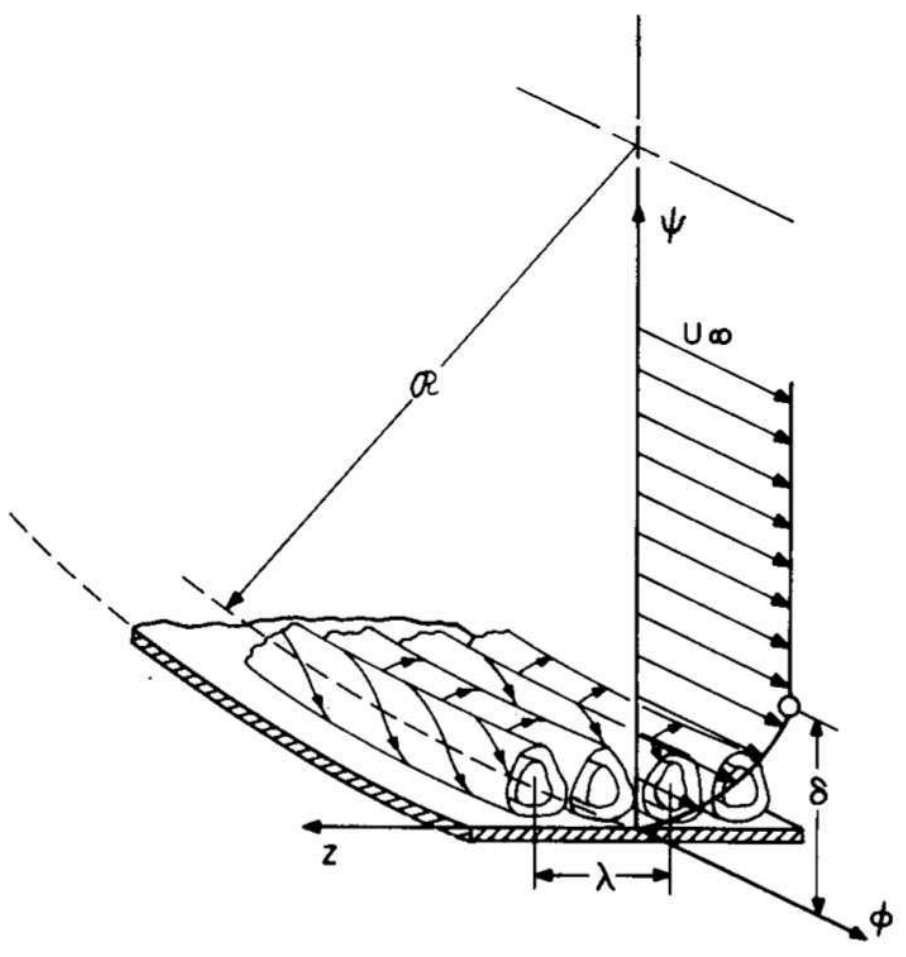

Figura 1.4: Ilustração dos vórtices de Görtler - Floryan [1982].

de velocidade $u$ na direção $x$ são ilustrados na figura 1.5. Nesta figura o escoamento está se deslocando da esquerda para direita, e cada linha apresentada na direção longitudinal representa um nível de velocidade, variando de 0,1 - mais próximo à parede, a 0,9 mais distante da parede. Pode-se observar que a estrutura do escoamento se modifica à medida que os vórtices vão se desenvolvendo. Pode-se observar nesta figura que o último perfil de velocidade já é bastante distorcido, e que nas laterais a distribuição de velocidade encontra-se mais próxima à parede. Isto torna a camada limite menos espessa, tornando mais eficiente a transferência de calor entre o fluido e a parede nesta região.

No presente estudo é analisada a taxa de transferência de calor na presença de vórtices de Görtler. Este estudo é realizado através de simulação numérica direta espacial. Os resultados obtidos foram comparados a outros resultados numéricos para verificação do código e com resultados experimentais para validação do mesmo. Com o presente código obtivemos resultados que avaliam a taxa de transferência e a física do escoamento neste tipo de escoamento. Foi verificado como a taxa de transferência de calor varia de acordo com o tipo de fluido, variando-se para isto o número de Prandtl - Pr. Além disto é verificado como a transferência de calor se comporta na região de instabilidade secundária (do tipo varicosa e sinuosa). 


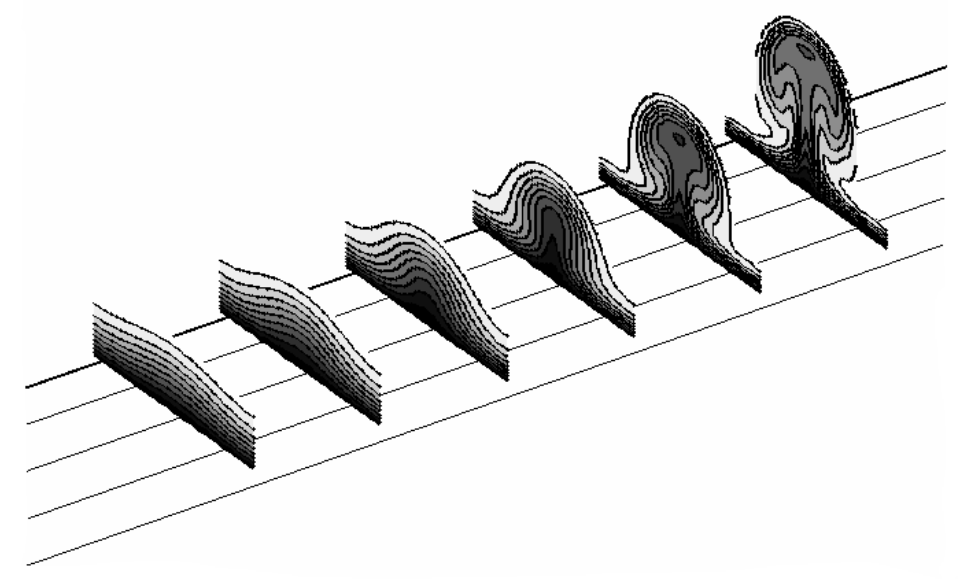

Figura 1.5: Distribuição da componente de velocidade $u$ em diversas posições $x$. 


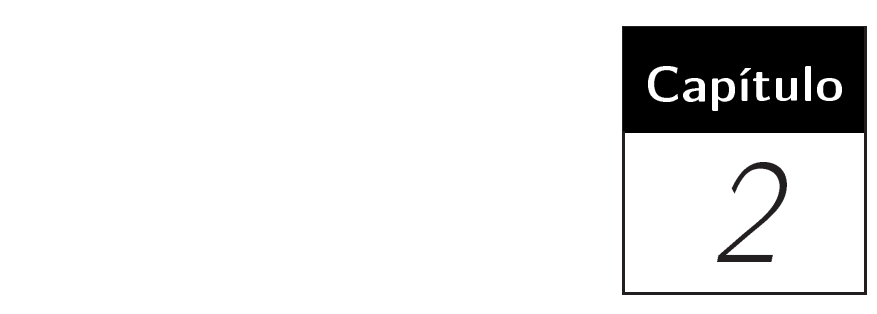

\section{Revisão Bibliográfica}

A maioria dos escoamentos existente na natureza e em aplicações em engenharia são turbulentos. Em muitas aplicações a turbulência é benéfica, porém, em muitos casos deseja-se que o escoamento permaneça no estado laminar. A principal vantagem do escoamento laminar em relação ao escoamento turbulento é que o cisalhamento é menor, acarretando em uma menor força de arrasto do escoamento quando o mesmo se dá sobre superfícies. Portanto, o fenômeno da transição laminar-turbulento de escoamentos é um assunto de intensa pesquisa, pois é de extremo interesse prático prever quando um dado escoamento é laminar ou turbulento. Assim, temos que a transferência de calor e o coeficiente de atrito são muito maiores em um corpo imerso em um escoamento turbulento que num escoamento laminar. Em todos os problemas de transição, uma pertubação é necessária para que a solução estável bifurque para um novo estado estável ou para a turbulência [Bottaro e Zebib, 1997]. Se as pertubações iniciais são de grande amplitude, a transição é abrupta e de forma não-linear. Por outro lado, se as pertubações iniciais forem de pequena amplitude, pode-se estudar a evolução das mesmas no escoamento e a física deste processo.

No presente trabalho, é estudada a intabilidade centrífuga em camada limite sobre superfícies côncavas, que geram vórtices de Görtler e a posterior instabilidade deste escoamento a pertubações não estacionárias, além da análise para a transferência de calor para o estudo da camada limite térmica. Uma descrição destas instabilidades, assim como alguns trabalhos anteriores, são apresentados nas seções 2.1, 2.2, 2.3 e 2.4 a seguir. 


\subsection{Instabilidade Hidrodinâmica}

Uma das primeiras contribuições da transição do escoamento laminar para o escoamento turbulento foi analisada minuciosamente na monografia do Professor Lin [1955] intitulada The Theory of Hydrodynamic Stability, onde descreve-se os aspectos físicos e matemáticos, dando uma ênfase especial em escoamentos de fluidos viscosos sobre uma placa plana, seguidos por Chandrasekhar [1961], Bethov e Criminale [1967], Drazin e Reid [1981] e Swinney e Gollub [1981].

$\mathrm{Na}$ essência, busca-se determinar em que condições uma determinada configuração descrita como fluxo-básico, deixa de ser observada quando restrições tais como o cizalhamento, temperatura, gradientes de pressão são impostas externamente. Em geral, estas restrições externas são quantificadas em termos de parâmetros de controle como o número de Reynolds. O conceito de estabilidade para pertubações explica essa mudança qualitativa do comportamento: em determinadas configurações de parâmetros de controle, a evolução temporal de pertubações infinitesimais linearmente superpostas sobre o fluxo básico no tempo $t=0$ é investigado. Se todas as possíveis pertubações iniciais são temporalmente amortecidas, o fluxo base é dito ser estável. No caso contrário, algumas pertubações aumentam a amplitude e trazem o escoamento em direção a um novo estado de equilíbrio que tem um comportamento qualitativamente distinto: o fluxo base é dito como sendo instável. Sobre estas condições, as perturbações evoluem como uma combinação de crescimento da instabilidade com diferentes frequências e números de onda que são representadas pelas estruturas vorticais observadas experimentalmente. Neste ponto, surge uma transição para um novo escoamento, que geralmente possui mais estruturas (um padrão espacial e/ ou uma variação temporal) que a solução original. Assim, o grande interesse do estudo das instabilidades hidrodinâmicas reside, em parte, na possibilidade de entender estruturas complexas na natureza.

A sensibilidade de muitos escoamentos para perturbações externas torna essencial introduzir os conceitos de instabilidades absolutas ou convectivas, Briggs [1964], Landau e Lifshitz [1987], Huerre e Monkewitz [1990]. Se pertubações iniciais, localizadas a montante e a jusante, se espalham sobre todo o domínio de interesse, o escoamento básico é dito absolutamente instável. Ao contrário, se as pertubações são levadas pelo escoamento, o escoamento é dito como sendo convectivamente instável.

Escoamentos convectivamente instáveis, especialmente a camada de mistura, exibem uma dinâmica complexa: a resposta do fluxo é determinada pela evolução espacial das ondas de instabilidade resultantes da amplificação de uma entrada externa, como seria o caso para um amplificador de ruído. Ao contrário, escoamentos absolutamente instáveis, como esteiras (de bluff-body) podem exibir dinâmica complexa (intrínsica) na forma de um modo global em uma frequência específica.

As noções desenvolvidas acimas são típicas da teoria da intabilidade linear. A fim 
de caracterizar um novo estado emergente na faixa instável dos parâmetros, os efeitos de amplitude finita devem ser levados em conta dentro de uma estrutura não-linear.

As formulações fracamentes não-lineares reduzem a descrição dinâmica para a evolução das pertubações. Aproximações fortemente não-lineares que normalmente são implementadas numericamente, levam a um conhecimento mais completo de estados finitos de amplitude que estão muito distantes da instabilidade primária.

As soluções de amplitudes finitas resultantes dessa intabilidade primária podem ser escolhidas como novos estados básicos, a fim de realizar uma análise da instabilidade secundária. Este processo pode ser repetido para se chegar a um cenário de bifurcações sucessivas conduzido pelo escoamento inicial laminar para o turbulento.

Instabilidades podem ainda ser classificadas de acordo com a natureza do mecanismo físico, como exemplo: a instabilidade primária pode sugir a partir de uma redistribuição puramente invíscida do campo de vorticidade básico na forma da instabilidade de KelvinHelmholtz, ou a partir de um mecanismo de desestabilização mais sutil, paradoxalmente, devido a viscosidade e dando origem as ondas de Tollmien-Schlichting.

A transição e a turbulência são limitadas pelo escoamento cisalhante, esses são conhecidos por terem estruturas vorticais que regem sua dinâmica. O escoamento transicional frequentemente desenvolve-se com resultado de uma instabilidade e desempenha um papel importante na decomposição do escoamento no estado laminar. Uma das estruturas vorticais mais predominantes encontradas em escoamentos cisalhantes de transição e turbulentos são os vórtices contra-rotativos na direção longitudinal.

Klebanoff et al. [1962] mostram que embora as ondas de Tollmien-Schilichting são a solução para a equação de Orr-Sommerfeld, descrevem a instabilidade inicial em camadas limites em fase de transição, uma crescente pertubação $3 D$ se desenvolve rapidamente, a qual é melhor descrita pelos vórtices contra-rotativos na direção longitudinal. Esses vórtices bombeam fluxo de baixa velocidade entre eles e para longe da parede o que leva um perfil de velocidade inflexional.

Experimentos realizados por Bippes [1978] mostraram que o crescimento e a quebra dos vórtices longitudinais, que são gerados numa parede côncava via ao mecanismo de instabilidade de Görtler, são bastante similar aos encontrados nos escoamentos de transição e na turbulência. Vórtices longitudinais gerados desta forma têm importantes vantangens que tornam mais fácil seu estudo. (i) suas escalas físicas são maiores; (ii) elas ocorrem no meio laminar; (iii) elas são estáveis no tempo; (iv) seu mecanismo de origem bem como o ponto de origem é conhecido.

\subsection{Instabilidade Centrífuga}

A instabilidade hidrodinâmica centrífuga pode ocorrer devido a efeitos de rotação ou de superfícies com curvatura [Drazin e Reid, 1981]. Três importantes exemplos de 
escoamentos para este tipo de instabilidade são mostrados na figura 2.1. No escoamento de Taylor-Couette, o fluido é contido entre dois cilindros coaxiais rotativos; o escoamento em um canal curvado devido ao gradiente de pressão atuando ao redor do canal; e a camada limite sobre uma superfície concava (escoamento de Görtler).

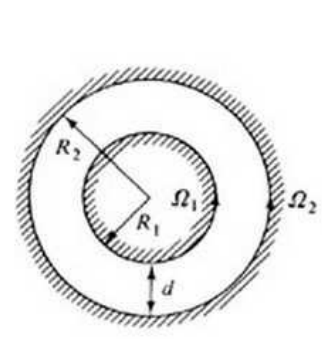

(a)

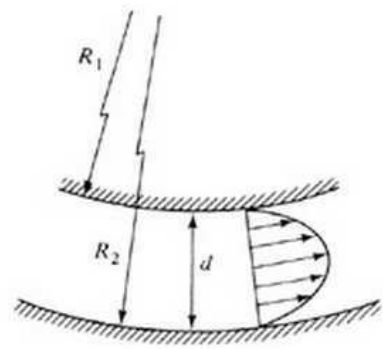

(b)

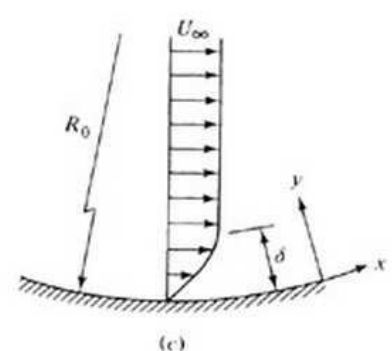

Figura 2.1: (a) Escoamento de Taylor-Couette. (b) Escoamento em um canal com curvatura. (c) Escoamento de uma camada limite sobre uma superfície concava - - Drazin e Reid [1981].

A instabilidade centrífuga ocorre em escoamentos sobre superfícies curvas devido ao desequilíbrio entre o gradiente de pressão na direção normal às linhas de corrente e a força centrífuga atuantes sobre uma partícula de fluido [Li e Malik, 1995b]. Tomando uma partícula qualquer dentro de uma camada limite e a deslocando de sua posição para uma nova posição mais próxima ou mais distante da parede, ela vai se encontrar em uma região de maior ou menor força centrífuga, respectivamente, e em ambos os casos o seu movimento vai ser reforçado. Assim sendo, os escoamentos sobre superfícies côncavas são instáveis a perturbações. Estas perturbações, em aparatos experimentais, podem surgir em função da rugosidade na parede (como uma rugosidade sobre um aerofólio), da turbulência do escoamento externo, de vibrações acústicas (como em superfícies hipersustentadoras da asa de um avião), entre outras fontes de perturbação.

Rayleigh (1917) foi o primeiro pesquisador a estudar o mecanismo invíscido da instabilidade centrífuga. Ele considerou um escoamento de um fluido ínviscido que se movia com velocidade angular $\Omega(r)$, uma função arbitrária da distância $r$ do eixo de rotação. Através de um argumento de simplificação física, ele derivou o critério de instabilidade. O críterio de circulação de Rayleigh afirma que a condição nescessária e suficiente para a existência da instabilidade invíscida e axissimétrica é que a pertubação é o quadrado da circulação e não diminui em qualquer lugar. Para que $\phi \geq 0$ em todo o campo de fluxo, 
onde $\phi$ é o discriminante de Rayleight, definido por:

$$
\phi(r)=\frac{1}{r^{3}} \frac{d}{d r}\left(r^{2} \Omega\right)^{2} .
$$

Rayleigh observou ainda que há uma analogia entre a estabilidade de fluxos de rotação e a estabilidade de um fluido estratificado em repouso em um campo gravitacional.

A instabilidade de um escoamento viscoso entre dois cilindros rotativos foi estudado largamente, tanto teórica como experimentalmente. Couette em 1890, estudou fluidos viscosos, o cilindro de dentro ficava fixo e o de fora girava com uma velocidade angular $\Omega_{2}$, medições de torque exercidas pelo fluido sobre o cilindro de dentro mostrou que é proporcional para $\Omega_{2}$ desde que $\Omega_{2}$ não ultrapasse um determinado valor. Para grandes valores de $\Omega_{2}$ o torque aumenta rapidamente, e esta troca é atribuida da transição do fluxo laminar para o fluxo turbulento.

Taylor 1923 investigou a instabilidade de pertubações infinitesimais axissimétricas. Se dois cilindros contra-rotativos, onde $\Omega_{1}>0$ e $\Omega_{2}>0$, então a instabilidade é prevista se a velocidade angular do cilindro de dentro excede algum valor crítico dependente de $\Omega_{2}$, $r_{1}, r_{2}$ e $\nu$, onde temos que o número de Taylor $(T)$ é dado por:

$$
T=\frac{2\left(\Omega_{1} r_{1}^{2}-\Omega_{2} r_{2}^{2}\right) \Omega d^{3}}{\nu^{2} r_{1}}
$$

Segundo a teoria linear, esta magnitude aumenta o escoamento secundário exponencialmente com o tempo, mas os termos não-lineares eventualmente acabam sendo negligenciados.

Clauser e Clauser [1937] realizaram um trabalho experimental onde foram estudados os efeitos de curvatura côncava e convexa na transição laminar-turbulento. Foi realizada uma análise teórica para a verificação de que um escoamento é mais instável sobre superfícies côncavas do que sobre superfícies convexas e isto foi comprovado experimentalmente. Este foi o primeiro trabalho que mostrou que a curvatura da parede tem um forte efeito na transição de camada limite.

Görtler [1940] tomando como base a análise teórica, mostrou em 1940, a existência de instabilidade centrífuga sobre superfícies côncavas e definiu um parâmetro adimensional que leva seu nome. Na análise feita por Görtler, baseada em evidências experimentais, assumiu-se o escoamento como sendo uma superposição de camada limite e pares de vórtices contra-rotativos, cujos centros eram paralelos à direção do escoamento principal, como mostra a figura 1.4.

Görtler, no seu estudo, considerou o escoamento médio paralelo à parede e as interações das perturbações infinetesimais. Introduzindo estas simplificações nas equações de NavierStokes, ele chegou no sistema de duas equações acopladas para $u$ e $v$, escritas abaixo: 


$$
\begin{aligned}
\nu \frac{\partial^{2} u}{\partial y^{2}}-\left(\alpha_{i}+\nu \beta^{2}\right) u & =v \frac{\partial \bar{u}}{\partial y} \\
\nu \frac{\partial^{4} u}{\partial y^{4}}-\left(\alpha_{i}+\nu \beta^{2}\right) \frac{\partial^{2} u}{\partial y^{2}}+\beta^{2}\left(\alpha_{i}+\nu \beta^{2}\right) v & =\frac{2 \beta^{2} \bar{u}}{R} u
\end{aligned}
$$

onde $u$ e $v$ são componentes de perturbação de velocidade das direções longitudinal $(x)$ e normal à parede $(y)$, respectivamente, $\bar{u}$ é a velocidade média na direção longitudinal, $\nu$ é a viscosidade cinemática, $\beta$ é o comprimento de onda na direção transversal, $\alpha_{i}$ é a taxa de amplificação da pertubação e $R$ é o raio de curvatura da parede. Resolvendo este sistema de equações, Görtler encontrou um diagrama de estabilidade para o escoamento sobre placas côncavas, que foi posteriormente realizado por Floryan [1982], conforme ilustrado na figura 2.2. Este gráfico mostra o número de onda transversal $(\beta)$ em função do número de Görtler $(G o)$. As linhas mais grossas correspondem a valores constantes de $\alpha_{i}$. Nos seus estudos, Görtler também encontrou outro adimensional, que é conhecido como comprimento de onda característico $(\Lambda)$, definido pela equação 2.4 :

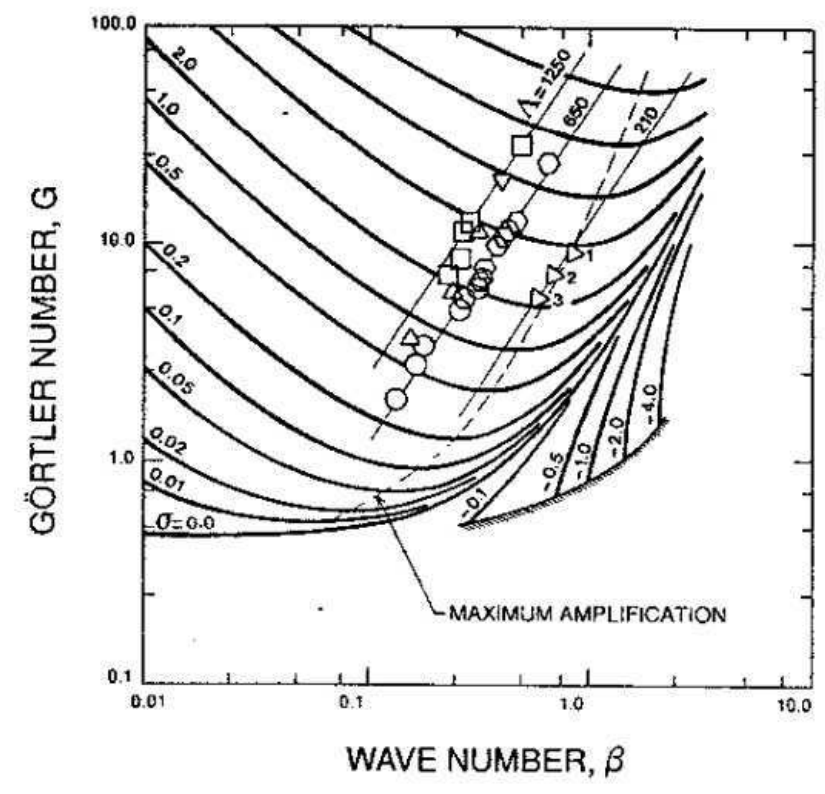

Figura 2.2: Comprimento de onda transversal - $\beta$ em função do número de Görtler - - Floryan [1982].

$$
\Lambda=\frac{U_{\infty} \lambda_{z}}{\nu} \sqrt{\frac{\lambda_{z}}{R}},
$$

onde $\lambda_{z}$ é o comprimento de onda na direção transversal ao escoamento e $U_{\infty}$ é a velocidade do escoamento fora da camada limite. Estudando-se o digrama de estabilidade de Görtler, pôde-se verificar que os vórtices que apresentam maior taxa de amplificação têm valor de comprimento de onda característico em torno de 210. Os valores das taxas de amplificação 
diminuem para valores de $\Lambda$ menores ou maiores que este valor $(\Lambda=210)$. A figura 2.3 mostra o gráfico de comprimento de onda característico em função do número de Görtler.

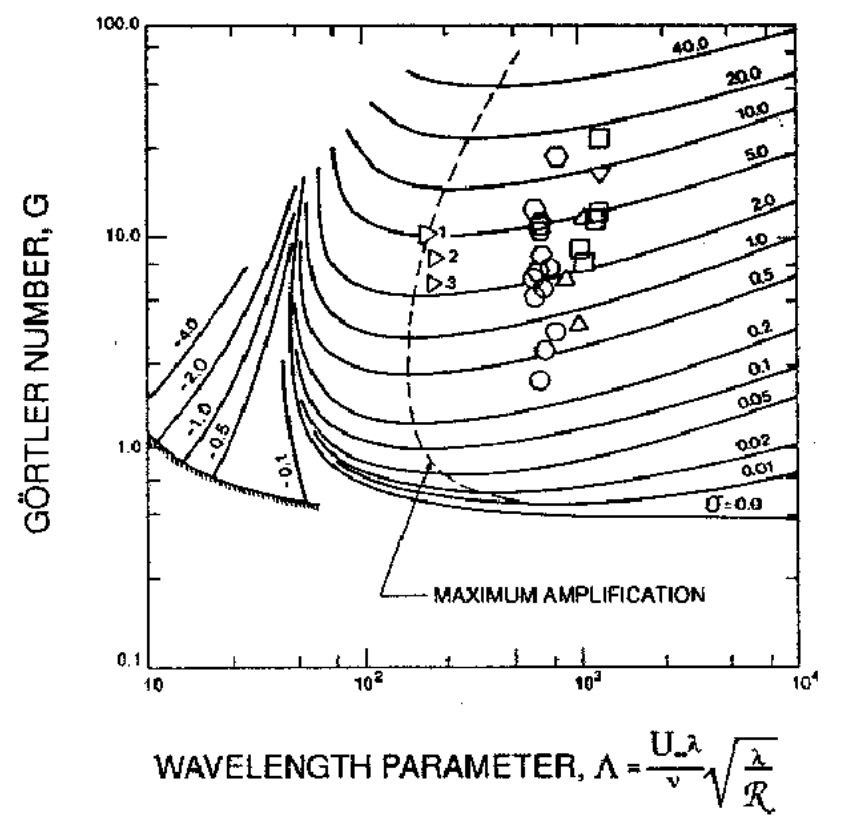

Figura 2.3: Número de onda característico - $\Lambda$ em função do número de Görtler - - Floryan [1982].

Na figura 2.4 pode-se observar que os vórtices contra-rotativos têm um efeito de alterar a distruibuição do componente de velocidade na direção longitudinal. Assim duas regiões são formadas: uma região ascendente, ou do termo inglês upwash, e uma região descendente, ou do termo inglês downwash. Na região ascendente o fluido próximo à parede é jogado para longe da mesma. Na região de descendente acontece o contrário, o fluido que se desloca a uma velocidade maior é jogado em direção à parede. Os vórtices se amplificam inicialmente de forma linear e à jusante quando a amplitude dos mesmos já é elevada, na região não-linear de desenvolvimento dos mesmos, há a formação de uma estrutura do tipo cogumelo com a distribuição da componente de velocidade na direção principal do escoamento.

Esta distribuição é verificada experimentalmente por Peerhossaini [1987], como mostra a figura 2.5, onde o fluido de cor clara é visualizado por fluorecência a laser. A figura 2.6 mostra um típico desenvolvimento não-linear realizado por Benmalek e Saric [1994], onde pesquisadores como Sabry e Liu [1991], Lee e Liu [1992], Liu e Domaradzki [1993] e Guo e Finlay [1994], obtiveram resultados semelhantes. Pode-se claramente ver uma grande distorção devido as mudanças no momento linear.

A consequência deste comportamento é mostrado na figura 2.7, que mostra perfis de velocidades em diferente posições longitudinais na região ascendente. Pode-se notar o desenvolvimento dos perfis de velocidade altamente inflexionais que podem dar origem à instabilidade de Rayleigh na região ascendente. 


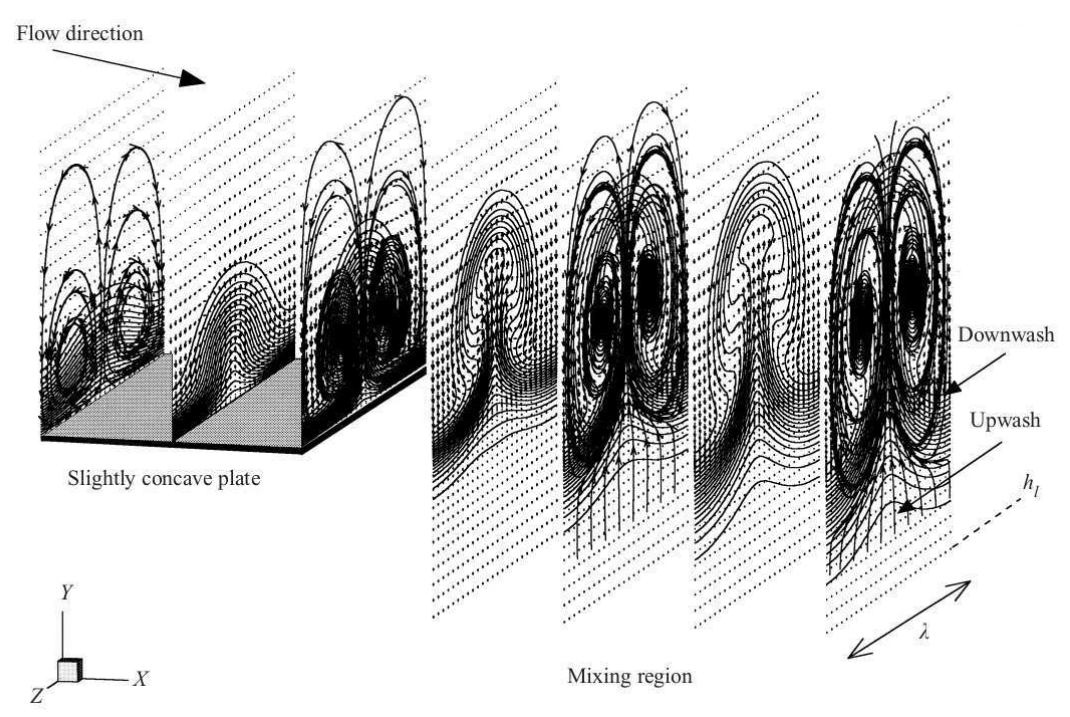

Figura 2.4: Ilustração das regiões ascendente e descendente geradas pelos vórtices de Görtler - Girgis e Liu [2002].

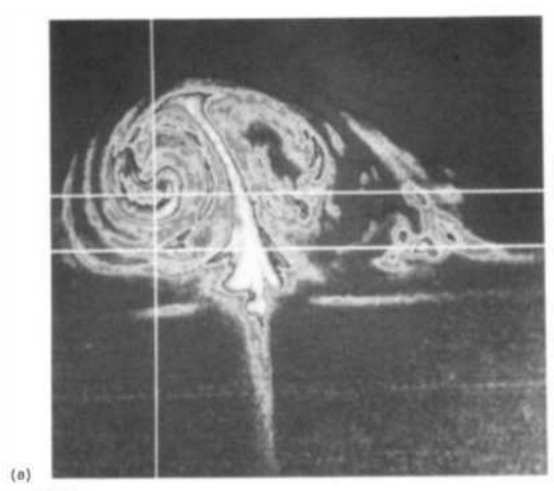

Figura 2.5: Transporte do momento para a estrutura vortical desenvolvido experimentalmente - - Peerhossaini [1987].

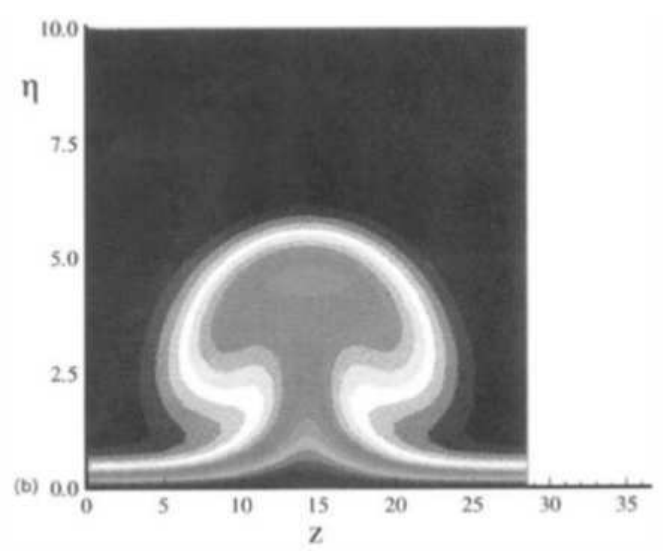

Figura 2.6: Contorno de velocidade realizado numericamente - - Benmalek e Saric [1994].

Floryan e Saric [1983] realizaram um estudo onde apresentam uma análise de efeitos de sucção com a presença da instabilidade de Görtler para um camada limite. Os resultados mostram que a sucção reduz o crescimento total de vórtices de Görtler estabilizando o fluxo, os níveis de sucção utilizados para a estabilização excedem significativamente o nível de sucção para eliminar as ondas de Tollmien-Schlichting.

Liu e Domaradzki [1993] usaram simulação númerica direta temporal para investigar a transição à turbulência em um fluxo de camada limite contendo dois vórtices contrarotativos, com eixos alinhados na direção longitudinal. Os vórtices foram gerados pelo mecanismo da instabilidade de Görtler na camada limite. As equações de Navier-Stokes tridimensional, em um sistema de coordenadas curvilíneas para um fluxo sobre uma parede côncava, foram resolvidas por um método pseudospectral. As simulações foram inicializadas com o modo mais instável da teoria de estabilidade linear, para este fluxo com 


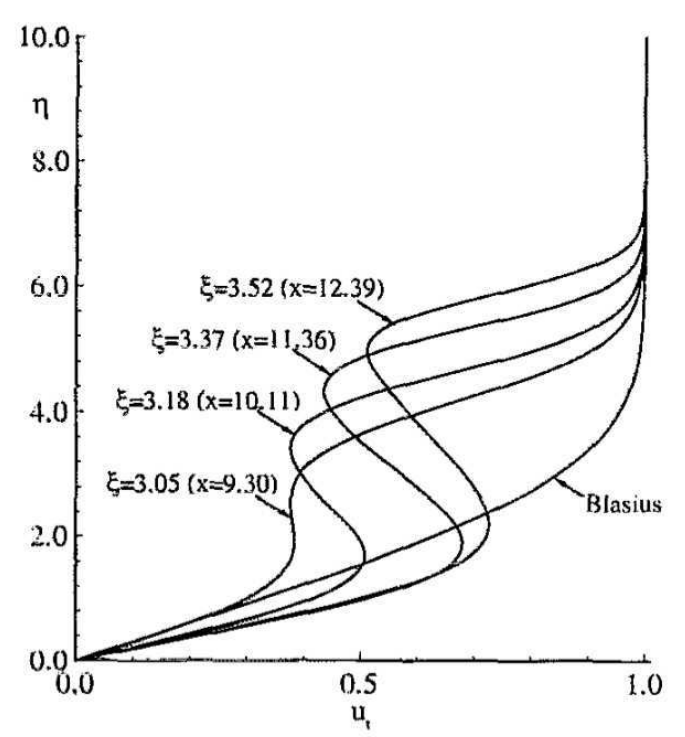

Figura 2.7: Distorção do perfil de velocidade para diferentes locais na coordenada $x$ - - Benmalek e Saric [1994].

sua amplitude tomada a partir das medições de Swearingen e Blackwelder [1987]. Os resultados indicam que o escoamento longitudinal desempenha um papel mais importante na transição para a turbulência do que o cisalhamento vertical, de acordo com a hipótese originalmente proposta por Swearingen e Blackwelder [1987]. Oscilações da instabilidade iniciam na direção longitudinal e são seguidas mais tarde por oscilações verticais. A análise da estabilidade linear prevê que as máximas taxas de crescimento estão associadas com os perfil longitudinais. Finalmente, a análise da equação do balanço da energia revela que a maioria da produção de energia nos estágios iniciais de transição ocorre na região caracterizada pelo grande cisalhamento longitudinal criada pela ação dos vórtices.

Em Girgis e Liu [2006] o gradiente de velocidade na direção longitudinal obtido pelos vórtices de Görtler é estudado em termos do coeficiente de atrito $C_{f}$. O coeficiente de atrito é devido as não-linearidades dos vórtices de Görtler que levam o escoamento laminar para a transição à turbulência. Os resultados foram novamente baseados na medição experimental de Swearingen e Blackwelder [1987]. A ênfase é colocada sobre a modificação não-linear do problema estável através das tensões de Reynolds e da onda de pertubação, verificando que o coeficiente de atrito aumenta bem acima do valor da camada limite turbulenta.

\subsection{Instabilidade Secundária}

A teoria da instabilidade secundária trata da análise de instabilidade de amplitudes finitas de estados estáveis ou de quasi-estáveis que resultam da instabilidade primária. Em muitos casos a instabilidade secundária é um precursor da transição para a turbulência. 
Consequentemente, a análise da instabilidade secundária é muitas vezes usadas para a previsão da turbulência [Schmid e Henningson, 2001].

Quando perturbações crescem para amplitudes finitas devido a instabilidade primária, podem saturar para um estado estacionário e estabelencer uma nova topologia para o escoamento médio, tipicamente mais complexa que a inicial. Este escoamento torna-se instável à pequenas perturbações. A esta nova instabilidade dá-se o nome de instabilidade secundária, o qual foi descoberda por Lord Rayleigh.

Os vórtices de Görtler distorcem o escoamento principal, dando origem a estrutura do tipo cogumelo para a distribuição de velocidade na direção longitudinal. Assim a instabilidade secundária que ocorre nos vórtices de Görtler pode ser de três maneiras: o modo varicoso, sinuoso e a misturas de ambos os modos [Saric, 1994]. O modo varicoso da instabilidade secundária é relacionada com a derivada $d u / d y$ e tem como característica o surgimento dos vórtices do tipo ferradura [Li e Malik, 1995a], já o modo sinuoso da instabilidade secundária ocorre devido as flutuações da perturbação no plano zy, e também pela tensão cisalhante na direção transversal ao escoamento [Bottaro e Klingmann, 1996].

Swearingen e Blackwelder [1987] apresentaram resultados experimentais onde foram utilizadas técnicas de visualização através de fumaça e medições utilizando-se um anemômetro de fio quente. Duas configurações de anemômetros foram empregadas simultaneamente para medir a flutuação da velocidade longitudinal. Na direção $y$ é medida a distribuição normal da velocidade longitudinal e na coordenada $z$ é medida a distribuição transversal da velocidade. Os resultados derivados deste estudo mostram que a camada limite inicial de Blasius na parede côncava, rapidamente se torna tridimensional como um sistema de vórtices longitudinais, de acordo com a análise linear de Görtler. No mesmo estudo eles apresentam as estruturas do tipo cogumelo e estruturas formadas pela instabilidade secundária dos tipos varicoso e sinuoso ilustradas nas figuras 2.8 e 2.9, respectivamente. Um dos primeiros resultados da instabilidade secundária está associado com o gradiente de velocidade inflexional, e a direção transversal que é a normal do gradiente de velocidade longitudinal. O estudo desenvolvido por eles compara a existência de ambos os modos da instabilidade secundária e totalmente turbulenta para dinâmica da camada limite, em particular a oscilação da instabilidade secundária resulta de uma instabilidade invíscida formando a interface entre a região de baixa velocidade e a região de alta velocidade.

O desenvolvimento não-linear de vórtices longitudinais aparece na camada limite em paredes côncavas e revelam que os números de onda na direção longitudinal mostram perfis de velocidade com ponto de inflexão tanto na direção transversal como na direção normal á parede [Swearingen e Blackwelder, 1987]. Os experimentos de Swearingen e Blackwelder [1987], Inagaki e Aihara [1995], Ito [1985], e [Peerhossaini e Wesfreid, 1988], analisaram os vórtices de Görtler estimulando estudos teóricos sobre o papel de vórtices longitudinais em camadas limites e suas consequências. 


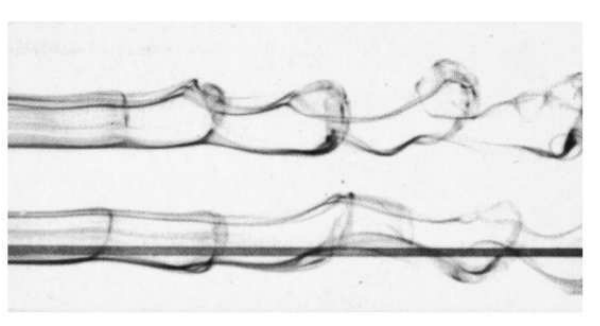

Figura 2.8: estruturas do tipo varicoso - - Swearingen e Blackwelder [1987].

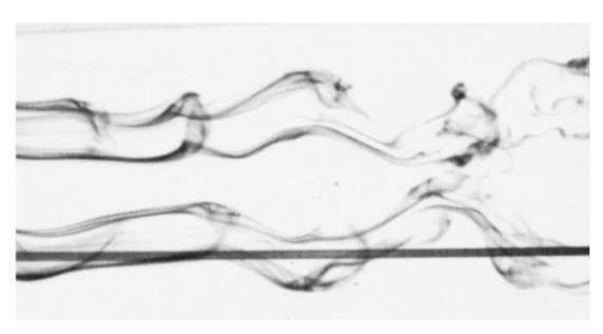

Figura 2.9: estruturas do tipo sinuoso - - Swearingen e Blackwelder [1987].

Sabry et al. [1989] realizaram o primeiro estudo em perfis transversais para ver as regiões sensíveis a instabilidade secundária como observado por [Swearingen e Blackwelder, 1987].

O escoamento primário depende unicamente da direção longitudinal. Para este caso Yu e Liu [1991] obtiveram uma simplificação 3D para a instabilidade para o escoamento paralelo com a velocidade constante.

Muitas das análises de instabilidade hidrodinâmica tem sido baseadas na evolução da pertubação de energia. A versão original é atribuida a Orr, o qual, não teve sucesso na obtenção no número de Reynolds crítico para o problema de escoamento paralelo em que as funções de forma utilizadas não satisfazeram as equações hidrodinâmicas. No entanto, as considerações de equilíbrio de energia foram consideráveis para a pertubação de energia do escoamento

Yu e Liu [1994] usaram em seu estudo o balanço da energia com colocação espectral. Este método fornece uma verificação numérica da taxa de amplificação do problema de auto valores para o fluxo paralelo e gera uma percepção física, onde se considerou o escoamento médio paralelo. Os resultados mostraram que o modo sinuoso é mais instável por ter uma maior taxa de amplificação. Além disto, eles descrevem que a distribuição transversal da velocidade é onde se desenvolve a mais intensa inflexão em $y$, devido a dinâmica da advecção do momento e da vortidade através da velocidade de pertubação primária. O modo sinuoso é aquele em que $u, v$ e $p$ são anti-simétricos e $w$ é simétrico em $z$ com a região de baixa velocidade (em $z=0$ ). O modo varicoso é aquele em que $u$, $v$ e $p$ são simétricos e $w$ é anti-simétrico em $z$ sobre a região de baixa velocidade.

Tomando como base o experimento de Swearingen e Blackwelder [1987], Li e Malik [1995a] realizaram um estudo invíscido da instabilidade secundária através dos vórtices de Görtler. Os resuldados mostram que o modo varicoso está correlacionado com a tensão de cisalhamento na direção normal à parede $d u / d y$ e o modo sinuoso esta correlacionado com o tensão de cisalhamento na direção longitudinal $d u / d z$. Eles mostraram que o modo sinuoso se torna mais ínstavel primeiramente, mas que o modo varicoso tem uma taxa de amplificação maior, assim crescendo mais que o modo sinuoso, contradizendo os estudos de [Yu e Liu, 1994] 
Zhang et al. [1995] realiazaram um estudo experimental em túnel de vento em que houve o desenvolvimento dos vórtices de Görtler. Os resultados mostraram o aparecimento de vórtices do tipo ferradura, que é a característica do modo varicoso da instabilidade secundária. Eles atribuíram a formação destas estruturas a tensão de cisalhamento na região a montade causada pela instabilidade de Kelvin-Helmholtz.

Segundo Mitsudharmadi et al. [2004] as inflexões tornam-se maiores a medida que o escoamento se desenvolve a jusante, indicando a amplificação dos vórtices. Em seu experimento entre $500 \mathrm{~mm}$ e $600 \mathrm{~mm}$ os vórtices evoluem para os vórtices do tipo ferradura. A transformação dos vórtices do tipo ferradura que se propagam a jusante, na estrutura do tipo cogumelo, é o resultado de um crescimento não-linear dos vórtices de Görtler. Isso determina o modo varicoso da instabilidade secundária [Swearingen e Blackwelder, 1987]. Neste mesmo experimento não houve amplificação do modo sinuoso, desta forma concorda com o estudado realizado por Li e Malik [1995a].

\subsection{Vórtices e Transferência de Calor}

O desenvolvimento de trocadores de calor mais eficientes e compactos são de grande interesse na engenharia. Para se obter isto deve-se intensificar a taxa de transferência de calor e, se for possível, minimizar a penalização do escoamento, evitando que ocorra um grande aumento de perda de carga no mesmo. Assim, a transferência de calor entre um corpo sólido, um líquido ou um gás é um problema o qual envolve a ciência do movimento do fluido. O movimento físico do fluido sobrepõe ao fluxo de calor, onde ambos interagem. A distribuição de temperatura em torno de um corpo quente em um escoamento, muitas vezes, tem o mesmo caráter que a distribuição de velocidade em uma camada limite, assim é necessário combinar as equações de movimento com a convecção de calor.

Fiebig [1996] apresenta estudos onde é analisada a influência de vórtices na transferência de calor. A geração de vórtice é um processo que geralmente é realizado através da inserção de geradores de vórtices do tipo winglet. Estes tipos de geradores de vórtices causam uma grande perda no sistema, porque, apesar de poder dobrar a taxa de transferência de calor, quase que quadruplica o arrasto [Fiebig, 1996].

Para o fluxo constante, os vórtices longitudinais são mais eficazes do que os vórtices transversais para o aumento da transferência de calor, porque vórtices longitudinais fornecem um modo adicional de transporte de energia térmica, transporte em espiral, enquanto vórtices transversais geram nenhum modo adicional de transporte longitudinal de energia. Vórtices transversais levam a uma alta oscilação e transição para turbulência com menor número de Reynolds do que os vórtices longitudinais.

Eibeck e Eaton [1986, 1987] examinaram com detalhes a influência da transferência de calor com vórtices longitudinais na camada limite turbulenta medindo o coeficiente de transferência de calor e as três componentes de velocidade. Os resultados mostram que 
a camada limite turbulenta distorce o escoamento principal aumentando o coeficiente de atrito.

Pauley e Eaton [1987a,b] incluíram no experimento pares de vórtices. Observaram uma ampla região de intensificação da transferência de calor entre os vórtices, levando a um aumento na média de transferência de calor na direção transversal. Eles acharam que os pares de vórtices induzem grandes distorções na camada limite. Observaram também, uma forte correlação existente entre a intensidade da turbulência perto da parede e o número de Stanton em toda a região de grandes efeitos tridimensionais, sugerindo que a turbulência perto da parede é importante para controlar a taxa de transferência de calor.

Torii e Yanagihara [1989], Yanagihara e Torii [1992], Torii e Yanagihara [1997] desenvolveram experimentos para mostrar a importância de se poder instensificar a transferência de calor. O objetivo foi estudar os vórtices longitudinais contrarrotativos e corrotativos, gerados por wings para intensificar a transferência de calor em camadas limites. A técnica padrão era produzir vórtices perto do bordo da camada limite, que mistura o fluido de alta velocidade do fluxo invíscido com a camada de cisalhamento perto da superfície. Os resultados mostram que a camada limite turbulenta, distorce o escoamento principal aumentando o coeficiente de transferência de calor. A comparação entre os casos mostram que os vórtices contrarrotativos apresentam maior aumento na transferência de calor do que os vórtices corrotativos para o mesmo ângulo de ataque.

Liu [2008] realizou estudos para explicar teoricamente a taxa de transferência de calor em uma superfície ligeiramente côncava, concluindo que pode-se aumentar consideravelmente a transferência de calor e paga-se por isto um aumento de quase um para um no arrasto.

MacCormack et al. [1970] realizaram experimentos para a formação de vórtices de Görtler sobre a transferência de calor da camada limite em uma parede côncava. Os resultados experimentais indicam que há um aumento significativo do número de Nusselt na presença dos vórtices.

Toe et al. [2002] relizaram um estudo experimental em túnel de vento, onde a transferência de calor é analisada na presença de vórtices de Görtler. Verificou-se que a transição gerada através da instabilidade centrífuga aumenta a taxa de transferência de calor entre o fluido e a parede côncava. Os testes foram executados levando em consideração a instabilidade centrífuga numa camada limite turbulenta. Neste tipo de camada limite, a intermitência no tempo e no espaço dos vórtices longitudinais, torna extremamente difícil a reprodução de experimentos sistemáticos, para que se possa acessar quantitativamente o aumento na taxa de transferência de calor devido á instabilidade centrífuga.

Experimentos mais recentes [Momayez et al., 2004a,b] conduzidos sobre condições bem controladas, foram realizadas em uma parede concava aquecida, a fim de entender os efeitos da instabilidade de Görtler e sua transição para turbulência sobre a transferência de calor na parede para a camade limite. Os resultados indicam que a taxa de transferência 
de calor em um escoamento contendo vórtices de Görtler partem de um valor igual ao laminar e a montante, na região onde os vórtices já são fortes, o valor da taxa de transferência de calor é maior que o observado para escoamentos turbulentos. Análises dos efeitos dos vórtices de Görtler e do comprimento de onda, mostram que vórtices com o comprimento de onda menor são mais rápidos na transição para turbulência. Outros resultados experimentais contemplando este assunto podem ser vistos em Crane [1991], Kottke [1986].

Em um experimento semelhante ao de [Momayez et al., 2004a], Tandiono et al. [2009] estudaram o desenvolvimento da tensão de cisalhamento na parede em uma camada limite sobre uma superfície côncava na presença dos vórtices de Görtler. Eles analisaram o fluxo por meio de medições por anemômetro de fio quente, e foram adotados fios de perturbação vertical para introduzir perturbações em um comprimento de onda selecionado. O estudo conclui que o coeficiente de transferência de calor, inicialmente segue a curva de Blasius, aumentando acima dos valores da camada limite turbulenta à jusante, devido aos efeitos não-lineares dos vórtices de Görtler e as instabilidades secundárias.

Momayez et al. [2009] relizaram experimentos em uma camada limite sobre uma superfície côncava, sujeita à instabilidade de Görtler na presença de comprimentos de onda. A transferência de calor é medida ao longo da superfície côncava, o qual permite calcular o número de Stanton St para várias posições na direção longitudinal, a velocidade e o comprimento de onda. As relações entre as variáveis é construída à partir de argumentos fenomenológicos na forma de correlações clássicas da lei da energia, onde correlações constantes são obtidas por método de algoritmos genéticos.

Malatesta et al. [2013] conduziram um estudo númerico através de simulação numérica direta espacial, do inglês Spatial Direct Numerical Simulation (SDNS) em uma camada limite sobre um surperfície côncava, para analisar o aumento da transferência de calor sem a presença da instabilidade secundária. O estudo foi pertubado com três diferentes comprimentos de onda na direção transversal $\lambda_{z}=0,09,0,18$ e 0,36. Todos os comprimentos de onda analisados apresentaram ganho na transferência de calor maior que o escoamento laminar. Para o comprimento de onda $\lambda_{z}=0,09$ obteve-se um aumento em $247 \%$ em relação a camada limite laminar e ficou apenas $14 \%$ menor do valor da camada limite tubulenta, para o comprimento de onda $\lambda_{z}=0,18$ o aumento em relação a camada limite laminar foi de $232 \%$ e ficou $19 \%$ abaixo da camada limite turbulenta, finalmente para o comprimento de onda $\lambda_{z}=0,36$ houve um aumento em $158 \%$ em relação a camada limite laminar e ficou $54 \%$ menor que a camada limite turbulenta.

Como a metodologia adotada para este estudo é numérica, no capítulo a seguir são apresentadas as equações adotadas como modelo matemático e no capítulo subsequênte, a descrição destas equações. 


\section{Capítulo \\ 3 \\ Formulação}

O modelo matemático para estudo de movimento de fluidos é dado pelas Equações de Navier-Stokes. No presente estudo a viscosidade e a densidade do fluido foram considerados constantes.

A forma adimensional é utilizada para apresentar os resultados obtidos através das simulações numéricas. Todas as informações específicas dos escoamentos são relacionadas a um número de Reynolds Re e um número de Görtler Go. Estes dois adimensionais aparecem nas equações de Navier-Stokes quando se adimensionaliza a mesma. O número de Reynolds adotado no estudo é dado por:

$$
R e=\frac{U_{\infty} L}{\nu},
$$

que é baseada na viscosidade cinemática $\nu$, na velocidade do escoamento fora da camada limite $U_{\infty}$ e em um comprimento característico $L$. Para o comprimento característico $L$, no presente estudo, adotou-se uma distância do bordo de ataque. O número de Görtler utilizado nas simulações é dado por:

$$
G o=R e^{\frac{1}{4}} \sqrt{\frac{L}{R}},
$$

onde $R$ é o raio de curvatura da superfície côncava. A vantagem em se utilizar quantidades adimensionais é que mesmos fenômenos físicos podem ser observados, desde que, os números de Reynolds e Görtler sejam iguais, tornando-se assim os resultados aqui obtidos mais gerais.

Neste capítulo, a formulação matemática adotada neste trabalho é apresentada. Primeiramente, são apresentadas as equações governantes utilizando variáveis primitivas, com a introdução de um termo de curvatura, a equação da continuidade e também 
a equação da energia. Em seguida são apresentadas as equações escritas na formulação vorticidade-velocidade.

\subsection{Sistemas de Coordenadas e Decomposição do Es- coamento}

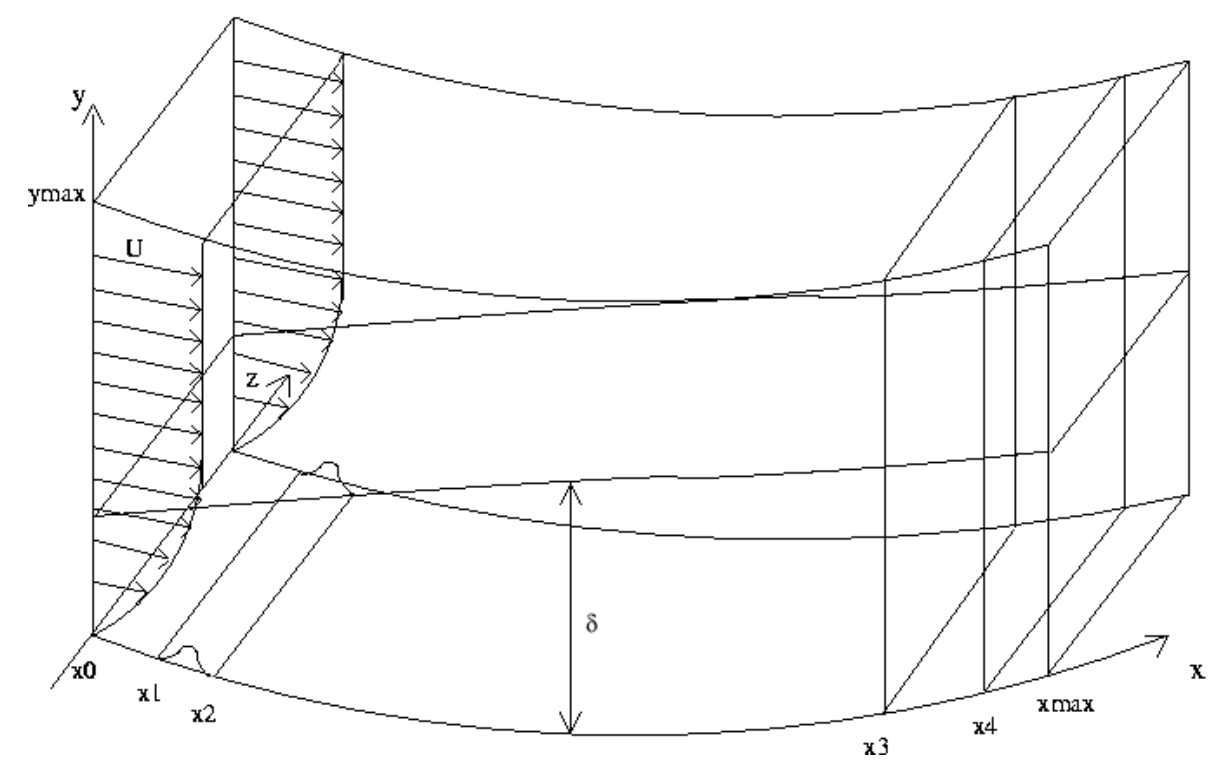

Figura 3.1: Domínio de integração.

O sistema de coordenadas é mostrado esquematicamente na figura 3.1. O escoamento não pertubado e uniforme é alinhado com a coordenada $x$. A origem do sistema de coordenadas, $\mathrm{x}=0$, a uma distância do bordo de ataque da placa côncava de raio $R$. A direção normal à placa é definida por $y$, com o valor de $\mathrm{y}=0$ na superfície da placa. A direção transversal, definida por $z$ é paralela ao bordo de ataque. Os componentes de velocidade total nas direções $x, y$ e $z$ são denotadas por $\widetilde{u}, \widetilde{v}, \widetilde{w}$, respectivamente. Como no estudo proposto as perturbações de velocidade são pequenas se comparadas com a velocidade total, o escoamento pode ser decomposto da seguinte forma: $\tilde{u}=\bar{u}+u, \tilde{v}=\bar{v}+v$, $\tilde{w}=\bar{w}+w$ e $\tilde{p}=\bar{p}+p$, onde $\bar{u}, \bar{v}$ e $\bar{w}$ são as componentes de perturbação de velocidade do escoamento base, na ausência de perturbações, $u, v$ e $w$ são os componentes de perturbação de velocidade, $\bar{p}$ e $p$ são a pressão do escoamento base e a flutuação de pressão, respectivamente. As perturbações podem ser estacionárias ou variáveis com o tempo. Os componentes de vorticidade nas três direções são definidos neste trabalho como o negativo do rotacional da velocidade $(\overrightarrow{\tilde{\omega}}=-\nabla \times \overrightarrow{\tilde{u}})$. Estes componentes podem ser decompostos em um componente base mais flutuação, da mesma forma que os componentes de velocidade. Um vórtice na direção $x$ é um movimento rotatório em volta de um eixo paralelo ao eixo $x$ e é associado à vorticidade $\tilde{\omega}_{x}$. É importante ressaltar que somente a presença de vorticidade não implica na presença de um vórtice. 


\subsection{Coordenadas Curvilíneas Ortogonais}

Nesta seção é dada uma introdução às coordenadas cuvilíneas e em seguinda dá-se o sistema de coordenadas curvilíneas ortogonais em $R^{3}$ para o escoamento sobre placa curva utilizada no presente estudo.

Podemos descrever qualquer ponto $(x, y, z)$ como a interseção de três planos em coordenadas cartesianas ou como a interseção das três superfícies que formam nossas novas coordenadas cilíndricas. Descrevendo as superfícies por coordenadas curvilíneas $q_{1}, q_{2}$ e $q_{3}$ podemos identificar nosso ponto por $\left(q_{1}, q_{2}, q_{3}\right)$ bem como por $(x, y, z)$, o qual é mostrado na figura 3.2 :

$$
\begin{aligned}
& x=x\left(q_{1}, q_{2}, q_{3}\right), \\
& y=y\left(q_{1}, q_{2}, q_{3}\right), \\
& z=z\left(q_{1}, q_{2}, q_{3}\right),
\end{aligned}
$$

e as relações das transformações inversas:

$$
\begin{aligned}
& q_{1}=q_{1}(x, y, z), \\
& q_{2}=q_{2}(x, y, z), \\
& q_{3}=q_{3}(x, y, z) .
\end{aligned}
$$

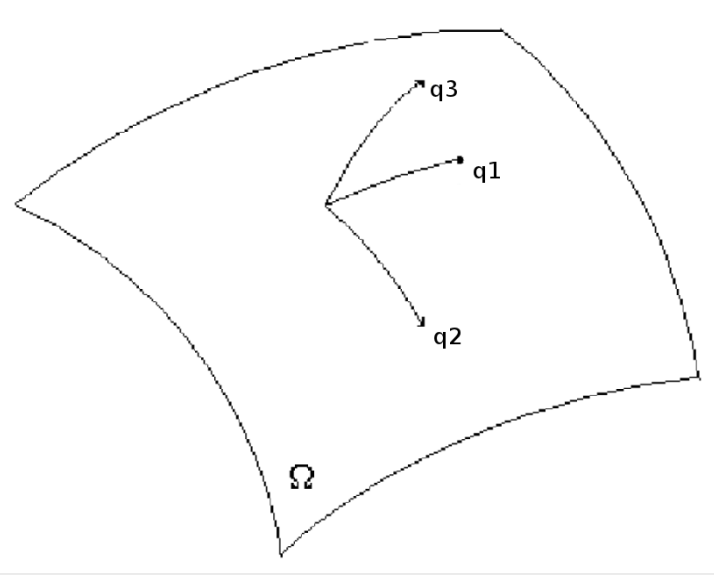

Figura 3.2: Coordenadas Curvilíneas

O comprimento de um elemento de arco, $(d s)^{2}$, é invariante ao sistema de coordenadas utilizado. Para o sistema genérico tem-se:

$$
(d s)^{2}=h_{1}^{2}\left(d q_{1}\right)^{2}+h_{2}^{2}\left(d q_{2}\right)^{2}+h_{3}^{2}\left(d q_{3}\right)^{2}
$$


ou em notação indicial,

$$
(d s)^{2}=h_{i}^{2}\left(d q_{i}\right)^{2}
$$

onde $h_{1}, h_{2}, h_{3}$ são os fatores de escala que dependem das três coordenadas $\left(q_{1}, q_{2}, q_{3}\right)$. Se as coordenadas $(x, y, z)$ são funções conhecidas de $\left(q_{1}, q_{2}, q_{3}\right)$, então os fatores de escala são dados por:

$$
\begin{aligned}
\left(h_{1}\right)^{2} & =\left(\frac{\partial x}{\partial q_{1}}\right)^{2}+\left(\frac{\partial y}{\partial q_{1}}\right)^{2}+\left(\frac{\partial z}{\partial q_{1}}\right)^{2}, \\
\left(h_{2}\right)^{2} & =\left(\frac{\partial x}{\partial q_{2}}\right)^{2}+\left(\frac{\partial y}{\partial q_{2}}\right)^{2}+\left(\frac{\partial z}{\partial q_{2}}\right)^{2}, \\
\left(h_{3}\right)^{2} & =\left(\frac{\partial x}{\partial q_{3}}\right)^{2}+\left(\frac{\partial y}{\partial q_{3}}\right)^{2}+\left(\frac{\partial z}{\partial q_{3}}\right)^{2} .
\end{aligned}
$$

Agora podemos reescrever os operadores em coordenadas curvilíneas ortogonais, temos que:

O gradiente de uma grandeza escalar $\Psi$ - o resultado da operação é um vetor:

$$
\nabla \Psi=\overrightarrow{e_{1}} \frac{1}{h_{1}} \frac{\partial \Psi}{\partial q_{1}}+\overrightarrow{e_{2}} \frac{1}{h_{2}} \frac{\partial \Psi}{\partial q_{2}}+\overrightarrow{e_{3}} \frac{1}{h_{3}} \frac{\partial \Psi}{\partial q_{3}}
$$

O divergente de uma grandeza vetorial V - o resultado da operação é um escalar:

$$
\nabla \cdot \vec{V}=\frac{1}{h_{1} h_{2} h_{3}}\left[\frac{\partial\left(h_{2} h_{3} V_{1}\right)}{\partial q_{1}}+\frac{\partial\left(h_{1} h_{3} V_{2}\right)}{\partial q_{2}}+\frac{\partial\left(h_{1} h_{2} V_{3}\right)}{\partial q_{3}}\right] .
$$

O rotacional de uma grandeza vetorial V - o resultado da operação é um vetor:

$$
\nabla \times \vec{V}=\frac{1}{h_{1} h_{2} h_{3}}\left|\begin{array}{ccc}
\overrightarrow{e_{1}} h_{1} & \overrightarrow{e_{2}} h_{2} & \overrightarrow{e_{3}} h_{3} \\
\frac{1}{q_{1}} & \frac{1}{q_{2}} & \frac{1}{q_{3}} \\
h_{1} V_{1} & h_{2} V_{2} & h_{3} V_{3}
\end{array}\right|
$$

O laplaciano de uma grandeza escalar $\Psi$ - o resultado da operação é um escalar:

$$
\nabla^{2} \Psi=\frac{1}{h_{1} h_{2} h_{3}}\left[\frac{\partial}{\partial q_{1}}\left(\frac{h_{2} h_{3}}{h_{1}} \frac{\partial \Psi}{\partial q_{1}}\right)+\frac{\partial}{\partial q_{2}}\left(\frac{h_{3} h_{1}}{h_{2}} \frac{\partial \Psi}{\partial q_{2}}\right)+\frac{\partial}{\partial q_{3}}\left(\frac{h_{1} h_{2}}{h_{3}} \frac{\partial \Psi}{\partial q_{3}}\right)\right]
$$

O gradiente de uma grandeza vetorial V - o resultado da operação é um tensor: 


$$
\nabla \vec{V}=\left\{\begin{array}{c}
V_{i i}=\frac{1}{h_{i}} \frac{\partial V_{i}}{\partial q_{i}}+\sum_{k \neq i} \frac{1}{h_{k}} \frac{V_{k}}{h_{i}} \frac{\partial h_{i}}{\partial q_{k}}, \\
V_{i j}=\frac{1}{h_{j}} \frac{\partial V_{j}}{\partial q_{1}}-\frac{1}{h_{i}} \frac{V_{j}}{h_{i}} \frac{\partial h_{j}}{\partial q_{i}} \text { para } i \neq j .
\end{array}\right.
$$

O divergente de uma grandeza tensorial $\tau_{i j}$ - o resultado da operação é um vetor:

$$
(\nabla \cdot \tau)=\frac{h_{i}}{h_{1} h_{2} h_{3}} \sum_{j} \frac{\partial}{\partial q_{1}}\left(\frac{\tau_{i j} h_{1} h_{2} h_{3}}{h_{i} h_{j}}\right) \overrightarrow{e_{1}}+\sum_{j} \frac{1}{h_{j}}\left(\frac{\tau_{i j}+\tau_{j i}}{h_{i}}\right) \frac{\partial h_{i}}{\partial q_{j}} \overrightarrow{e_{2}}-\sum_{j} \frac{1}{h_{j}}\left(\frac{\tau_{j j}}{h_{j}}\right) \frac{\partial h_{j}}{\partial q_{i}} \overrightarrow{e_{3}} .
$$

O laplaciano de uma grandeza vetorial V - o resultado da operação é um vetor:

$$
\nabla^{2} \vec{V} \equiv \underbrace{\nabla(\nabla \cdot \vec{V})}_{I}-\underbrace{\nabla \times(\nabla \times \vec{V})}_{I I} .
$$

onde os termos $I$ e $I I$ são mostrados abaixo respectivamente:

$$
\begin{aligned}
I & =\nabla(\nabla \cdot \vec{V})=\frac{1}{h_{1}} \frac{\partial}{\partial q_{1}}\left[\frac{1}{h_{1} h_{2} h_{3}} \frac{\partial}{\partial q_{1}}\left(\frac{h_{1} h_{2} h_{3} h_{1}}{h_{1}}\right)+\frac{1}{h_{1} h_{2} h_{3}} \frac{\partial}{\partial q_{2}}\left(\frac{h_{1} h_{2} h_{3} V_{2}}{h_{2}}\right)+\frac{1}{h_{1} h_{2} h_{3}} \frac{\partial}{\partial q_{3}}\left(\frac{h_{1} h_{2} h_{3} V_{3}}{h_{3}}\right)\right] \overrightarrow{e_{1}} \\
& +\frac{1}{h_{2}} \frac{\partial}{\partial q_{2}}\left[\frac{1}{h_{1} h_{2} h_{3}} \frac{\partial}{\partial q_{1}}\left(\frac{h_{1} h_{2} h_{3} h_{1}}{h_{1}}\right)+\frac{1}{h_{1} h_{2} h_{3}} \frac{\partial}{\partial q_{2}}\left(\frac{h_{1} h_{2} h_{3} V_{2}}{h_{2}}\right)+\frac{1}{h_{1} h_{2} h_{3}} \frac{\partial}{\partial q_{3}}\left(\frac{h_{1} h_{2} h_{3} V_{3}}{h_{3}}\right)\right] \overrightarrow{e_{2}} \\
& +\frac{1}{h_{3}} \frac{\partial}{\partial q_{3}}\left[\frac{1}{h_{1} h_{2} h_{3}} \frac{\partial}{\partial q_{1}}\left(\frac{h_{1} h_{2} h_{3} h_{1}}{h_{1}}\right)+\frac{1}{h_{1} h_{2} h_{3}} \frac{\partial}{\partial q_{2}}\left(\frac{h_{1} h_{2} h_{3} V_{2}}{h_{2}}\right)+\frac{1}{h_{1} h_{2} h_{3}} \frac{\partial}{\partial q_{3}}\left(\frac{h_{1} h_{2} h_{3} V_{3}}{h_{3}}\right)\right] \overrightarrow{e_{3}},
\end{aligned}
$$

$$
\begin{aligned}
& I I=\quad \nabla \times(\nabla \times \vec{V})= \\
& \left.\frac{1}{h_{1} h_{2} h_{3}} \mid \begin{array}{ccc}
\overrightarrow{e_{1}} h_{1} & \overrightarrow{e_{2}} h_{2} & \overrightarrow{e_{3}} h_{3} \\
\frac{1}{q_{1}} & \frac{1}{q_{2}} & \frac{1}{q_{3}} \\
\frac{h_{1}}{h_{1} h_{2} h_{3}}\left[\frac{\partial}{\partial q_{2}}\left(h_{3} V_{3}\right)-\frac{\partial}{\partial q_{3}}\left(h_{2} V_{2}\right)\right] & \frac{h_{2}}{h_{1} h_{2} h_{3}}\left[\frac{\partial}{\partial q_{3}}\left(h_{1} V_{1}\right)-\frac{\partial}{\partial q_{1}}\left(h_{3} V_{3}\right)\right] & \frac{h_{3}}{h_{1} h_{2} h_{3}}\left[\frac{\partial}{\partial q_{1}}\left(h_{2} V_{2}\right)-\frac{\partial}{\partial q_{2}}\left(h_{1} V_{1}\right)\right]
\end{array}\right] .
\end{aligned}
$$

\subsubsection{Equações de Navier-Stokes em um Sistema de Coordenadas Ortogonais}

As equações de Navier-Stokes para um sistema de coordenadas curvilíneas ortogonal podem ser escritas com o auxílio dos operadores vetoriais definidos na seção anterior. Para referência, a equação de Navier-Stokes na forma não conservativa utilizando a representação de vetores é:

$$
\rho\left[\frac{\partial \vec{V}}{\partial t}+\vec{V} \cdot \nabla \vec{V}\right]=\nabla \cdot T_{i j}
$$


onde o tensor de tensões $T_{i j}$ é dado por:

$$
T_{i j}=-P \delta_{i j}+\lambda(\nabla \cdot \vec{V}) \delta_{i j}+2 \mu D_{i j}
$$

onde $\lambda$ e $\mu$ são os coeficientes de viscosidade; e o tensor das deformações definido como:

$$
D_{i j}=\frac{1}{2}\left[\nabla \vec{V}+(\nabla \vec{V})^{T}\right] .
$$

Desta forma, com o auxílio dos operadores definidos na seção anterior podemos escrever as equações de Navier-Stokes em coordenadas curvilíneas ortogonais em $R^{3}$, com todos os termos:

$$
\begin{aligned}
& \rho\left(\frac{\partial V_{1}}{\partial t}+\frac{V_{1}}{h_{1}} \frac{\partial V_{1}}{\partial q_{1}}+\frac{V_{2}}{h_{2}} \frac{\partial V_{1}}{\partial q_{2}}+\frac{V_{3}}{h_{3}} \frac{\partial V_{1}}{\partial q_{3}}+\frac{V_{1}}{h_{1}} \frac{V_{2}}{h_{2}} \frac{\partial h_{1}}{\partial q_{2}}-\frac{V_{2}}{h_{1}} \frac{V_{2}}{h_{2}} \frac{\partial h_{2}}{\partial q_{1}}+\frac{V_{1}}{h_{1}} \frac{V_{3}}{h_{3}} \frac{\partial h_{2}}{\partial q_{3}}-\frac{V_{3}}{h_{1}} \frac{V_{3}}{h_{3}} \frac{\partial h_{3}}{\partial q_{1}}\right) \\
& =\frac{1}{h_{1}^{2} h_{2} h_{3}}\left[\frac{\partial h_{1} h_{2} h_{3} T_{q_{1} q_{1}}}{\partial q_{1}}+\frac{\partial h_{1} h_{1} h_{3} T_{q_{1} q_{2}}}{\partial q_{2}}+\frac{\partial h_{1} h_{1} h_{2} T_{q_{1} q_{3}}}{\partial q_{3}}\right. \\
& \left.-\frac{1}{h_{1} h_{1}} \frac{\partial h_{1}}{\partial q_{1}} T_{q_{1} q_{1}}-\frac{1}{h_{1} h_{2}} \frac{\partial h_{2}}{\partial q_{1}} T_{q_{2} q_{2}}-\frac{1}{h_{1} h_{3}} \frac{\partial h_{3}}{\partial q_{1}} T_{q_{3} q_{3}}\right] \\
& \rho\left(\frac{\partial V_{2}}{\partial t}+\frac{V_{1}}{h_{1}} \frac{\partial V_{2}}{\partial q_{1}}+\frac{V_{2}}{h_{2}} \frac{\partial V_{2}}{\partial q_{2}}+\frac{V_{3}}{h_{3}} \frac{\partial V_{2}}{\partial q_{3}}+\frac{V_{1}}{h_{1}} \frac{V_{2}}{h_{2}} \frac{\partial h_{2}}{\partial q_{1}}-\frac{V_{1}}{h_{1}} \frac{V_{1}}{h_{2}} \frac{\partial h_{1}}{\partial q_{2}}+\frac{V_{2}}{h_{2}} \frac{V_{3}}{h_{3}} \frac{\partial h_{2}}{\partial q_{3}}-\frac{V_{3}}{h_{2}} \frac{V_{3}}{h_{3}} \frac{\partial h_{3}}{\partial q_{2}}\right) \\
& =\frac{1}{h_{1} h_{2}^{2} h_{3}}\left[\frac{\partial h_{2} h_{2} h_{3} T_{q_{1} q_{2}}}{\partial q_{1}}+\frac{\partial h_{1} h_{2} h_{3} T_{q_{2} q_{2}}}{\partial q_{2}}+\frac{\partial h_{1} h_{2} h_{2} T_{q_{2} q_{3}}}{\partial q_{3}}\right. \\
& \left.-\frac{1}{h_{1} h_{2}} \frac{\partial h_{1}}{\partial q_{2}} T_{q_{1} q_{1}}-\frac{1}{h_{2} h_{2}} \frac{\partial h_{2}}{\partial q_{2}} T_{q_{2} q_{2}}-\frac{1}{h_{2} h_{3}} \frac{\partial h_{3}}{\partial q_{2}} T_{q_{3} q_{3}}\right] \\
& \rho\left(\frac{\partial V_{3}}{\partial t}+\frac{V_{1}}{h_{1}} \frac{\partial V_{3}}{\partial q_{1}}+\frac{V_{2}}{h_{2}} \frac{\partial V_{3}}{\partial q_{2}}+\frac{V_{3}}{h_{3}} \frac{\partial V_{3}}{\partial q_{3}}+\frac{V_{1}}{h_{1}} \frac{V_{3}}{h_{3}} \frac{\partial h_{3}}{\partial q_{1}}-\frac{V_{1}}{h_{1}} \frac{V_{1}}{h_{3}} \frac{\partial h_{1}}{\partial q_{3}}+\frac{V_{2}}{h_{2}} \frac{V_{3}}{h_{3}} \frac{\partial h_{3}}{\partial q_{2}}-\frac{V_{2}}{h_{2}} \frac{V_{2}}{h_{3}} \frac{\partial h_{2}}{\partial q_{3}}\right) \\
& =\frac{1}{h_{1} h_{2} h_{3}^{2}}\left[\frac{\partial h_{2} h_{3} h_{3} T_{q_{1} q_{3}}}{\partial q_{1}}+\frac{\partial h_{1} h_{3} h_{3} T_{q_{2} q_{3}}}{\partial q_{2}}+\frac{\partial h_{1} h_{2} h_{3} T_{q_{3} q_{3}}}{\partial q_{3}}\right. \\
& \left.-\frac{1}{h_{1} h_{3}} \frac{\partial h_{1}}{\partial q_{3}} T_{q_{1} q_{1}}-\frac{1}{h_{2} h_{3}} \frac{\partial h_{2}}{\partial q_{3}} T_{q_{2} q_{2}}-\frac{1}{h_{3} h_{3}} \frac{\partial h_{3}}{\partial q_{3}} T_{q_{3} q_{3}}\right]
\end{aligned}
$$

e a equação da continuidade tem a forma:

$$
\frac{\partial \rho}{\partial t}+\frac{1}{h_{1} h_{2} h_{3}}\left[\frac{\partial \rho h_{2} h_{3} V_{1}}{\partial q_{1}} \frac{\partial \rho h_{1} h_{3} V_{2}}{\partial q_{2}}+\frac{\partial \rho h_{1} h_{2} V_{3}}{\partial q_{3}}\right]=0
$$


onde as componentes do tensor de tensões são:

$$
\begin{aligned}
& T_{q 1 q 1}=-P+2 \mu\left(\frac{1}{h_{1}} \frac{\partial V_{1}}{\partial q_{1}}+\frac{V_{2}}{h_{1} h_{2}} \frac{\partial h_{1}}{\partial q_{2}}+\frac{V_{3}}{h_{1} h_{3}} \frac{\partial h_{1}}{\partial q_{3}}\right)+\lambda(\nabla \cdot \vec{V}), \\
& T_{q 2 q 2}=-P+2 \mu\left(\frac{1}{h_{2}} \frac{\partial V_{2}}{\partial q_{2}}+\frac{V_{1}}{h_{1} h_{2}} \frac{\partial h_{2}}{\partial q_{1}}+\frac{V_{3}}{h_{2} h_{3}} \frac{\partial h_{2}}{\partial q_{3}}\right)+\lambda(\nabla \cdot \vec{V}), \\
& T_{q 3 q 3}=-P+2 \mu\left(\frac{1}{h_{3}} \frac{\partial V_{3}}{\partial q_{3}}+\frac{V_{1}}{h_{1} h_{3}} \frac{\partial h_{3}}{\partial q_{1}}+\frac{V_{3}}{h_{2} h_{3}} \frac{\partial h_{3}}{\partial q_{2}}\right)+\lambda(\nabla \cdot \vec{V}), \\
& T_{q 1 q 2}=\mu\left(\frac{1}{h_{1}} \frac{\partial u_{2}}{\partial q_{1}}+\frac{1}{h_{2}} \frac{\partial u_{1}}{\partial q_{2}}-\frac{u_{2}}{h_{1} h_{2}} \frac{\partial h_{2}}{\partial q_{1}}-\frac{u_{1}}{h_{1} h_{2}} \frac{\partial h_{1}}{\partial q_{2}}\right), \\
& T_{q 1 q 3}=\mu\left(\frac{1}{h_{1}} \frac{\partial u_{3}}{\partial q_{1}}+\frac{1}{h_{3}} \frac{\partial u_{1}}{\partial q_{3}}-\frac{u_{3}}{h_{1} h_{3}} \frac{\partial h_{3}}{\partial q_{1}}-\frac{u_{1}}{h_{1} h_{3}} \frac{\partial h_{1}}{\partial q_{3}}\right), \\
& T_{q 2 q 3}=\mu\left(\frac{1}{h_{2}} \frac{\partial u_{3}}{\partial q_{2}}+\frac{1}{h_{3}} \frac{\partial u_{2}}{\partial q_{3}}-\frac{u_{3}}{h_{2} h_{3}} \frac{\partial h_{3}}{\partial q_{2}}-\frac{u_{2}}{h_{2} h_{3}} \frac{\partial h_{2}}{\partial q_{3}}\right) .
\end{aligned}
$$

Agora já podemos escrever o sistema em coordenadas curvilíneas para o escoamento sobre uma placa curva utilizado no presente estudo, assim os fatores de escala são definidos como:

$$
\begin{aligned}
& h_{1}=1-y \underbrace{\frac{(G o)^{2}}{\sqrt{R e}}}_{k}=h, \\
& h_{2}=1, \\
& h_{3}=1 .
\end{aligned}
$$

Utilizando a equação (3.7), temos:

$$
\begin{gathered}
\left(h_{1}\right)^{2}=\left(\frac{\partial x}{\partial q_{1}}\right)^{2}+\left(\frac{\partial y}{\partial q_{1}}\right)^{2}+\left(\frac{\partial z}{\partial q_{1}}\right)^{2}, \\
\left(h_{1}\right)^{2}=(\underbrace{\frac{\partial x}{\partial x}}_{1} \frac{\partial x}{\partial q_{1}})^{2}+\underbrace{\left(\frac{\partial y}{\partial x} \frac{\partial x}{\partial q_{1}}\right)^{2}}_{0}+\underbrace{\left(\frac{\partial z}{\partial x} \frac{\partial x}{\partial q_{1}}\right)^{2}}_{0}, \\
\frac{\partial x}{\partial q_{1}}=h .
\end{gathered}
$$

Aplicando o divergente equação (3.9), temos a equação da continuidade. 


$$
\begin{aligned}
\nabla \cdot \vec{V} & =\frac{1}{h_{1} h_{2} h_{3}}\left[\frac{\partial\left(h_{2} h_{3} V_{1}\right)}{\partial q_{1}}+\frac{\partial\left(h_{1} h_{3} V_{2}\right)}{\partial q_{2}}+\frac{\partial\left(h_{1} h_{2} V_{3}\right)}{\partial q_{3}}\right] \\
& =\frac{1}{h}\left[\frac{\partial(u)}{\partial q_{1}}+\frac{\partial(v h)}{\partial q_{2}}+\frac{\partial(w h)}{\partial q_{3}}\right] \\
& =\frac{1}{h}\left[\frac{\partial(u)}{\partial x} \frac{\partial(x)}{\partial q_{1}}+v \frac{\partial(h)}{\partial q_{2}}+h \frac{\partial(v)}{\partial q_{2}}+w \frac{\partial(h)}{\partial q_{3}}+h \frac{\partial(w)}{\partial q_{3}}\right] \\
& =\frac{\partial u}{\partial x}+\frac{\partial v}{\partial y}+\frac{\partial w}{\partial z}-v k,
\end{aligned}
$$

$\mathrm{Ou}$

$$
\frac{\partial u}{\partial x}+\frac{\partial v}{\partial y}+\frac{\partial w}{\partial z}-v k=0
$$

Substituindo os valores na primeira equação do momento (3.18) e simplificando, temos:

$$
\frac{\partial u}{\partial t}+u \frac{\partial u}{\partial x}+v \frac{\partial u}{\partial y}+w \frac{\partial u}{\partial z}-u v k+\frac{\partial p}{\partial x}=\frac{1}{R e}\left[\frac{\partial^{2} u}{\partial x^{2}}+\frac{\partial^{2} u}{\partial y^{2}}+\frac{\partial^{2} u}{\partial z^{2}}+k \frac{\partial u}{\partial y}\right]
$$

Da mesma forma que anterior, substituindo nas equações (3.19) e (3.20), obtemos as equações:

$$
\begin{gathered}
\frac{\partial v}{\partial t}+u \frac{\partial v}{\partial x}+v \frac{\partial v}{\partial y}+w \frac{\partial v}{\partial z}-k u^{2}+\frac{\partial p}{\partial y}=\frac{1}{R e}\left[\frac{\partial^{2} v}{\partial x^{2}}+\frac{\partial^{2} v}{\partial y^{2}}+\frac{\partial^{2} v}{\partial z^{2}}+k \frac{\partial u}{\partial y}\right] \\
\frac{\partial w}{\partial t}+u \frac{\partial w}{\partial x}+v \frac{\partial w}{\partial y}+w \frac{\partial w}{\partial z}+\frac{\partial p}{\partial z}=\frac{1}{R e}\left[\frac{\partial^{2} w}{\partial x^{2}}+\frac{\partial^{2} w}{\partial y^{2}}+\frac{\partial^{2} w}{\partial z^{2}}+k \frac{\partial w}{\partial y}\right]
\end{gathered}
$$

Os componentes de vorticidade nas três direções, definidos como o negativo do rotacional da velocidade são:

$$
\begin{aligned}
& \tilde{\omega}_{x}=\frac{\partial \tilde{v}}{\partial z}-\frac{\partial \tilde{w}}{\partial y}, \\
& \tilde{\omega}_{y}=\frac{\partial \tilde{w}}{\partial x}-\frac{\partial \tilde{u}}{\partial z}, \\
& \tilde{\omega}_{z}=\frac{\partial \tilde{u}}{\partial y}-\frac{\partial \tilde{v}}{\partial x} .
\end{aligned}
$$

Tomando-se o rotacional da equação de quantidade de movimento na forma vetorial e explorando a equação da continuidade, depois de simplificadas, eliminando-se os termos 
de curvatura de ordem elevada, obtém-se as equações de transporte dos componentes de vorticidade nas três direções:

$$
\begin{aligned}
\frac{\partial \widetilde{\omega}_{x}}{\partial t}+\frac{\partial \widetilde{a}}{\partial y}-\frac{\partial \widetilde{b}}{\partial z}+\frac{G o^{2}}{\sqrt{R e}} \frac{\partial \widetilde{d}}{\partial z} & =\frac{1}{R e} \nabla^{2} \widetilde{\omega}_{x}, \\
\frac{\partial \widetilde{\omega}_{y}}{\partial t}+\frac{\partial \widetilde{c}}{\partial z}-\frac{\partial \widetilde{a}}{\partial x} & =\frac{1}{R e} \nabla^{2} \widetilde{\omega}_{y}, \\
\frac{\partial \widetilde{\omega}_{z}}{\partial t}+\frac{\partial \widetilde{b}}{\partial x}-\frac{\partial \widetilde{c}}{\partial y}-\frac{G o^{2}}{\sqrt{R e}} \frac{\partial \widetilde{d}}{\partial x} & =\frac{1}{R e} \nabla^{2} \widetilde{\omega}_{z}, \\
\frac{\partial \tilde{u}}{\partial x}+\frac{\partial \tilde{v}}{\partial y}+\frac{\partial \tilde{w}}{\partial z} & =0
\end{aligned}
$$

onde

$$
\begin{aligned}
\widetilde{a} & =\widetilde{\omega}_{x} \widetilde{v}-\widetilde{\omega}_{y} \widetilde{u}, \\
\widetilde{b} & =\widetilde{\omega}_{z} \widetilde{u}-\widetilde{\omega}_{x} \widetilde{w}, \\
\widetilde{c} & =\widetilde{\omega}_{y} \widetilde{w}-\widetilde{\omega}_{z} \widetilde{v}, \\
\widetilde{d} & =\widetilde{u}^{2},
\end{aligned}
$$

são os produtos não-lineares. As variáveis $\left(\widetilde{u}, \widetilde{v}, \widetilde{w}, \widetilde{\omega}_{x}, \widetilde{\omega}_{y}, \widetilde{\omega}_{z}\right)$ são os componentes da velocidade e vorticidade na direção principal ao escoamento $x$, normal à parede $y$ e transversal ao escoamento $z$, e $t$ é o tempo.

Derivando-se a equação (3.38) em relação a $z$ e utilizando-se a equação de continuidade (3.32), obtém-se a equação de Poisson para a velocidade $\tilde{u}$ :

$$
\frac{\partial^{2} \tilde{u}}{\partial x^{2}}+\frac{\partial^{2} \tilde{u}}{\partial z^{2}}=-\frac{\partial \tilde{\omega}_{y}}{\partial z}-\frac{\partial^{2} \tilde{v}}{\partial x \partial y} .
$$

Derivando-se a equação de continuidade (3.32) em relação a $y$ e utilizando as definições dos componentes de vorticidade nas direções $x$ - equação (3.37) e $z$ - equação (3.39), obtém-se a equação de Poisson para a velocidade $\tilde{v}$ :

$$
\frac{\partial^{2} \tilde{v}}{\partial x^{2}}+\frac{\partial^{2} \tilde{v}}{\partial y^{2}}+\frac{\partial^{2} \tilde{v}}{\partial z^{2}}=-\frac{\partial \tilde{\omega}_{z}}{\partial x}+\frac{\partial \tilde{\omega}_{x}}{\partial z} .
$$

Derivando-se a equação (3.38) em relação a $x$ e utilizando a equação de continuidade (3.32), obtém-se a equação de Poisson para a velociadade $\tilde{w}$ : 


$$
\frac{\partial^{2} \tilde{w}}{\partial x^{2}}+\frac{\partial^{2} \tilde{w}}{\partial z^{2}}=\frac{\partial \tilde{\omega}_{y}}{\partial x}-\frac{\partial^{2} \tilde{v}}{\partial y \partial z}
$$

Para transferência de calor a seguinte equação de transporte de temperatura é utilizada:

$$
\frac{\partial \tilde{\theta}}{\partial t}+\frac{\partial \tilde{u} \tilde{\theta}}{\partial x}+\frac{\partial \widetilde{v} \tilde{\theta}}{\partial y}+\frac{\partial \widetilde{w} \tilde{\theta}}{\partial z}=\frac{1}{R e \operatorname{Pr}} \nabla^{2} \widetilde{\theta}
$$

onde $\operatorname{Pr}$ é o número de Prandtl e $\widetilde{\theta}$ é a temperatura adimensional dada por $\widetilde{\theta}=(T-$ $\left.T_{0}\right) /\left(T_{\infty}-T_{0}\right)$, onde $T$ é a temperatura, e $T_{\infty}$ e $T_{0}$ são os valores da temperatura fora da camada limite e na parede, respectivamente.

As variáveis das equações (3.34) a (3.36) são adimensionais e são relacionadas com variáveis dimensionais através de:

$$
\begin{aligned}
& x=\frac{x^{*}}{L} ; \quad y=\frac{y^{*}}{L} ; \quad z=\frac{z^{*}}{L} ; \\
& \tilde{u}=\frac{u^{*}}{U_{\infty}} ; \quad \tilde{v}=\frac{v^{*}}{U_{\infty}} ; \quad \tilde{w}=\frac{w^{*}}{U_{\infty}} ; \quad t=\frac{t^{*} U_{\infty}}{L} .
\end{aligned}
$$

O comprimento de referência é um comprimento característico da placa $L$ e a velocidade de referência é a velocidade não perturbada fora da camada limite $U_{\infty}$. O número de Prandtl é dado por $\operatorname{Pr}=\nu / \alpha$, onde $\nu$ é a viscosidade cinemática, $\alpha$ é a difusividade térmica do fluido, e os termos $G o^{2} \frac{\partial \widetilde{d}}{\partial x} /(\sqrt{R e})$ e $G o^{2} \frac{\partial \widetilde{d}}{\partial z} /(\sqrt{R e})$ são os termos de curvatura da parede.

\subsection{Formulação Perturbação}

Uma formulação perturbação é adotada no presente projeto, onde o escoamento é decomposto em um escoamento base e uma perturbação:

$$
\widetilde{\kappa}=\kappa_{b}+\kappa
$$

com esta formulação, a análise de estabilidade de qualquer tipo de escoamento base (Blasius, Falkner-Skan, etc.), pode ser realizada facilmente, assim como os termos lineares e não-lineares podem ser isolados. Algumas desvantagens desta formulação são o acesso indireto as variáveis instantâneas e o uso de maior quantidade de memória, causado pelo maior número de variáveis.

As variáveis $\widetilde{\kappa}=\left\{\widetilde{u}, \widetilde{v}, \widetilde{w}, \widetilde{\omega}_{x}, \widetilde{\omega}_{y}, \widetilde{\omega}_{z}, \widetilde{\theta}\right\}$ são as variáveis totais. O escoamento base, neste estudo, será considerado bi-dimensional, portanto somente $u_{b}, v_{b}, \omega_{z_{b}}$ e $\theta_{b}$ serão levados em consideração, onde o índice $b$ indica o escoamento base. 
Se a decomposição da equação (3.53) é introduzinda na equações (3.40), (3.41), (3.42) e (3.51), e também em (3.48), (3.49) e (3.50) e subtraindo as equações que compõem o escoamento base, obtém-se no final um conjunto de equações da seguinte forma:

$$
\begin{aligned}
\frac{\partial \omega_{x}}{\partial t}+\frac{\partial a}{\partial y}-\frac{\partial b}{\partial z}+\frac{G o^{2}}{\sqrt{R e}} \frac{\partial d}{\partial z} & =\frac{1}{R e} \nabla^{2} \omega_{x} \\
\frac{\partial \omega_{y}}{\partial t}+\frac{\partial c}{\partial z}-\frac{\partial a}{\partial x} & =\frac{1}{R e} \nabla^{2} \omega_{y} \\
\frac{\partial \omega_{z}}{\partial t}+\frac{\partial b}{\partial x}-\frac{\partial c}{\partial y}-\frac{G o^{2}}{\sqrt{R e}} \frac{\partial d}{\partial x} & =\frac{1}{R e} \nabla^{2} \omega_{z} \\
\frac{\partial \theta}{\partial t}+\frac{\partial e}{\partial x}+\frac{\partial f}{\partial y}+\frac{\partial g}{\partial z} & =\frac{1}{R e P r} \nabla^{2} \theta \\
\frac{\partial^{2} u}{\partial x^{2}}+\frac{\partial^{2} u}{\partial z^{2}} & =-\frac{\partial \omega_{y}}{\partial z}-\frac{\partial^{2} v}{\partial x \partial y} \\
\frac{\partial^{2} v}{\partial x^{2}}+\frac{\partial^{2} v}{\partial y^{2}}+\frac{\partial^{2} v}{\partial z^{2}} & =-\frac{\partial \omega_{z}}{\partial x}+\frac{\partial \omega_{x}}{\partial z} \\
\frac{\partial^{2} w}{\partial x^{2}}+\frac{\partial^{2} w}{\partial z^{2}} & =\frac{\partial \omega_{y}}{\partial x}-\frac{\partial^{2} v}{\partial y \partial z}
\end{aligned}
$$

onde os termos não-lineares $a, b, c, d, e, f$ e $g$ são:

$$
\begin{aligned}
a & =\omega_{x}\left(v_{b}+v\right)-\omega_{y}\left(u_{b}+u\right), \\
b & =\left(\omega_{z_{b}}+\omega_{z}\right)\left(u_{b}+u\right)-\omega_{x} w, \\
c & =\omega_{y} w-\left(\omega_{z_{b}}+\omega_{z}\right)\left(v_{b}+v\right), \\
d & =2 u_{b} u+u^{2} \\
e & =u_{b} \theta+u \theta_{b}+u \theta \\
f & =v_{b} \theta+v \theta_{b}+v \theta, \\
g & =w\left(\theta_{b}+\theta\right) .
\end{aligned}
$$

No próximo capítulo são apresentados os métodos numéricos utilizados para a discretização das equações apresentadas neste capítulo e as condições de contorno utilizadas. 



\section{Capítulo}

\section{Método Numérico}

Neste capítulo é apresentado o método numérico adotado para a discretização das equações apresentadas no capítulo anterior. Primeiramente, é apresentado o método espectral usado na direção transversal z. As derivadas temporais são aproximadas utilizando-se um método do tipo Runge-Kutta de $4^{a}$ ordem de precisão Ferziger e Peric [1997]. A seguir são apresentadas as derivadas espaciais, as quais serão discretizadas utilizando-se esquemas de diferenças finitas compactas de alta ordem de precisão [Souza et al., 2005, Souza, 2003, Lele, 1992]. Por último, é apresentada a equação de Poisson para velocidade $V$, que é resolvida utilizando-se um método multimalha paralelizado do tipo FAS (do inglês Full Approximation Scheme) Stüben e Trottenberg [1981]. Como pretende-se utilizar malhas refinadas e muitos pontos para se obter resultados que representem a física do fenômeno, é adotada uma paralelização do código, com partição do domínio na direção $x$.

\subsection{Método Espectral}

Baseado em evidências experimentais, assume-se o escoamento periódico na direção transversal ao experimento $(z)$. Desta forma, as variáveis podem ser expandidas em séries de Fourier com $k$ modos de Fourier na direção transversal:

$$
\psi(x, y, z, t)=\sum_{k=0}^{K} \hat{\Psi}_{k}(x, y, t) e^{-i \beta_{k} z}
$$

onde

$$
\psi(x, y, z, k) \rightarrow u, v, w, \omega_{x}, \omega_{y}, \omega_{z}, \theta, a, b, c, d, e, f, g
$$


são as variáveis no espaço físico e

$$
\hat{\Psi}_{k}(x, y, t) \rightarrow U_{k}, V_{k}, W_{k}, \Omega_{x_{k}}, \Omega_{y_{k}}, \Theta_{k}, \Omega_{z_{k}}, A_{k}, B_{k}, C_{k}, D_{k}, E_{k}, F_{k}, G_{k}
$$

são as variáveis no espaço de Fourier. Nesta equação, $\beta_{k}$ é o número de onda na direção transversal dado por $\beta_{k}=2 \pi k / \lambda_{z}, \lambda_{z}$ é o comprimento de onda na direção transversal do modo fundamental de Fourier, $k$ representa o modo de Fourier, e $i=\sqrt{-1}$.

Substituindo estas transformações nas equações de transporte de vorticidade (equações 3.53 a 3.55); na equação de transporte de temperatura (equação 3.56) e nas equações do tipo Poisson para as velocidades (equações 3.57 a 3.59) pode-se obter as equações no espaço de Fourier para cada modo k:

$$
\begin{aligned}
\frac{\partial \Omega_{x_{k}}}{\partial t}+\frac{\partial A_{k}}{\partial y}+i \beta_{k} B_{k}-\frac{G o^{2}}{\sqrt{R e}} i \beta_{k} D_{k}^{2} & =\frac{1}{R e} \nabla_{k}^{2} \Omega_{x_{k}} \\
\frac{\partial \Omega_{y_{k}}}{\partial t}-i \beta_{k} C_{k}-\frac{\partial A_{k}}{\partial x} & =\frac{1}{R e} \nabla_{k}^{2} \Omega_{y_{k}} \\
\frac{\partial \Omega_{z_{k}}}{\partial t}+\frac{\partial B_{k}}{\partial x}+\frac{\partial C_{k}}{\partial y}-\frac{G o^{2}}{\sqrt{R e}} \frac{\partial D_{k}^{2}}{\partial x} & =\frac{1}{R e} \nabla_{k}^{2} \Omega_{z_{k}} \\
\frac{\partial \Theta_{k}}{\partial t}+\frac{\partial E_{k}}{\partial x}+\frac{\partial F_{k}}{\partial x}-i \beta_{k} G & =\frac{1}{R e P r} \nabla_{k}^{2} \Theta_{k} \\
\frac{\partial^{2} U_{k}}{\partial x^{2}}-\beta_{k}^{2} U_{k} & =i \beta_{k} \Omega_{y_{k}}-\frac{\partial^{2} V_{k}}{\partial x \partial y} \\
\frac{\partial^{2} V_{k}}{\partial x^{2}}+\frac{\partial^{2} V_{k}}{\partial y^{2}}-\beta_{k}^{2} V_{k} & =-\frac{\partial \Omega_{z_{k}}}{\partial x}-i \beta_{k} \Omega_{x_{k}} \\
\frac{\partial^{2} W_{k}}{\partial x^{2}}-\beta_{k}^{2} W_{k} & =\frac{\partial \Omega_{y_{k}}}{\partial x}+i \beta_{k} \frac{\partial V_{k}}{\partial y}
\end{aligned}
$$

onde $\nabla_{k}^{2}=\left(\frac{\partial^{2}}{\partial x^{2}}+\frac{\partial^{2}}{\partial y^{2}}-\beta_{k}^{2}\right)$.

As equações (4.2) a (4.8) são resolvidas numericamente em um domínio de integração mostrado esquematicamente na figura (3.1). Os cálculos são realizados em uma malha uniforme, ortogonal, paralela a parede. O fluido entra no domínio computacional em $x=x_{0}$ e sai no contorno de saída em $x=x_{\max }$. As perturbações são introduzidas no campo através de sucção e injeção de massa em uma fenda na parede. Esta fenda é localizada entre $x_{1}$ e $x_{2}$. Na região localizada entre $x_{3}$ e $x_{4}$ uma região de relaminarização é implementada de forma a evitar reflexões de perturbações no contorno de saída. Nas simulações realizadas uma camada limite baseada na solução das equações de NavierStokes bidimensional é adotada como escoamento base. 


\subsection{Derivadas Temporais}

Neste estudo deseja-se captar os efeitos transientes, e para simular adequadamente estes efeitos é necessário empregar incrementos de tempo na simulação numérica $(\triangle t)$ relativamente pequenos, da mesma ordem de grandeza necessária para que se satisfaçam os critérios de estabilidade numérica. Desta forma optou-se pelo método explícito do tipo Runge-Kutta de $4^{a}$ ordem de precisão.

As equações de transporte de vorticidade (equações 4.2 a 4.4), são usadas para se determinar o valor dos componentes de vorticidade em cada ponto do domínio computacional no tempo $t=t_{0}+\triangle t$, exceto nos contornos inferior e de entrada do domínio. $\mathrm{O}$ método adotado funciona em 4 passos, de acordo com as equações abaixo:

$$
\begin{aligned}
\Omega^{\left(n+\frac{1}{2}\right)^{*}}= & \Omega^{n}+\frac{\Delta t}{2} f\left(t^{n}, \Omega^{n}\right), \\
\Omega^{\left(n+\frac{1}{2}\right)^{* *}}= & \Omega^{n}+\frac{\Delta t}{2} f\left(t^{n+\frac{1}{2}}, \Omega^{\left(n+\frac{1}{2}\right)^{*}}\right), \\
\Omega^{(n+1)^{*}}= & \Omega^{n}+\Delta t f\left(t^{n+\frac{1}{2}}, \Omega^{\left(n+\frac{1}{2}\right)^{* *}}\right), \\
\Omega^{n+1}= & \Omega^{n}+\frac{\Delta t}{6}\left[f\left(t^{n}, \Omega^{n}\right)+2 f\left(t^{n+\frac{1}{2}}, \Omega^{\left(n+\frac{1}{2}\right)^{*}}\right)\right. \\
& \left.+2 f\left(t^{n+\frac{1}{2}}, \Omega^{\left(n+\frac{1}{2}\right)^{* *}}\right)+f\left(t^{n+1}, \Omega^{(n+1)^{*}}\right)\right] .
\end{aligned}
$$

\subsection{Derivadas Espaciais}

O cálculo das derivadas espaciais nas direções $x$ e $y$ é realizado através do método de diferenças finitas compactas, ou diferenças compactas. As diferenças compactas, também conhecidas como diferenças Hermitianas, datam de 1878, de acordo com Kopal [1961]. Kopal mostra em seu livro a utilização de interpolação Hermitiana e mostra que a ordem de precisão obtida através desta formulação é muito superior à obtida através da forma lagrangiana. Collatz [1966] na introdução de métodos hermitianos, diz que o ganho em precisão por este método não é obtido com a inclusão de mais pontos, como ocorre em outros métodos, mas baseado no fato de que a derivação de cada equação individual de diferenças é satisfeita em diversos pontos ao mesmo tempo ao invés de em um apenas. Collatz mostra que em 1935 já existiam trabalhos científicos que utilizavam diferenças finitas compactas de $4^{a}$ ordem para o cálculo de segunda derivada. Collatz mostra ainda que a inclusão de derivada de primeira e segunda ordem em uma mesma fórmula, aumenta a precisão da mesma, como é proposto por Mahesh [1998].

Vários pesquisadores já realizaram pesquisa otimizando e mostrando as vantagens em 
se utilizar diferenças finitas compactas (Hirsh [1975], Adam [1977], Mahesh [1998], Lele [1992], Souza et al. [2005]). Os esquemas adotados neste estudo são de $5^{a}$ e $6^{a}$ ordens de precisão. A vantagem do esquema adotado é que a matriz que deve ser resolvida, para se obter os valores da derivada é tridiagonal. Para os pontos próximos ao contorno, Lele propõe aproximações de $3^{a}$ e $4^{a}$ ordem. Neste estudo adota-se aproximações de $6^{a}$ ordem para o ponto próximo ao contorno e aproximações de $5^{a}$ ordem para o ponto no contorno. Aproximações de $6^{a}$ ordem para o contorno foram testadas, mas resultaram em instabilidades numéricas.

A seguir são mostradas as matrizes adotadas para o cálculo das primeiras e segundas derivadas. Estas matrizes são utilizadas para o cálculo das derivadas nas direções $x$ e $y$. Portanto, nas matrizes abaixo mostradas, o valor de $N$ pode ser imax ou jmax, e deve-se substituir o $h$ pelo $d x$ ou $d y$ conforme a direção da derivada. As vantagens em se utilizar estas aproximações em estudos de transição laminar-turbulento são apresentadas em Souza et al. [2005].

\subsubsection{Cálculo da Primeira Derivada}

Para o ponto no contorno, $i=1$, adotou-se a aproximação descentrada de $5^{a}$ ordem:

$f_{1}^{\prime}+4 f_{2}^{\prime}=\frac{1}{24 . h}\left(-74 f_{1}+16 f_{2}+72 f_{3}-16 f_{4}+2 f_{5}\right)+O\left(h^{5}\right)$.

Para o ponto próximo a parede, $i=2$, adotou-se a aproximação descentrada de $6^{a}$ ordem:

$$
f_{1}^{\prime}+6 f_{2}^{\prime}+2 f_{3}^{\prime}=\frac{1}{120 . h}\left(-406 f_{1}-300 f_{2}+760 f_{3}-80 f_{4}+30 f_{5}-4 f_{6}\right)+O\left(h^{6}\right) .
$$

Para os pontos centrais adotou-se a seguinte aproximação:

$$
f_{i-1}^{\prime}+3 f_{i}^{\prime}+f_{i+1}^{\prime}=\frac{1}{12 . h}\left(-f_{i-2}-28 f_{i-1}+28 f_{i+1}+f_{i+2}\right)+O\left(h^{6}\right) .
$$

Para o caso $i=N$ e $i=N-1$ as aproximações são análogas as utilizadas para os pontos $i=1$ e $i=2$, com inversão do sinal. Para o cálculo de todas as derivadas, há a necessidade de inversão de uma matriz ou da aplicação do algoritmo de Thomas, para uma matriz tridiagonal. A equação a ser resolvida é: $E f^{\prime}=G f$, que resulta em:

$$
\left[\begin{array}{ccccccccc}
1 & 4 & & & & & & & \\
1 & 6 & 2 & & & & & & \\
& \cdot & \cdot & \cdot & & & & & \\
& & & 1 & 3 & 1 & & & \\
& & & & & \cdot & \cdot & \cdot & \\
& & & & & & 2 & 6 & 1 \\
& & & & & & & 4 & 1
\end{array}\right]\left[\begin{array}{c}
f_{1}^{\prime} \\
f_{2}^{\prime} \\
\cdot \\
f_{i}^{\prime} \\
\cdot \\
f_{N-1}^{\prime} \\
f_{N}^{\prime}
\end{array}\right]=
$$




$$
=\frac{1}{h}\left[\begin{array}{c}
\frac{1}{24}\left(-74 f_{1}+16 f_{2}+72 f_{3}-16 f_{4}+2 f_{5}\right) \\
\frac{1}{120}\left(-406 f_{1}-300 f_{2}+760 f_{3}-80 f_{4}+30 f_{5}-4 f_{6}\right) \\
\cdot \\
\frac{1}{12}\left(-f_{i-2}-28 f_{i-1}+28 f_{i+1}+f_{i+2}\right) \\
\cdot \\
\frac{1}{120}\left(406 f_{N}+300 f_{N-1}-760 f_{N-2}+80 f_{N-3}-30 f_{N-4}+4 f_{N-5}\right) \\
\frac{1}{24}\left(74 f_{N}-16 f_{N-1}-72 f_{N-2}+16 f_{N-3}-2 f_{N-4}\right)
\end{array}\right] .
$$

\subsubsection{Cálculo da Segunda Derivada}

Para o ponto no contorno, $i=1$, adotou-se a aproximação descentrada de $5^{a}$ ordem: $13 f_{1}^{\prime \prime}+137 f_{2}^{\prime \prime}=\frac{1}{120 \cdot h^{2}}\left(9775 f_{1}-20285 f_{2}+11170 f_{3}-550 f_{4}-145 f_{5}+36 f_{6}\right)+O\left(h^{5}\right)$.

Para o ponto próximo a parede, $i=2$, adotou-se a aproximação descentrada de $6^{a}$ ordem:

$f_{1}^{\prime \prime}+12 f_{2}^{\prime \prime}+3 f_{3}^{\prime \prime}=\frac{1}{360 . h^{2}}\left(4834 f_{1}-8424 f_{2}+1890 f_{3}+2320 f_{4}-810 f_{5}+216 f_{6}-26 f_{7}\right)+O\left(h^{6}\right)$.

Para os pontos centrais utilizou-se a seguinte aproximação:

$2 f_{i-1}^{\prime \prime}+11 f_{i}^{\prime \prime}+2 f_{i+1}^{\prime \prime}=\frac{1}{4 . h^{2}}\left(3 f_{i-2}+48 f_{i-1}-102 f_{i}+48 f_{i+1}+3 f_{i+2}\right)+O\left(h^{6}\right)$.

Para os pontos $i=N$ e $i=N-1$ as aproximações são análogas às obtidas para os pontos $i=1$ e $i=2$. A equação a ser resolvida é: $H f^{\prime \prime}=I f$, que resulta em:

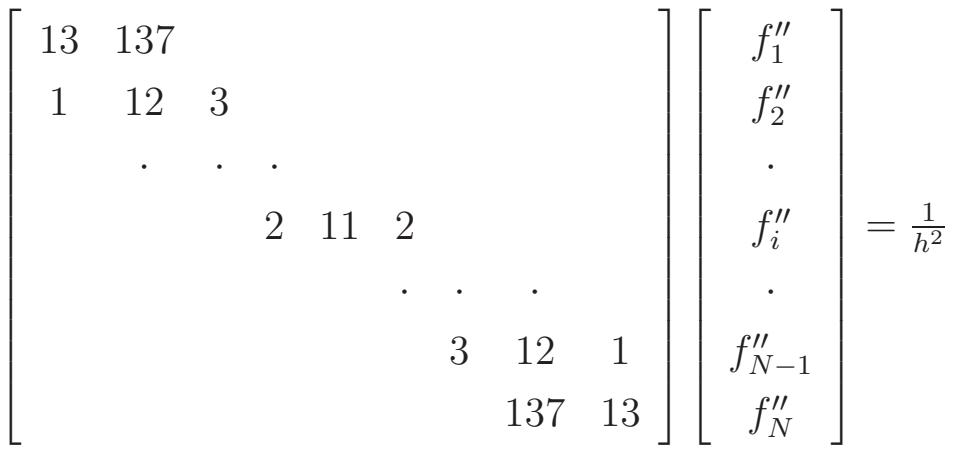

$$
\begin{aligned}
& {\left[\begin{array}{c}
\frac{1}{120}\left(9775 f_{1}-20285 f_{2}+11170 f_{3}-550 f_{4}-145 f_{5}+36 f_{6}\right) \\
\frac{1}{360}\left(4834 f_{1}-8424 f_{2}+1890 f_{3}+2320 f_{4}-810 f_{5}+216 f_{6}-26 f_{7}\right) \\
\cdot \\
\frac{1}{4}\left(3 f_{i-2}+48 f_{i-1}-102 f_{i}+48 f_{i+1}+3 f_{i+2}\right) \\
\cdot \\
\frac{1}{360}\left(4834 f_{N}-8424 f_{N-1}+1890 f_{N-2}+2320 f_{N-3}-810 f_{N-4}+216 f_{N-5}-26 f_{N-6}\right) \\
\frac{1}{120}\left(9775 f_{N}-20285 f_{N-1}+11170 f_{N-2}-550 f_{N-3}-145 f_{N-4}+36 f_{N-5}\right)
\end{array}\right] .}
\end{aligned}
$$

Como já foi comentado, há a necessidade da solução de um sistema tridiagonal para se encontrar o valor das derivadas, onde se leva em consideração todos os pontos na direção 
em que se está calculando a derivada. Na direção $x$, onde há o particionamento do domínio para paralelização do código, é necessária a adaptação do algoritmo de Thomas (ver Press et al. [1987]). Esta adaptação foi feita usando a técnica de pipeline, já que o mesmo sistema tem que ser resolvido para todos as linhas do domínio nas direções $y$ e $z$. Isto foi feito visando minimizar o tempo gasto para solução destes sistemas tridiagonais.

\subsection{Equação de Poisson}

Na tese de Souza [2003] foi verificado que a subrotina mais cara na presente formulação é a solução numérica da equação de Poisson. Como foi feita a opção de decomposição do domínio na direção $x$, é utilizado um algoritmo multigrid paralelizado. Os métodos multigrid podem resolver equações diferenciais parciais elípticas discretizadas em $N$ pontos em $N$ operações, enquanto outros métodos como por exemplo o método da sobre relaxação sucessiva (SOR - do inglês Successive Over Relaxation) resolve em $N \log N$ operações. Um estudo da performance de métodos de solução da equação de Poisson em um código de simulação de escoamentos de fluidos incompressíveis é apresentada por Souza et al. [2006].

Existem vários métodos multigrid que resolvem problemas elípticos. Para maiores detalhes de métodos multigrid pode-se consultar Briggs [1987], Gupta et al. [1997], Spitaleri [2000], Zhang [1996, 1997], entre outros. O algoritmo aqui adotado é o esquema de aproximação total (FAS - do inglês Full Approximation Scheme) (Stüben e Trottenberg [1981]). Neste estudo, optou-se pela utilização de um ciclo $V$ com 4 malhas. A equação de Poisson (Eq. 4.7), pode ser escrita na seguinte forma:

$$
\nabla^{2} f c=t f
$$

onde $\nabla^{2}$ é o operador laplaciano, $f c$ é igual a $V_{k}$, ou seja, a componente da velocidade na direção normal à parede do modo $k$ de Fourier e $t f$ é o termo fonte da equação. Esta equação é resolvida em cada malha, utilizando-se um método de sobre relaxação sucessiva por linha (LSOR - do inglês Line Successive Over Relaxation). O valor do fator de relaxação usado no método LSOR, quando se está indo da malha mais grossa para a mais fina deve ser igual a 1, caso contrário não ocorre a suavização das altas frequências, que é crucial para o funcionamento do método.

Levando-se em consideração o método espectral, e que $i$ corresponde a uma linha na direção $y$ e $j$ corresponde uma uma linha na direção $x$, a discretização da equação é realizada da seguinte maneira: 
- Na direção $x$ :

$$
\begin{aligned}
& \frac{\partial^{2} V_{k}}{\left.\partial x^{2}\right|_{2, j}=} \frac{1}{12 \Delta x^{2}}\left[10 V_{k_{1, j}}-15 V_{k_{2, j}}-4 V_{k_{3, j}}+\right. \\
&\left.+14 V_{k_{4, j}}-6 V_{k_{5, j}}+V_{k_{6, j}}\right]+O\left(\Delta x^{4}\right) \\
&\left.\frac{\partial^{2} V_{k}}{\partial x^{2}}\right|_{3 \leq i \leq p t s x-2, j}= \frac{1}{12 \Delta x^{2}}\left[-V_{k_{i-2, j}}+16 V_{k_{i-1, j}}-30 V_{k_{i, j}}+\right. \\
& \frac{\left.\left.\partial^{2} V_{k}\right|_{p x^{2}}\right|_{p t s x-1, j}=}{\left.16 V_{k_{i+1, j}}-V_{k_{i+2, j}}\right]+O\left(\Delta x^{4}\right)} \\
&\left.+14 V_{k_{p t s x-3, j}}-6 V_{k_{p t s x-4, j}}+V_{k_{p t s x-5, j}}\right]+O\left(\Delta x^{4}\right),
\end{aligned}
$$

onde $p t s x$ corresponde ao último ponto, na direção $x$, de cada subdomínio que é resolvido em um nó do cluster.

- Na direção y as seguintes aproximações são utilizadas:

Para $j=2$ :

$$
\left.4 \frac{\partial^{2} V_{k}}{\partial y^{2}}\right|_{i, 2}+\left.\frac{\partial^{2} V_{k}}{\partial y^{2}}\right|_{i, 3}=\frac{1}{36 \Delta y^{2}}\left[254 V_{k_{i, 1}}-432 V_{k_{i, 2}}+162 V_{k_{i, 3}}+16 V_{k_{i, 4}}\right]+O\left(\Delta y^{5}\right)
$$

Para $3 \leq j \leq j \max -2$ :

$$
\begin{aligned}
\left.2 \frac{\partial^{2} V_{k}}{\partial y^{2}}\right|_{i, j-1}+\left.11 \frac{\partial^{2} V_{k}}{\partial y^{2}}\right|_{i, j}+\left.2 \frac{\partial^{2} V_{k}}{\partial y^{2}}\right|_{i, j+1}= & \frac{1}{4 \Delta y^{2}}\left[3 V_{k_{i, j-2}}+48 V_{k_{i, j-1}}-102 V_{k_{i, j}}+\right. \\
& \left.+48 V_{k_{i, j+1}}+3 V_{k_{i, j+2}}\right]+O\left(\Delta y^{6}\right) .
\end{aligned}
$$


Para $j=j \max -1$ :

$$
\left.\frac{\partial^{2} V_{k}}{\partial y^{2}}\right|_{i, j \max -1}=\frac{1}{\Delta y^{2}}\left[V_{k_{i, j \max -2}}-2 V_{k_{i, j \max -1}}+V_{k_{i, j \max }}\right]+O\left(\Delta y^{2}\right) .
$$

Para $j=j \max$ :

$$
\left.\frac{\partial^{2} V_{k}}{\partial y^{2}}\right|_{i, j \max }=\frac{-7 V_{k_{i, j \max }}+8 V_{k_{i, j \max -1}}-V_{k_{i, j \max -2}}}{2 \Delta y^{2}}+\left.\frac{3}{\Delta y} \frac{\partial V_{k}}{\partial y}\right|_{i, j \max }+O\left(\Delta y^{2}\right) .
$$

onde jmax corresponde ao último ponto na direção normal à parede.

- Na direção z a discretização já foi realizada no momento em que se adotou método espectral nesta direção, portanto para cada modo $k$ de Fourier tem-se:

$$
\frac{\partial^{2} v}{\partial z^{2}}=-k^{2} \beta^{2} V_{k}
$$

Os valores de jmax e ptsx variam de acordo com o tamanho do domínio e da distância entre dois pontos consecutivos necessária à simulação. Com as aproximações acima é montada uma matriz pentadiagonal que é resolvida para cada coluna do domínio. A solução desta matriz para todas as colunas do domínio é chamada de iteração.

O esquema multigrid funciona da seguinte maneira, tomando $h$ como sendo a distância entre 2 pontos da malha mais fina primeiro realiza-se 2 iterações na malha mais fina $(h)$ :

$$
\nabla^{2} f c_{h}=t f_{h}
$$

Após, é calculado o resíduo $\left(d_{h}\right)$ :

$$
d_{h}=t f_{h}-\nabla^{2} f c_{h}
$$

Para passar os valores das variáveis de uma malha mais fina $(h)$ para uma mais grossa (2h) faz-se uma operação chamada de restrição. Os seguintes termos sofrem esta operação:

$$
\begin{aligned}
f c_{h}^{i} & \Rightarrow f c_{2 h}^{0} \quad(S I), \\
d_{h}^{i} & \Rightarrow d_{2 h}^{0} \quad(F W),
\end{aligned}
$$

onde SI (do inglês Straight Injection) significa que os valores da variável na malha mais fina são passados para a malha mais grossa sem calcular-se uma média e $F W$ (do inglês Full Weight) significa que há uma ponderação dos valores da variável da malha mais fina para a malha mais grossa. 
Em seguida é realizado o cálculo do termo fonte para a segunda malha $(2 h)$ através de:

$$
t f_{2 h}=d_{2 h}^{0}+\nabla^{2} f c_{2 h}^{0}
$$

Novamente faz-se 2 iterações na segunda malha $(2 h)$ :

$$
\nabla^{2} f c_{2 h}=t f_{2 h}
$$

Calcula-se do resíduo $\left(d_{2 h}\right)$ nesta malha:

$$
d_{2 h}=t f_{2 h}-\nabla^{2} f c_{2 h},
$$

e assim sucessivamente, até a malha mais grossa (8h), onde são realizadas 10 iterações:

$$
\nabla^{2} f c_{8 h}=t f_{8 h}
$$

Para retornar à malha mais fina, primeiro calcula-se a correção da malha mais grossa:

$$
\operatorname{corr}_{8 h}=f c_{8 h}^{i}-f c_{8 h}^{0} .
$$

Para se passar os valores da variável $\operatorname{corr}_{8 h}$ da malha mais grossa para a malha mais fina subsequente faz-se uma interpolação bilinear destes valores:

$$
\operatorname{corr}_{8 h} \Rightarrow \operatorname{corr}_{4 h}
$$

Em seguida, calcula-se os novos valores do termo $f c_{4 h}$ :

$$
f c_{4 h}=f c_{4 h}^{i}+\operatorname{corr}_{4 h}
$$

Realiza-se uma iteração na terceira malha $(4 h)$ :

$$
O f c_{4 h}=f_{4 h},
$$

e assim sucessivamente até a iteração na malha mais fina $(h)$ :

$$
O f c_{h}=t f_{h} .
$$

O número de ciclos $V$ utilizados para a solução da equação depende do valor do resíduo na malha mais fina. Se o maior valor do resíduo em todos os nós for menor que um valor de referência estipulado o procedimento é interrompido e a aproximação obtida é tomada como a resposta. O valor de referência adotado nas simulações realizadas no presente estudo foi de $10^{-6}$.

Para resolução com a divisão do domínio em subdomínios para serem resolvidos em 
nós separados é necessário uma atenção especial na comunicação dos valores da função $f c$ entre os subdomínios. Estas comunicações são realizadas em todas as malhas do método multigrid. As comunicações são realizadas nos seguintes pontos:

- A cada iteração no método LSOR;

- Depois de efetuada a operação de restrição;

- Depois de efetuada a operação de correção.

A figura 4.1 ilustra as comunicações que ocorrem entre dois nós do método multigrid paralelizado. Nesta ilustração são utilizadas 4 malhas sendo a "Malha 1"a mais refinada e a "Malha 4"a malha mais grossa. A discretização da derivada segunda na direção $x$ é realizada através de diferenças finitas com 5 pontos de estêncil nos pontos na região central do domínio. Portanto tem que se deixar 4 pontos de interseção na malha mais grossa - Malha 4. Com isto, à medida que se refina a malha, até a malha mais fina, o número de pontos utilizados na interseção aumenta. Portanto o número de malhas e o estêncil adotados no método multigrid é que definem o número de pontos de interseção.

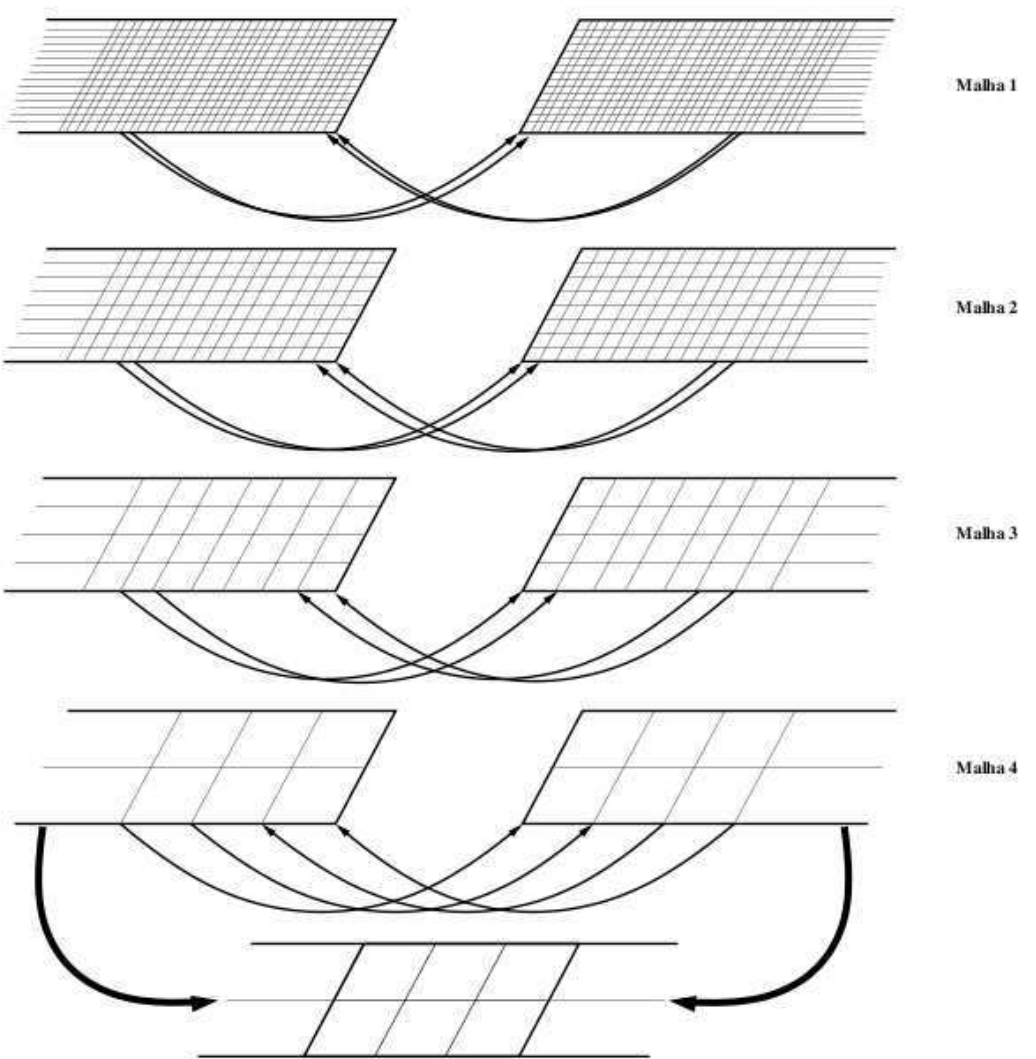

Figura 4.1: Ilustração do número de pontos utilizado para comunicação. 


\subsection{Condições de Contorno}

As equações governantes são completadas por condições de contorno específicas. Na parede $(y=0)$, a condição de não escorregamento foi imposta para as componentes de velocidade na direção longitudinal $\left(U_{k}\right)$ e na transversal $\left(W_{k}\right)$. A componente de velocidade normal a parede $\left(V_{k}\right)$ foi especificada na região entre sucção e injeção de massa entre $x_{1}$ e $x_{2}$ da figura (3.1), onde as perturbações foram introduzidas. Fora desta região, a componente de velocidade foi tomada como sendo zero. A função que gera a perturbação, para gerar os vórtices de Görlter, usada para a velocidade normal a parede $V_{k}=1$ é:

$$
V_{k=1}(i, 0, t)=A \sin ^{3}(\varepsilon) \quad \text { para } \quad x_{1} \leq x_{2},
$$

$\mathrm{e}$

$$
V_{k=1}(i, 0, t)=0 \quad \text { para } \quad x<x_{1}, \quad \text { e } \quad x>x_{2},
$$

onde $\varepsilon=\left(x-x_{1}\right) /\left(x_{2}-x_{1}\right)$ e $A$ é uma constante real escolhida para ajustar a amplitude de perturbação. Para todos os 21 modos de Fourier diferentes de 1, o valor da velocidade na parede foi de $V_{k}=0$.

Na condição de entrada $\left(x=x_{0}\right)$, as componentes de velocidade, vorticidade e temperatura são especificadas como base nas soluções de similaridade. Na condição de saída $\left(x=x_{\max }\right)$ a derivada segunda com respeito a direção longitudinal da velocidade e vorticidade são zero. No limite superior $\left(y=y_{\max }\right)$, o escoamento é considerado não rotacional. Isto é satisfeito pelas componentes de vorticidade e suas derivadas serem zero. A componente de velocidade normal a parede no limite superior é colocada de acordo com a condição:

$$
\left.\frac{\partial V_{k}}{\partial y}\right|_{x, y_{\max }, t}=0 .
$$

esta é a condição imposta na solução da velocidade $U_{k}$ na equação de Poisson (4.6). As equações usadas para avaliar as componentes de velocidade na parede são:

$$
\begin{aligned}
\frac{\partial^{2} \Omega_{x k}}{\partial x^{2}}-\beta_{k}^{2} \Omega_{x k} & =-\frac{\partial^{2} \Omega_{y k}}{\partial x \partial y}-\beta_{k} \nabla_{k}^{2} V_{k} \\
\frac{\partial \Omega_{z, k}}{\partial x} & =\beta_{k} \Omega_{x k}-\nabla_{k}^{2} V_{k}
\end{aligned}
$$

Uma zona de amortecimento perto da condição de saída é definida para que todas as perturbações sejam gradualmente amortecidas até zero [Kloker et al., 1993]. Esta técnica foi usada para evitar reflexões na condição de saída. Meitz and Fasel [2000] adotaram 
polinómios de quinta ordem, e a mesma função foi usada no presente código. A ideia básica é multiplicar as componentes de vorticidade pela função $f_{1}(x)$ depois de cada subpasso do método de integração. Usando esta técnica as componentes de vorticidades são tomadas como:

$$
\Omega_{k}(x, y, t)=f_{1}(x) \Omega_{k}^{*}(x, y, t),
$$

onde $\Omega_{k}^{*}(x, y, t)$ é a perturbação da componente de vorticidade que resulta da integração de Runge-Kutta e $f_{1}(x)$ é a função que varia suavemente de 1 a 0 . A função implementada foi:

$$
f_{1}(x)=f(\varepsilon)=1-6 \varepsilon^{5}+15 \varepsilon^{4}-10 \varepsilon^{3},
$$

onde $\varepsilon=\left(x-x_{3}\right) /\left(x_{4}-x_{3}\right)$ para $x_{3} \leq x \leq x_{4}$.

Uma outra zona de amortecimento localizada perto do inflow também foi implementada neste código. Como apontado por Meitz [1996], nas simulações que envolvem vórtices longitudinais, reflexões através de vórtices na entrada do escoamento podem contaminar os resultados numéricos. A função de amortecimento é similar a usada na condição de saída.

$$
f_{2}(x)=f(\varepsilon)=6 \varepsilon^{5}-15 \varepsilon^{4}+10 \varepsilon^{3},
$$

onde $\varepsilon=(x-1) /\left(x_{1}-1\right)$ para $1 \leq x \leq x_{1}$. Todas as componentes de vorticidade foram multiplicadas por esta função nesta região a cada passo do Runge-Kutta

As condições de contorno para a perturbação da temperatura $(\theta)$ foram:

- No Inflow $\theta=0$;

- No Outflow $\theta=0$, desde que a mesma zona de amortecimento para a vorticidade também foi aplicada para a temperatura;

- Na parede $\theta=0$;

- No limite superior: os valores foram obtidos a partir da equação de transporte da temperatura.

No próximo capítulo são apresentadas a verificação e validação do presente código. 


\section{Capítulo 5 \\ Verificação e Validação}

Neste capítulo são apresentados resultados da avaliação do código adotado para estudo de transição. De acordo com os pesquisadores que se dedicam ao estudo de verificação e validação de códigos computacionais [Oberkampf e Trucano, 2002, Roache, 1997], a verificação está relacionada à implementação correta do modelo em um código computacional e a validação está relacionada à adequabilidade do modelo matemático em representar o problema físico que deseja estudar. De acordo com Roache [1997], em dinâmica dos fluidos computacional, a verificação significa resolver corretamente as equações do modelo e a validação significa resolver as equações corretas que representam um problema físico.

Reed et al. [1998] apresentam um estudo de verificação e validação na modelagem de transição, onde são apresentados os desafios a serem transpostos e a atual posição de códigos computacionais. Nesse trabalho, os autores atribuem os erros de verificação a erros de discretização, programação e precisão da máquina. A validação de acordo com eles, deve ser realizada através de comparação bem sucedida dos resultados obtidos numericamente com resultados de experimentos disponíveis na literatura.

Souza et al. [2005] apresentam um estudo de verificação de um código de simulação numérica direta desenvolvida para estudos de transição laminar-turbulento. Em Homero et al. [2010] utiliza-se o método das soluções manufaturadas - MMS, do inglês Method of Manufactured Solutions para a verificação do código. Com o método adotado foi possível avaliar a ordem de precisão do código como um todo, assim como a precisão da discretização realizada em cada direção separadamente.

No presente capítulo a verificação é realizada comparando-se os resultados obtidos com resultados obtidos através de outro código computacional [Liu e Lee, 1995], e a validação é realizada comparando-se os resultados obtidos com resultados experimentais [Swearingen e Blackwelder, 1987, Mitsudharmadi et al., 2004] disponíveis na literatura. Em todos as 
simulações apresentadas no presente capítulo, a solução de Navier-Stokes bidimensional foi utilizada como escoamento base.

Para a verificação, adotou-se os mesmos parâmetros de Liu e Lee [1995], onde o raio de curtatura da parede foi de $R=3,20 \mathrm{~m}$ e a velocidade de corrrente livre foi de $U_{\infty}=5$ $\mathrm{m} / \mathrm{s}$. O comprimento característico adotado foi de $L=0,1 \mathrm{~m}$. O número de Reynolds $R e=33124$ foi baseado no comprimento característico. O comprimento de onda usado foi de $\lambda_{z}=18 \mathrm{~mm}$, e o número de modos de Fourier foi $k=11$, com 32 pontos no espaço físico.

A figura 5.1 mostra a média do coeficiente de atrito na direção transversal $\left(C_{f}\right)$, normalizado pelo valor correspondente da camada limite laminar de Blasius. O coeficiente de atrito é calculado por:

$$
C_{f}=2 \frac{\left.\mu \frac{\partial u}{\partial y}\right|_{\text {wall }}}{U_{\infty}^{2}} .
$$

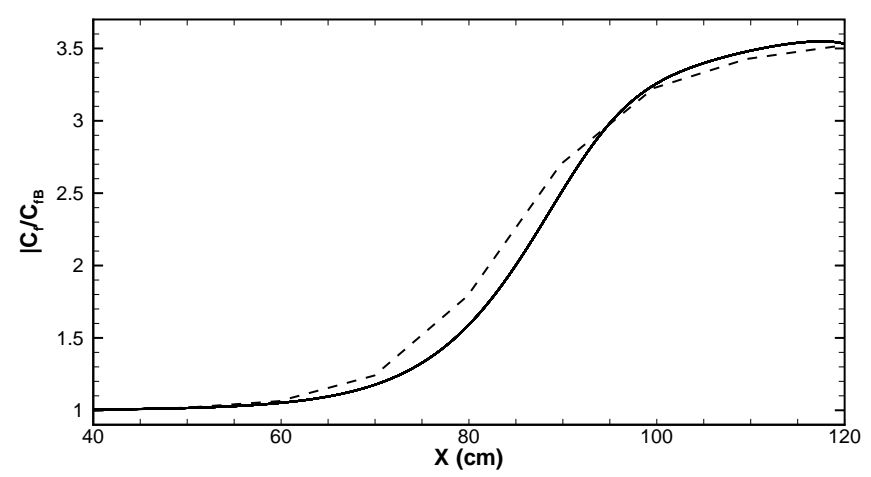

Figura 5.1: Comparação da média do coeficiente de atrito na direção transversal. Linha sólida - Presente código. Linha Tracejada - Resuldados numéricos Liu e Lee [1995].

Na Fig. 5.1 o resultado obtido com o presente código foi comparado com o de Liu e Lee [1995]. Uma similaridade dos resultados é observada, mostrando que a física do campo do escoamento é bem resolvida com o presente código. A comparação para verificar a transferência de calor no presente código foi realizada comparando a média do número de Nusselt na direção transversal. Novamente, comparando os valores com a camada limite de Blasius. Assim a transferência de calor é verificada com a evolução da média do número de Stanton da direção transversal $S t_{x}$ dado por:

$$
S t_{x}=\frac{N u_{x}}{\operatorname{Pr} R e_{x}}
$$

onde o número de Nusselt, $N u_{x}$, é dado por:

$$
N u_{x}=q_{w a l l} \frac{x}{k\left(T_{0}-T_{\infty}\right)}
$$


e $q_{\text {wall }}$ é o fluxo de calor na parede

$$
q_{w a l l}=-\left.k \frac{\partial T}{\partial y}\right|_{\text {wall }} .
$$

Duas comparações são realizadas, o primeiro caso com a média do número de Nusselt na direção transversal, e o segundo caso com a média do número de Nusselt em relação a distribuição local na direção transversal. Em ambas as comparações foram testados os números de Prandtl $\operatorname{Pr}=0,72$ e $\operatorname{Pr}=7,07$. O resultado obtido para o primeiro caso, com $\operatorname{Pr}=0,72$, são mostrados na figura 5.2. A variação em $x$ da média de $N u$ na direção $z$ é mostrado em comparação com os resultados obtidos por Liu e Lee [1995].

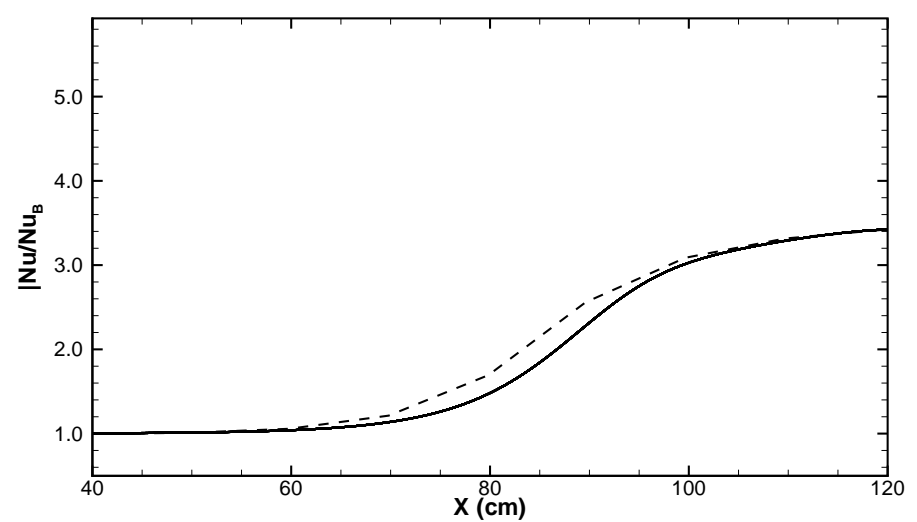

Figura 5.2: Comparação da variação em $x$ da média do de $N u$ na direção $z$ para $\operatorname{Pr}=0,72$. Linha sólida - Presente código. Linha Tracejada - Resuldados numéricos Liu e Lee [1995].

A figura 5.3 mostra o resultado obtido para a variação de $N u$ na direção $x$ com $\operatorname{Pr}=7,07$. Neste caso podemos observar um afastamento dos resultados entre $x=90$ e $x=120$. Isto pode ser explicado pelo fato dos resultados de Liu e Lee [1995] serem baseados num código de segunda ordem de precisão, e o presente código é baseado em um código de alta ordem.

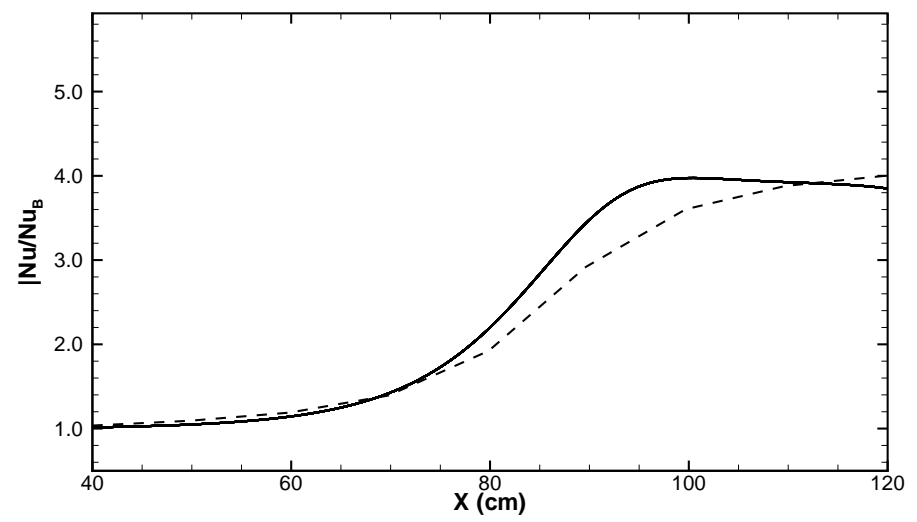

Figura 5.3: Comparação da variação em $x$ da média do de $N u$ na direção $z$ para $\operatorname{Pr}=7,07$. Linha sólida - Presente código. Linha Tracejada - Resuldados numéricos Liu e Lee [1995].

Os resultados obtidos para a distribuição de $N u$ na direção $z$ em três diferentes posições 
com $\operatorname{Pr}=0,72$ é mostrado na figura 5.4. Novamente, podemos notar um bom acordo com os resultados númericos de Liu e Lee [1995].

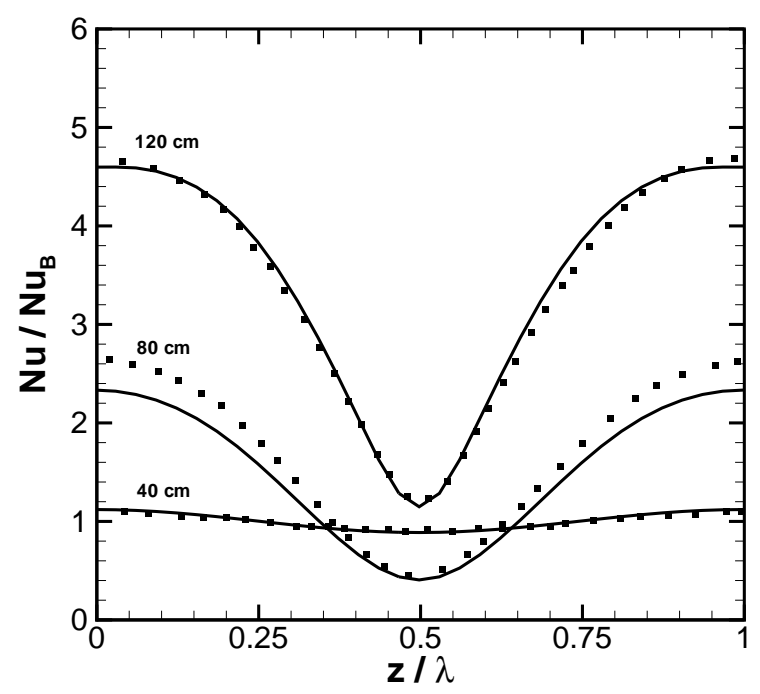

Figura 5.4: Distruibuição transversal do número de Nusselt, normalizado pelos valores correspondentes a placa plana de Blasius-Pohlhausen com o número de Prandtl $\mathrm{Pr}=0,72 \mathrm{em}$ três posições. $(x=40--80--120 \mathrm{~cm})$ Linha sólida - Presente código. Linha pontilhada Resuldados numéricos Liu e Lee [1995].

A figura 5.5 mostra os resultados da distribuição de $N u$ na direção $z$ em três diferentes posições obtidos para o caso dois com $\operatorname{Pr}=7,07$.

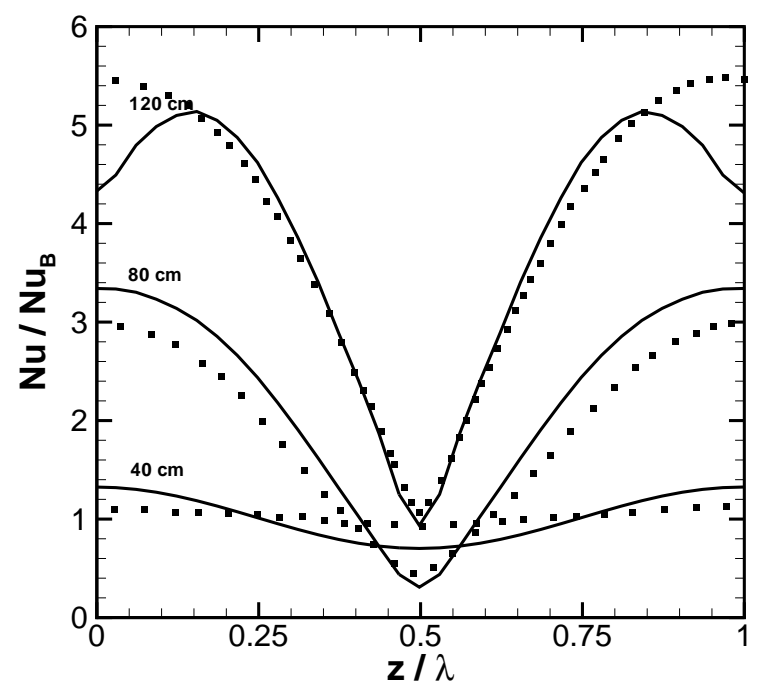

Figura 5.5: Distruibuição transversal do número de Nusselt, normalizado pelos valores correspondentes a placa plana de Blasius-Pohlhausen com o número de Prandtl $\operatorname{Pr}=7,07$. $(x=40--80--120 \mathrm{~cm})$ Linha sólida - Presente código. Linha pontilhada - Resuldados numéricos Liu e Lee [1995].

Para validação do código foram adotados os mesmos parâmetros de Mitsudharmadi 
et al. [2004, 2005a,b], onde o raio de curvatura da parede foi de $R=2 \mathrm{~m}$ e a velocidade de corrente livre $U_{\infty}=3 \mathrm{~m} / \mathrm{s}$. A distância entre dois pontos consecutivos em $x$ foi de $d x=0,0035$ e na direção $y$ o primeiro espaçamento foi de $d y=0,0004$ com estiramento de $1 \%$ a cada ponto da malha. O número de Prandtl adotado foi de $\operatorname{Pr}=0,72$, o número de pontos na direção $x$ e $y$ foram 1177, e 201, respectivamente. O número de modos de Fourier foi $k=21$ com 64 pontos no espaço físico.

A máxima perturbação de velocidade $U_{\max }$ para diferentes modos na direção $z$ é mostrada na figura 5.6. A figura mostra a comparação com Mitsudharmadi et al. [2004], onde a perturbação imposta no código concorda com o resultado experimental.

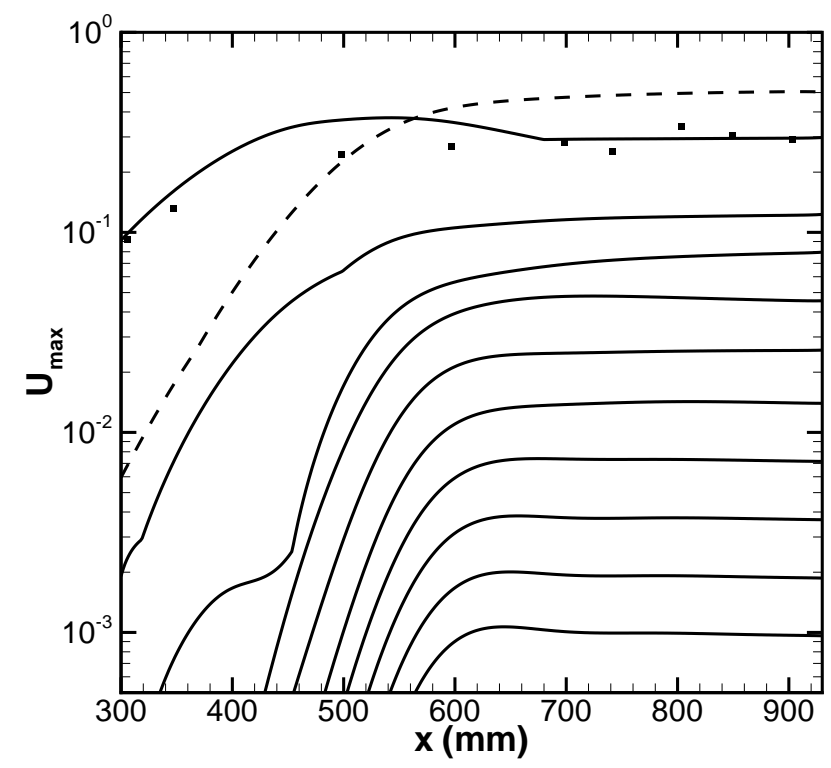

Figura 5.6: Distruibuição máxima da amplitude de perturbação. Linha sólida - Presente código. Símbolos - Resuldados experimentais Mitsudharmadi et al. [2004].

A comparação dos contornos de velocidade na direção longitudinal é mostrada nas figuras 5.7 a 5.22. Nota-se que para todos as posições uma grande semelhança na estrutura formada. Pode-se observar com estes resultados que o código numérico desenvolvido captura perfeitamente o crescimento dos vórtices de Görtler e os efeitos que os mesmos causam na camada limite, distorcendo-a. Portanto considera-se que o código foi validado, e que as equações adotadas representam de forma fidedigna a física do escoamento com transferência de calor a serem estudados.

No próximo capítulo são apresentados os resultados do escoamento contendo vórtices de Görtler em sua região linear e não-linear, e em seguida são apresentados os resultados com a taxa de tranferência de calor para a instabilidade primária, e também, para a instabilidade secundária. 


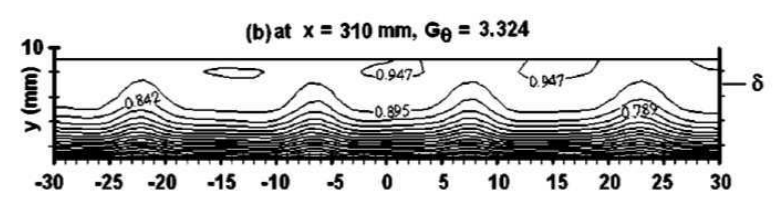

Figura 5.7: Contornos de velocidade, $x=$ $350 \mathrm{~mm}$ - - Mitsudharmadi et al. [2004].

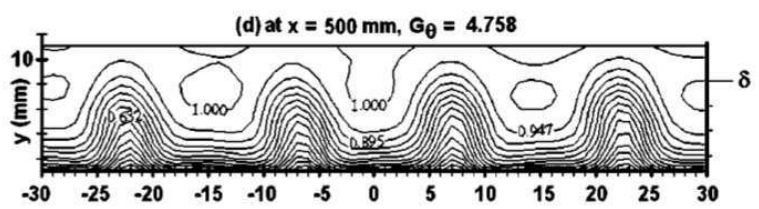

Figura 5.9: Contornos de velocidade, $x=$ $500 \mathrm{~mm}$ - - Mitsudharmadi et al. [2004].

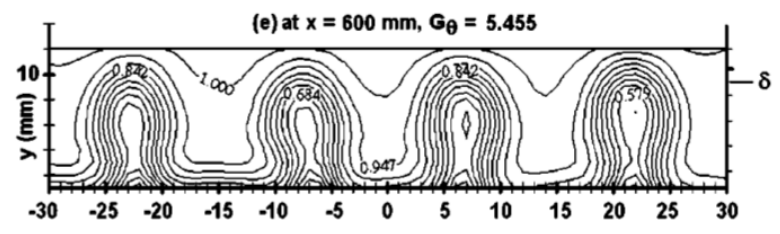

Figura 5.11: Contornos de velocidade, $x=600 \mathrm{~mm}$ - - Mitsudharmadi et al. [2004].

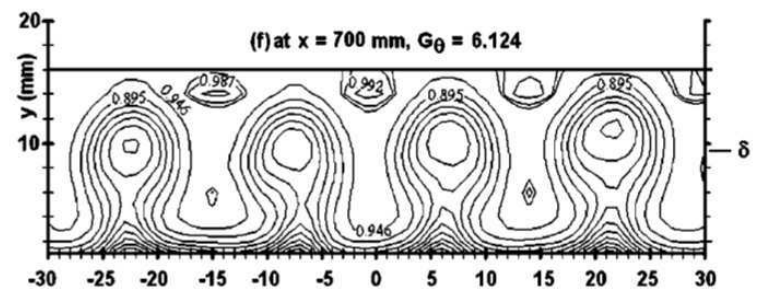

Figura 5.13: Contornos de velocidade, $x=700 \mathrm{~mm}$ - - Mitsudharmadi et al. [2004].

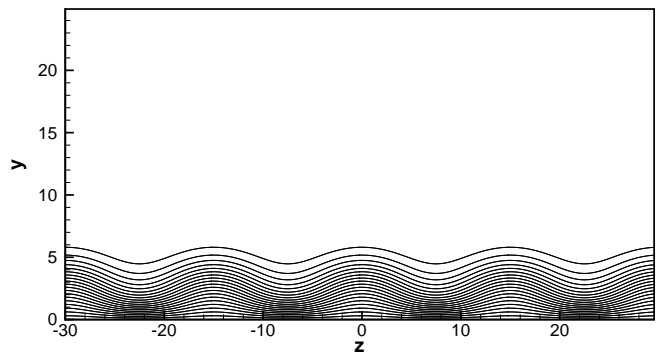

Figura 5.8: Contornos de velocidade, $x=$ $350 \mathrm{~mm}$

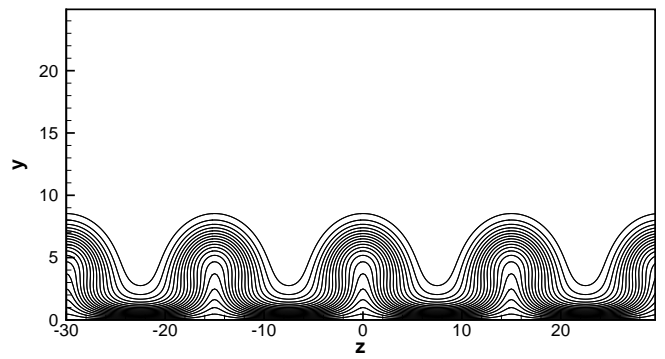

Figura 5.10: Contornos de velocidade, $x=$ $500 \mathrm{~mm}$.

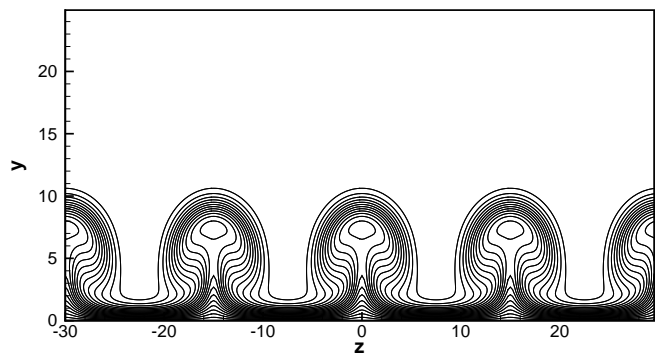

Figura 5.12: Contornos de velocidade, $x=$ $600 \mathrm{~mm}$

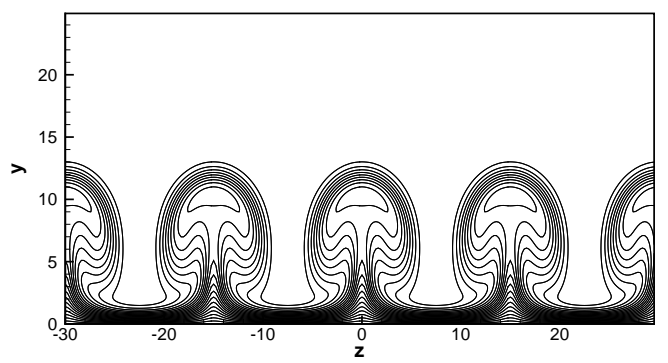

Figura 5.14: Contornos de velocidade, $x=$ $700 \mathrm{~mm}$. 


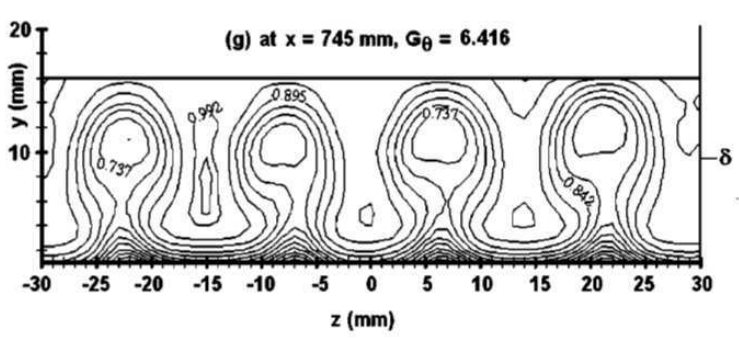

Figura 5.15: Contornos de velocidade, $x=745 \mathrm{~mm}$ - - Mitsudharmadi et al. [2004].

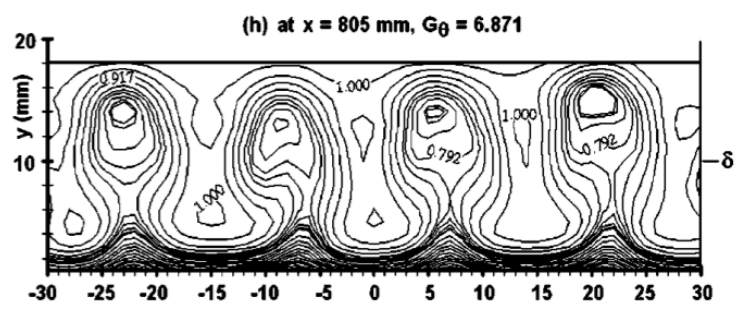

Figura 5.17: Contornos de velocidade, $x=805 \mathrm{~mm}$ - - Mitsudharmadi et al. [2004].

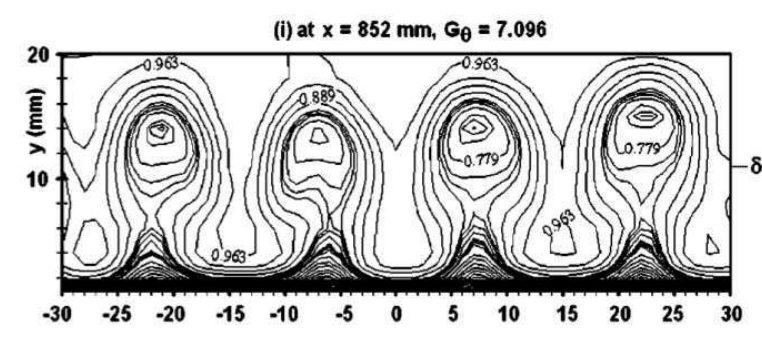

Figura 5.19: Contornos de velocidade, $x=852 \mathrm{~mm}$ - - Mitsudharmadi et al. [2004].

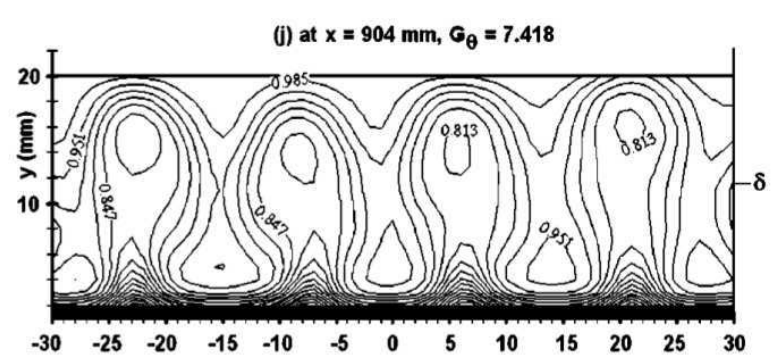

Figura 5.21: Contornos de velocidade, $x=904 \mathrm{~mm}$ - - Mitsudharmadi et al. [2004].

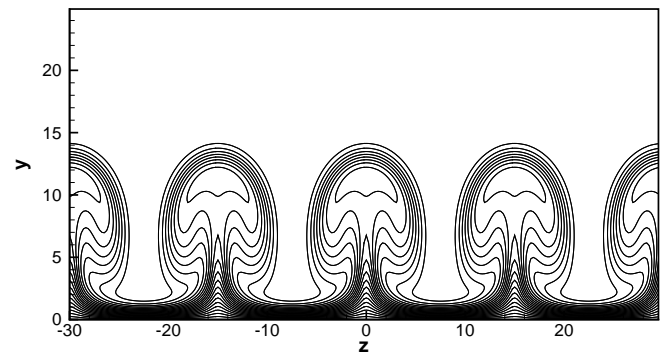

Figura 5.16: Contornos de velocidade, $x=$ $745 \mathrm{~mm}$.

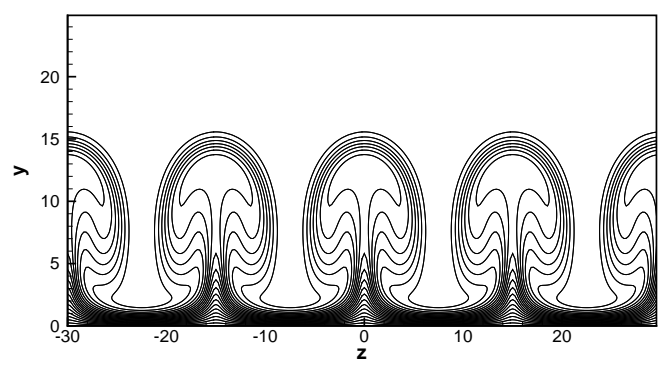

Figura 5.18: Contornos de velocidade, $x=$ $805 \mathrm{~mm}$.

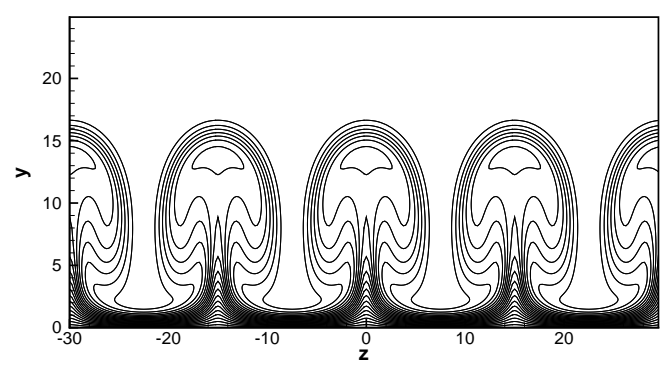

Figura 5.20: Contornos de velocidade, $x=$ $852 \mathrm{~mm}$.

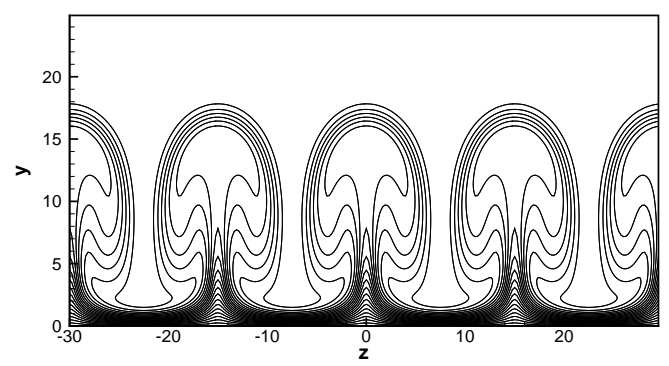

Figura 5.22: Contornos de velocidade, $x=$ $904 \mathrm{~mm}$. 



\section{Capítulo \\ 6 \\ Resultados}

Neste capítulo são apresentados os resultados obtidos para as simulações numéricas de escoamento sobre placas côncavas em escoamentos contendo vórtices de Görtler, e a influência destes vórtices na taxa de transferência de calor.

Inicialmente é analisado o desenvolvimento linear e não-linear dos vórtices de Görtler e sua influência na transferência de calor, em seguida é analisada a instabilidade secundária deste escoamento contendo vórtices de Görtler. As simulações realizadas utilizaram como escoamento base o resultado de simulação bidimensional das equações de Navier-Stokes.

\subsection{Vórtices de Görtler e transferência de calor}

Nesta seção é apresentado o desenvolvimento dos vórtices de Görtler e transferência de calor, a partir dos parâmetros experimentais de Swearingen e Blackwelder [1987], dos parâmetros numéricos de Li e Malik [1995a], em seguida são apresentados resultados baseados nos parâmetros experimentais de Momayez et al. [2004a,b] e de Mitsudharmadi et al. [2004, 2005a,b].

\subsubsection{Análise da transfêrencia de calor adotando os parâmetros experimentais de Swearingen e Blackwelder [1987]}

Os parâmetros adotados na simulação foram: o número de Reynolds, $R e=33124$; o número de Görtler, $G o=2,385$; a distância entre dois pontos consecutivos na direção $x$ e na direção $y$ foram $d x=0,015$ e $d y=0,00069$ respectivamente, o número de Prandtl foi $\operatorname{Pr}=0,72$, o número de pontos na direção $x$ e $y$ foram, respectivamente 857 e 561, o passo temporal foi de $d t=0,003$; a perturbação introduzida na posição $1,735 \leq x \leq 2,185$ com 
uma amplitude de $A=5,0 \times 10^{-3}$; na direção $z$ foram usados 21 modos de Fourier com 64 pontos no espaço físico. O comprimento de onda transversal foi de $\lambda_{z}=0,18$.

Para apresentação dos resultados a seguir utilizaremos a métrica $R e_{x}$ na direção longitudinal que é dado por:

$$
R e_{x}=\frac{U_{\infty} x}{\nu}
$$

A figura 6.1 mostra a distribuição do log da energia na direção longitudinal para cada modo de Fourier de 1 a 10, e também o modo do escoamento médio. A energia $(E)$ de cada modo é obtida por:

$$
E_{k}=\int_{0}^{\infty}\left(\left|U_{k}\right|^{2}+\left|V_{k}\right|^{2}+\left|W_{k}\right|^{2}\right) d y
$$

para $k>0$, e

$$
E_{k}=\frac{1}{2} \int_{0}^{\infty}\left(\left|U_{k}\right|^{2}+\left|V_{k}\right|^{2}\right) d y
$$

para $k=0$.

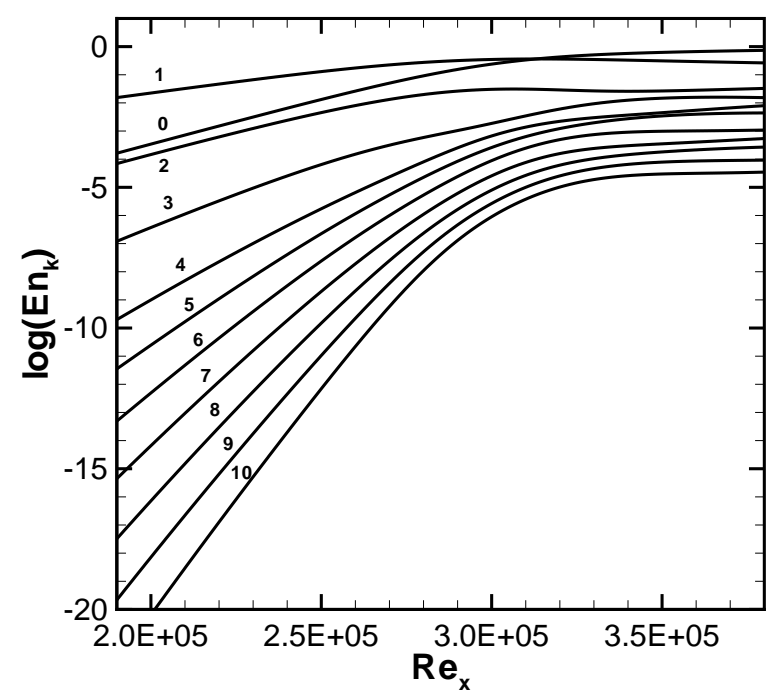

Figura 6.1: Distribuição de energia na direção longitudinal para cada modo de Fourier transversal. Comprimento de onda transversal fundamental de $\lambda_{z}=0,18$.

Depois de $R e_{x} \sim 3 \times 10^{5}$ os vórtices saturam e a amplitude de todos os modos permanecem constantes. Na região da saturação, a diferença entre a amplitude dos modos permanece praticamente constante.

Os vórtices são amplificados inicialmente de maneira linear; quando a amplitude já é elevada, na região não-linear do seu desenvolvimento, ocorre a formação da estrutura na forma de cogumelo, com uma distribuição da componente de velocidade na direção do escoamento principal. 
A figura 6.2 mostra os contornos de isovelocidade e isotemperatura em $R e_{x}=3,2 \times 10^{5}$. A camada limite hidrodinâmica é mostrada com linhas tracejadas, e a camada limite térmica é mostrada com as linhas sólidas. Como o número de Prandtl adotado foi de $\operatorname{Pr}=0,72$, a camada limite térmica é mais espessa do que a camada limite hidrodinâmica. Pode-se perceber que a região de downwash é maior que a região de upwash, resultando na média em intensificação da taxa de transferência de calor.

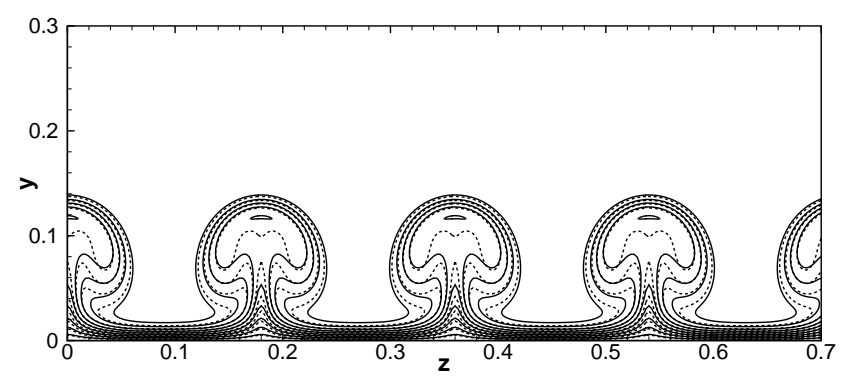

Figura 6.2: Contornos de isovelocidade (linhas tracejadas) e isotemperatura (linhas sólidas) no plano $z y$ em $R e_{x}=3,2 \times 10^{5}$ para $\lambda_{z}=0,18$.

A evolução da média na direção longitudinal do número de Stanton é mostrado na figura 6.3. No começo quando os vórtices estão na região-linear, a curva do escoamento de Görtler está junto ao escoamento laminar. Isto pode ser observado até $R e_{x} \sim 1,9 \times 10^{5}$ quando o escoamento de Görtler começa a intensificar a transferência de calor. Em $R e_{x}=$ $3,7 \times 10^{5}$, o número de Stanton devido aos vórtices de Görtler é $219 \%$ maior que o escoamento laminar e apenas $19 \%$ menor que o escoamento turbulento.

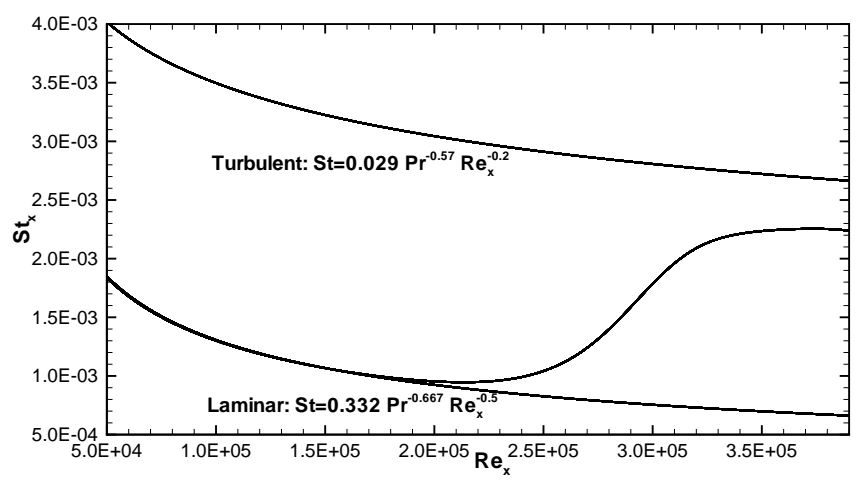

Figura 6.3: Evolução na direção longitudinal da média do número de Stanton na direção transversal para $\lambda_{z}=0,18$.

\subsubsection{Análise da transferência de calor adotando os parâmetros numéricos de Li e Malik [1995a]}

Com base nos parâmetros experimentais utilizados por Swearingen e Blackwelder [1987], Li e Malik [1995a] desenvolveram numericamente estudos a partir do comprimento de onda de referência de $\lambda_{z}=0,18$. Assim, utilizaram a metade do comprimento 
de onda transversal de referência $\lambda_{z}=0,09$, e também o dobro do comprimento de onda transversal de referência $\lambda_{z}=0,36$. Para as presentes simulações foram adotadas, portanto, os mesmos parâmetros adotados na seção anterior, com excessão do número de onda transversal, que foram utilizados: $\lambda_{z}=0,09$ e $\lambda_{z}=0,36$.

Para este presente caso, com comprimentos de onda $\lambda_{z}=0,09$ e $\lambda_{z}=0,36$, foram adotado os mesmos parâmetros (físicos e numericos) que a seção anterior.

Resultados para $\lambda_{z}=0,09$

A figura 6.4 mostra a distribuição de energia na direção longitudinal para $\lambda_{z}=0,09$. A região de saturação inicia-se na posição de $R e_{x} \sim 3 \times 10^{5}$, a mesma posição que o caso com $\lambda_{z}=0,18$. Estes valores estão em acordo com os dados numéricos de Li e Malik [1995a].

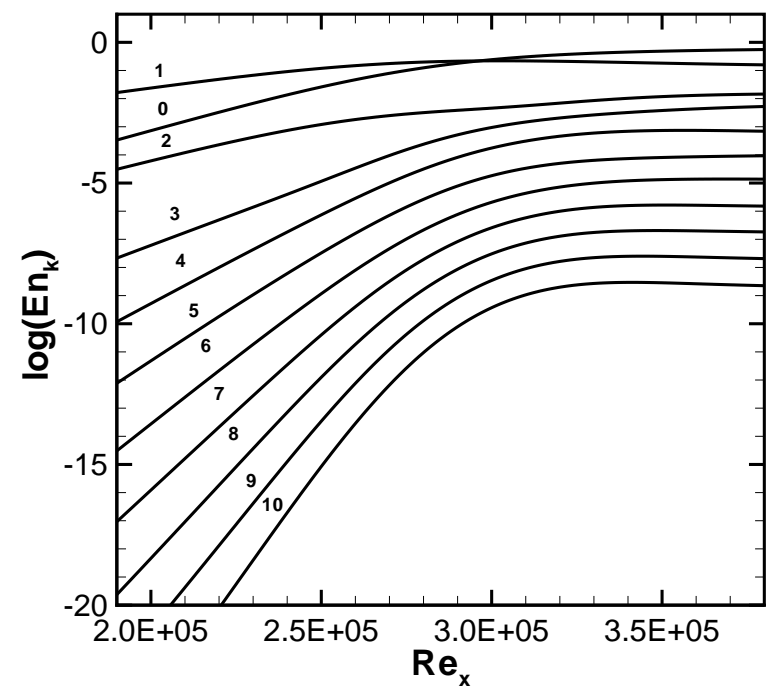

Figura 6.4: Distribuição de energia na direção longitudinal para cada modo de Fourier transversal. Comprimento de onda transversal fundamental de $\lambda_{z}=0,09$.

Os contornos de isovelocidade e isotemperatura em $R e_{x} \sim 3,2 \times 10^{5}$ são mostrados na figura 6.5. A estrutura do tipo-cogumelo típica do escoamento de Görtler pode ser observada. Esta distribuição ajuda no entendimento do aumento do número de Stanton causado pelos vórtices de Görtler, pois pode-se perceber que a região de downwash ocupa uma maior área que a região de upwash.

A figura 6.6 mostra a evolução da média do número de Stanton na direção longitudinal para $\lambda=0,09$. Este mesmo fenômeno acontence para o caso de referência $\left(\lambda_{z}=0,18\right)$. Pode-se verificar que a partir de $R e_{x}=1,6 \times 10^{5}$, o escoamento de Görtler intensifica a transferência de calor. Em $R e_{x}=3,7 \times 10^{5}$ o aumento da taxa de transferência de calor em relação ao escoamento laminar foi de $247 \%$ e em relação ao escoamento turbulento foi registrado uma pequena perda de $14 \%$. 


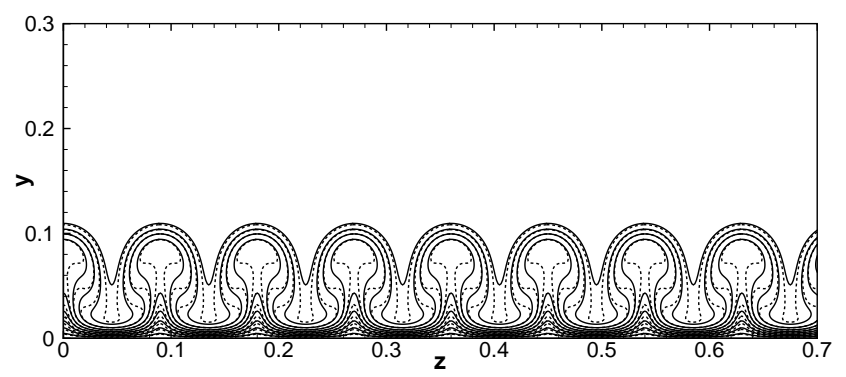

Figura 6.5: Contornos de isovelocidade (linhas tracejadas) e isotemperatura (linhas sólidas) no plano $z y$ em $R e_{x}=3,2 \times 10^{5}$ para $\lambda_{z}=0,09$.

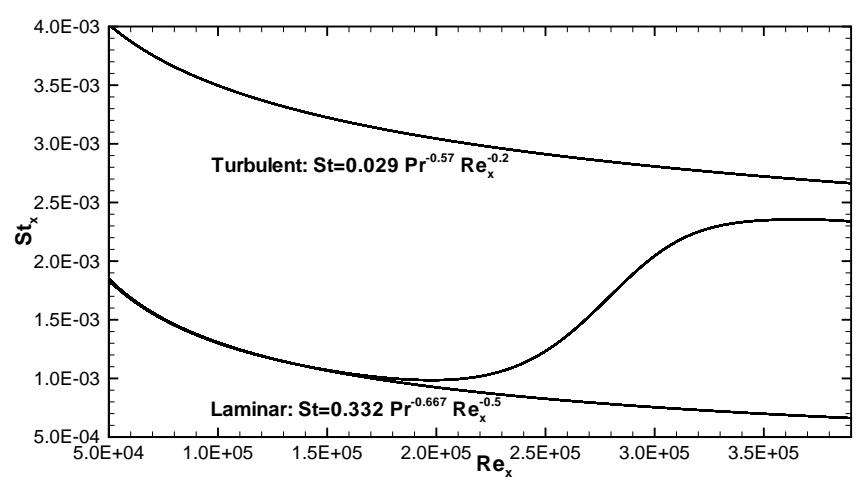

Figura 6.6: Evolução na direção longitudinal da média do número de Stanton na direção transversal para $\lambda_{z}=0,09$.

\section{Resultados para $\lambda_{z}=0,36$}

A figura 6.7 mostra a distribuição de energia para cada modo de 0 a 10 para $\lambda_{z}=0,36$. Os contornos de isovelocidade e isotemperatura em $R e_{x} \sim 3,32 \times 10^{5}$ é mostrado na figura 6.8. Uma configuração similar aos casos anteriores pode ser observado. A região de downwash é maior que nos outros casos.

A figura 6.9 mostra a evolução longitudinal do número de Stanton para $\lambda_{z}=0,36$. No presente caso, a média na direção transversal da derivada da tempeturatura $(\theta)$ foi menor que os casos anteriores. Assim, em $R e_{x} \sim 3,7 \times 10^{5}$, o número de Stanton com o escoamento de Görtler teve um ganho de $158 \%$ em relação ao escoamento laminar e ficou $54 \%$ menor que o escoamento turbulento. O caso $\lambda_{z}=0,09$ apesar de ter uma região menor de downwash que o presente caso, na média, a camada limite térmica está mais próxima á parede que o presente caso aumentando assim o fluxo de calor.

\subsubsection{Análise da transferência de calor adotando os parâmetros experimentais de Momayez et al. [2004a,b]}

Os parâmetros adotados nas simulações foram: o número de Reynolds, $R e=10000$; o número de Görtler, Go $=2,385$; a velocidade de corrente livre, $U_{\infty}=3 \mathrm{~m} / \mathrm{s}$; as distâncias entre dois pontos consecutivos na direção $x$ e na direção $y$ foram $d x=0,015$ 


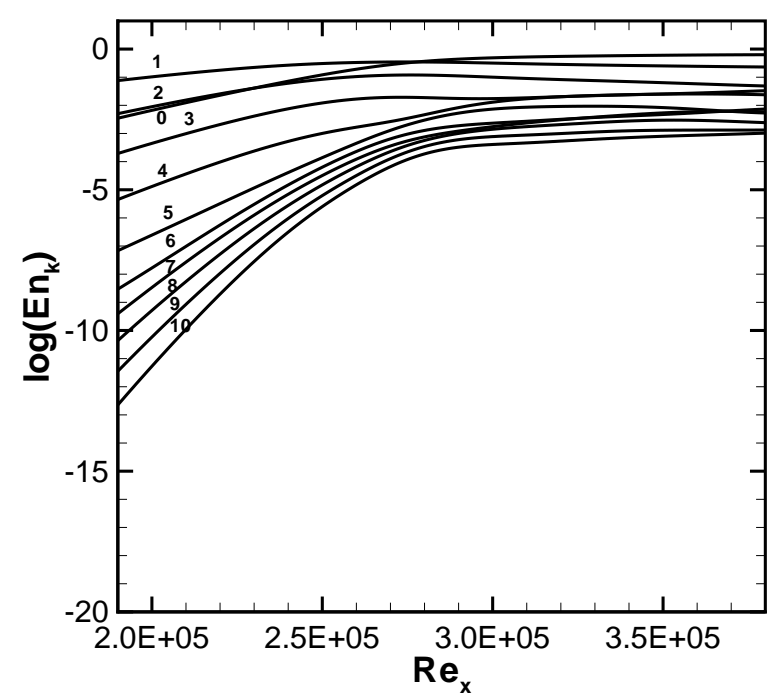

Figura 6.7: Distribuição de energia na direção longitudinal para cada modo de Fourier transversal. Comprimento de onda transversal fundamental de $\lambda_{z}=0,36$.

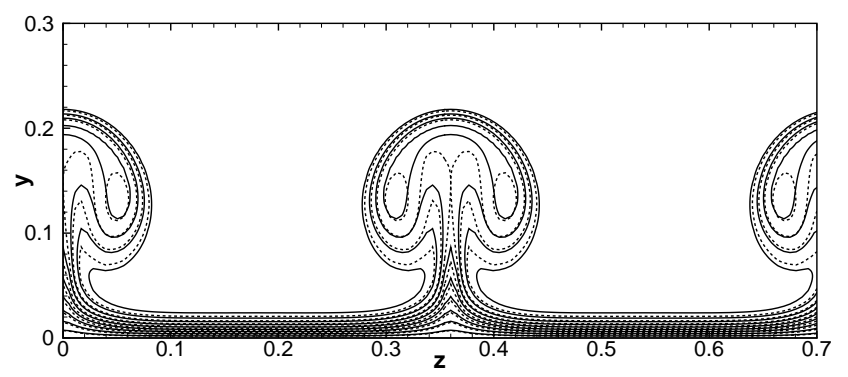

Figura 6.8: Contornos de isovelocidade (linhas tracejadas) e isotemperatura (linhas sólidas) no plano $z y$ em $R e_{x}=3,2 \times 10^{5}$ para $\lambda_{z}=0,36$.

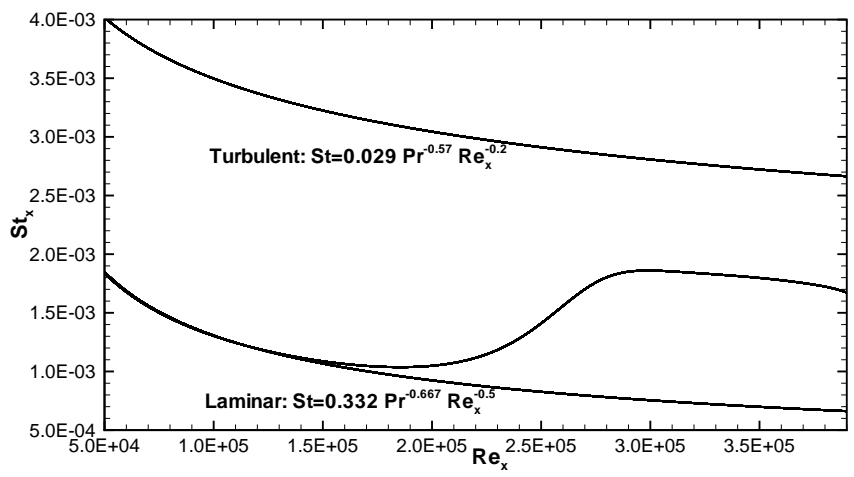

Figura 6.9: Evolução na direção longitudinal da média do número de Stanton na direção transversal para $\lambda_{z}=0,36$.

e $d y=0,00069$, o número de Prandtl foi $\operatorname{Pr}=0,72$, o número de pontos na direção $x$ e $y$ foram respectivamente 857 e 561, o passo no integrador temporal foi de $d t=0,003$; a perturbação foi introduzida na posição $1,735 \leq x \leq 2,185$ com uma amplitude de $A=5,0 \times 10^{-3}$; na direção $z$ foram usados 21 modos de Fourier com 64 pontos no 
espaço físico. A perturbação foi introduzida para seis diferentes comprimentos de onda: $\lambda_{z}=0,05 ; 0,10 ; 0,15 ; 0,20 ; 0,25$ e 0,30 .

Resultados para $\lambda_{z}=0,05$

A figura 6.10 mostra a distribuição de energia na direção longitudinal para os modos de 1 a 10, e também a distorção do escoamento, médio modo 0 . Entre $R e_{x}=2,5 \sim 10^{4}$ até $1,0 \times 10^{5}$, os vórtices de Görtler crescem de acordo com a teoria de estabilidade linear. Depois de $R e_{x}=1,0 \times 10^{5}$, os vórtices saturam e quase todos os modos permanecem com amplitude constante. Na região de saturação, a diferença entre a amplitude dos modos consecutivos permacem quase constantes e, neste caso, a amplitude do último modo é muito pequena.

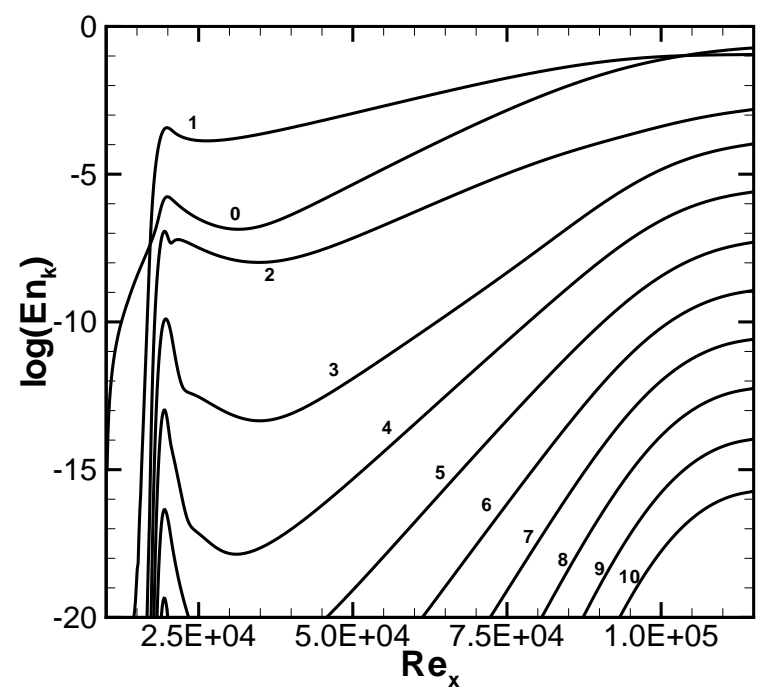

Figura 6.10: Distribuição de energia na direção longitudinal para cada modo de Fourier transversal. Comprimento de onda transversal fundamental de $\lambda_{z}=0,05$.

A figura 6.11 mostra os contornos de isovelocidade e isotemperatura em $R e_{x}=3,32 \times$ $10^{5}$. A camada limite hidrodinâmica é mostrada com linhas tracejadas, e a camada limite térmica é mostrada com linhas sólidas. Novamente, para este caso, o número de Prandtl adotado foi de $\operatorname{Pr}=0,72$, isto significa que a camada limite térmica é maior que a camada limite hidrodinâmica. A região de downwash é mais significativa que a região de upwash, desta forma é intensificada a taxa de transferência de calor média na direção transversal.

A evolução na direção longitudinal da média na direção transversal do número de Stanton é mostrado na figura 6.12. A perturbação é imposta na região $R e_{x} \sim 0,6 \times 10^{5}$. No começo os vórtices desenvolvem-se linearmente junto com a curva do escoamento laminar. A partir de $R e_{x} \sim 6,0 \times 10^{4}$ a taxa de transferência de calor começa a aumentar. Em $R e_{x}=1,09 \times 10^{5}$ o número de Stanton com o escoamento de Görlter apresenta um 


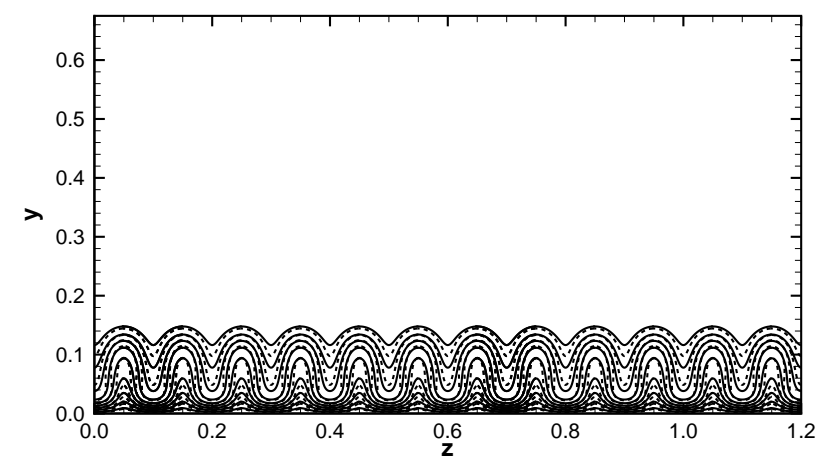

Figura 6.11: Contornos de isovelocidade (linhas tracejadas) e isotemperatura (linhas sólidas) no plano $z y$ em em $R e_{x}=3,32 \times 10^{5}$ para $\lambda_{z}=0,05$.

aumento de $143 \%$ em relação ao escoamento laminar, e fica $13 \%$ menor que o escoamento turbulento.

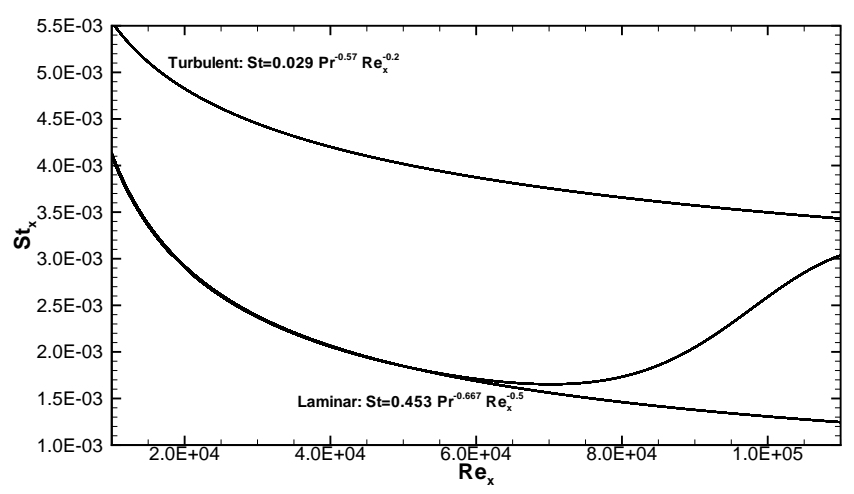

Figura 6.12: Evolução na direção longitudinal da média do número de Stanton na direção transversal para $\lambda_{z}=0,05$.

Momayez et al. [2004a,b]

Resultados para $\lambda_{z}=0,10$

A figura 6.13 mostra a distribuição de energia na direção longitudinal. A energia de saturação dos modos obtida neste caso é maior que o primeiro caso $\left(\lambda_{z}=0,05\right)$. A região de saturação começa na posição longitudinal $R e_{x} \sim 8,0 \times 10^{4}$.

Os contornos de isovelocidade e isotemperatura em $R e_{x}=3,32 \times 10^{5}$ são mostrados na figura 6.14. A estrutura do tipo cogumelo com a distribuição da velocidade $u$ no plano $z \times y$ é observado. Nesta figura podemos observar que a região de downwash é mais acentuada que a região de upwash.

A figura 6.15 mostra a evolução longitudinal da média transversal do número de Stanton para $\lambda_{z}=0,10$. Pode-se observar que depois de $R e_{x}=5,0 \times 10^{4}$ o escoamento de Görtler intensifica a taxa de transferência de calor. Em $R e_{x}=1,09 \times 10^{5}$ o número de Stanton com o escoamento de Görtler foi de $299 \%$ e $45 \%$ maior que o escoamento laminar e 


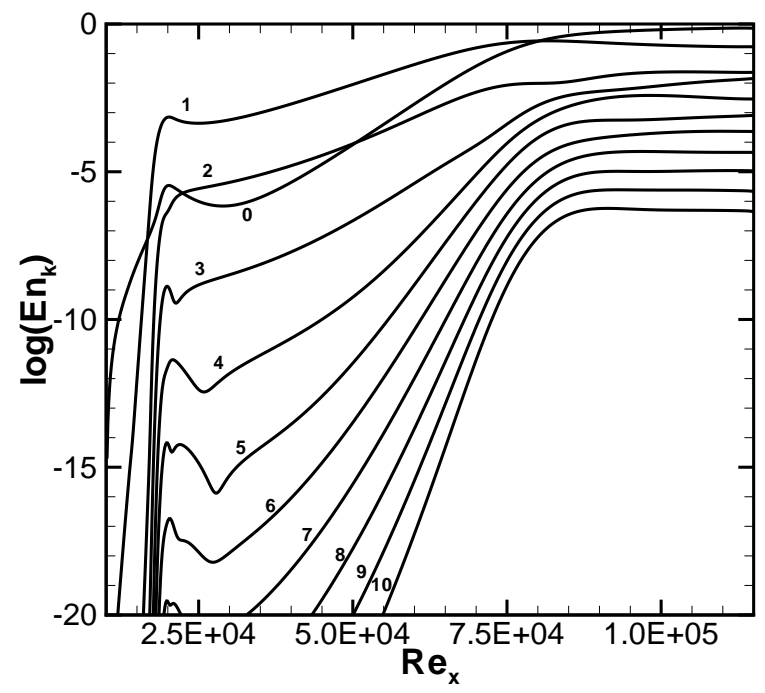

Figura 6.13: Distribuição de energia na direção longitudinal para cada modo de Fourier transversal. Comprimento de onda transversal fundamental de $\lambda_{z}=0,10$.

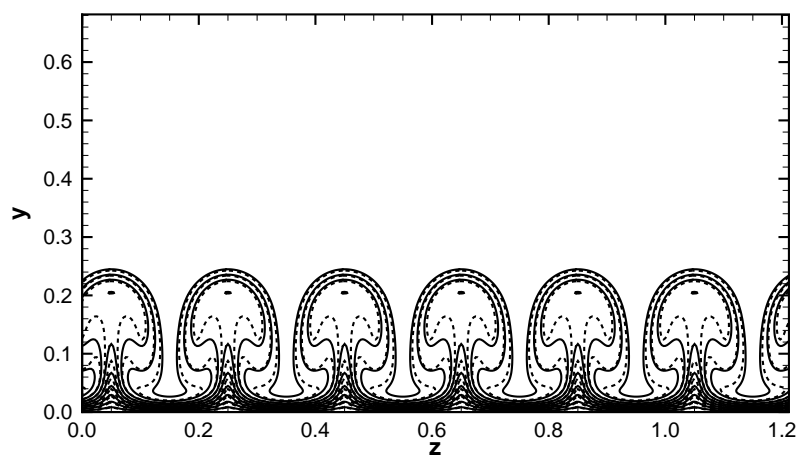

Figura 6.14: Contornos de isovelocidade (linhas tracejadas) e isotemperatura (linhas sólidas) no plano $z y$ em $R e_{x}=3,32 \times 10^{5}$ para $\lambda_{z}=0,10$.

turbulento, respectivamente. Neste caso temos o maior aumento na taxa de transferência de calor para os parâmetros referentes a Momayez et al. [2004a,b].

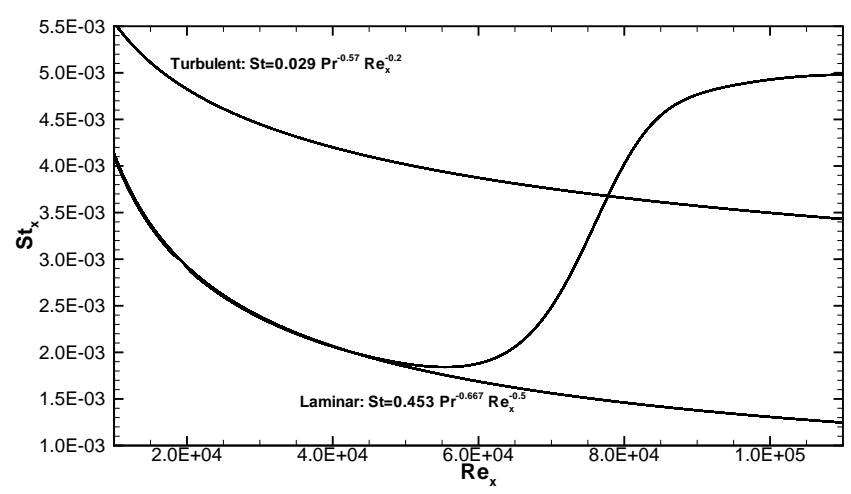

Figura 6.15: Evolução na direção longitudinal da média do número de Stanton na direção transversal para $\lambda_{z}=0,10$. 
Resultados para $\lambda_{z}=0,15$

A figura 6.16 mostra a distribuição de energia para cada modo de 0 a 10 para $\lambda_{z}=0,15$. A região de saturação inicia-se na posição $R e_{x}=8,0 \times 10^{4}$, a mesma posição que foi observada para $\lambda_{z}=0,10$.

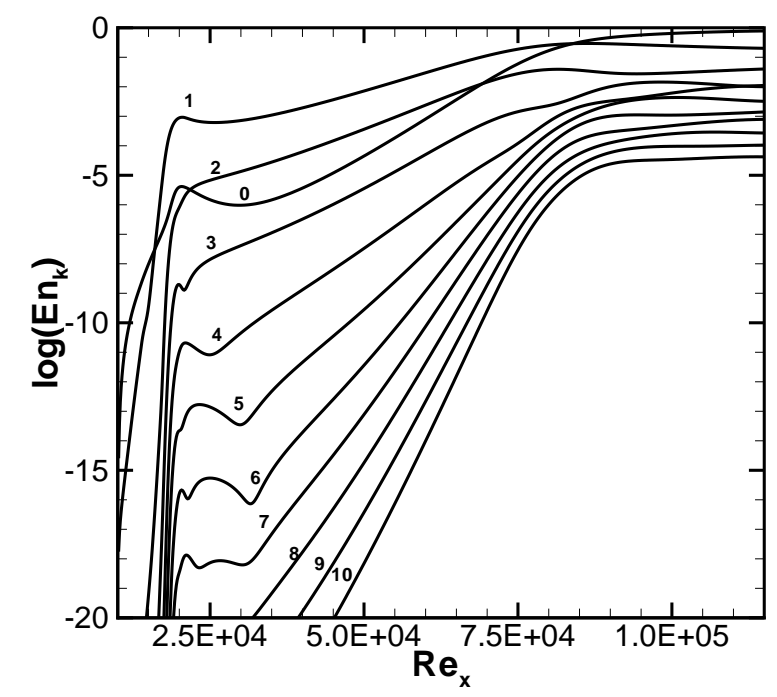

Figura 6.16: Distribuição de energia na direção longitudinal para cada modo de Fourier transversal. Comprimento de onda transversal fundamental de $\lambda_{z}=0,15$.

A distribuição da isovelocidade $u$ é da isotemperatura em $R e_{x}=3,32 \times 10^{5}$ é mostradas na figura 6.17 .

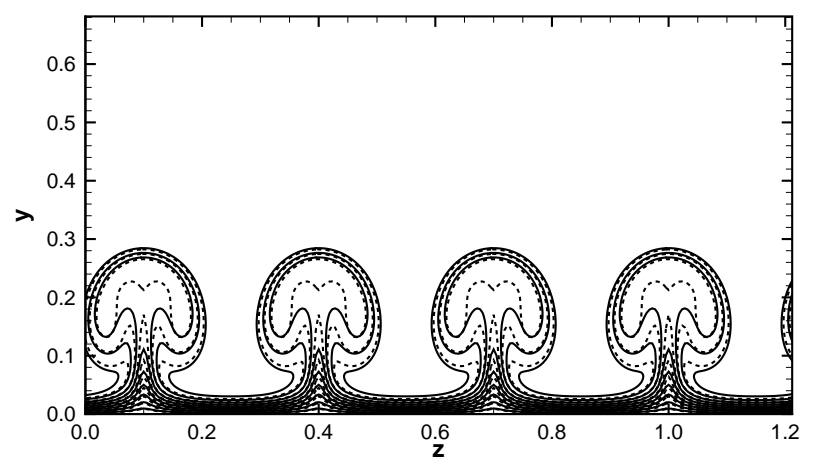

Figura 6.17: Contornos de isovelocidade (linhas tracejadas) e isotemperatura (linhas sólidas) no plano $z y$ em $R e_{x}=3,32 \times 10^{5}$ para $\lambda_{z}=0,15$.

A figura 6.18 mostra a evolução longitudinal do número de Stanton para $\lambda_{z}=0,15$. No presente caso em $R e_{x}=1,09 \times 10^{5}$, o número de Stanton é $234 \%$ e $22 \%$ maior que o escoamento laminar e o escoamento turbulento, respectivamente. 


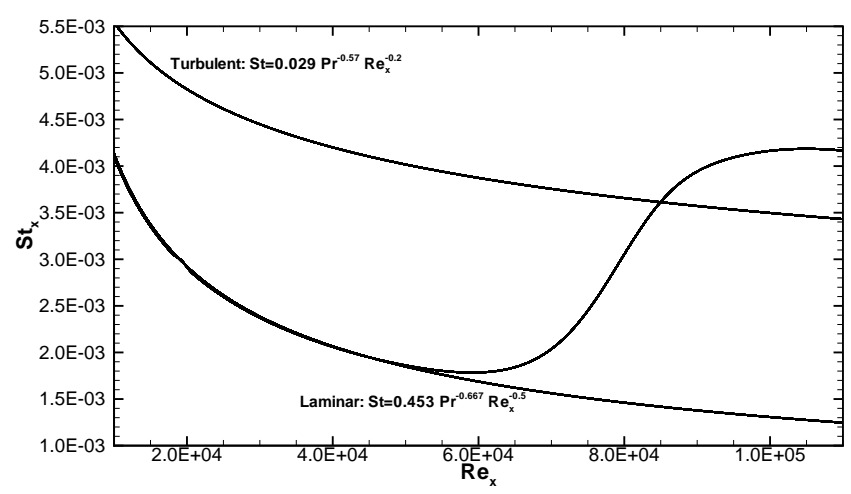

Figura 6.18: Evolução na direção longitudinal da média do número de Stanton na direção transversal para $\lambda_{z}=0,15$.

Resultados para $\lambda_{z}=0,20$

A figura 6.19 mostra a distribuição de energia na direção longitudinal para os modos estáveis de 1 a 10 e também a distorção do escoamento médio, modo 6. A região de saturação inicia-se na posição longitudinal $R e_{x}=8,0 \times 10^{4}$, o mesmo orrido com os $\lambda_{z}=0,10$ e $\lambda_{z}=0,15$.

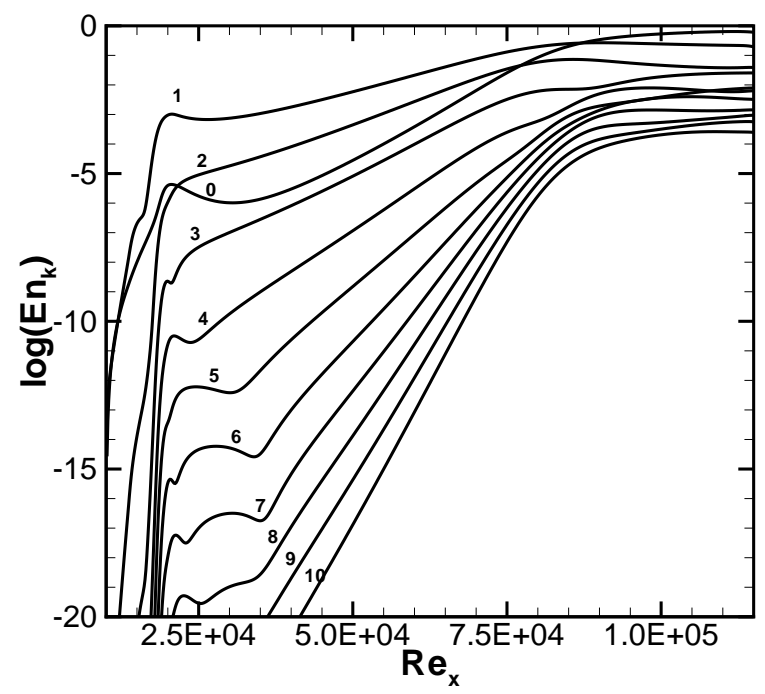

Figura 6.19: Distribuição de energia na direção longitudinal para cada modo de Fourier transversal. Comprimento de onda transversal fundamental de $\lambda_{z}=0,20$.

Os contornos de isovelocidade e isotemperatura em $R e_{x}=3,32 \times 10^{5}$ são mostrado na figura 6.20 .

A figura 6.21 mostra a evolução longitudinal do número de Stanton para $\lambda_{z}=0,20$. No presente caso em $R e_{x}=1,09 \times 10^{5}$, o número de Stanton com o escoamento de Görtler é $173 \%$ maior que o escoamento laminar e aproximadamente o mesmo que o escoamento turbulento. 


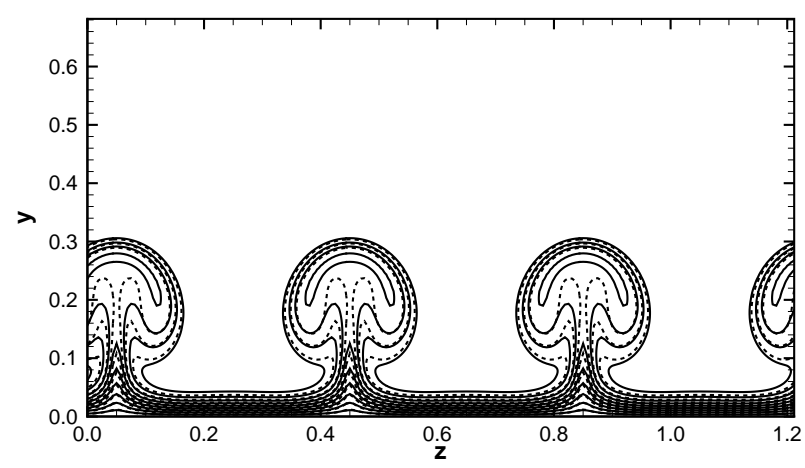

Figura 6.20: Contornos de isovelocidade (linhas tracejadas) e isotemperatura (linhas sólidas) no plano $z y \mathrm{em} R e_{x}=3,32 \times 10^{5}$ para $\lambda_{z}=0,20$.

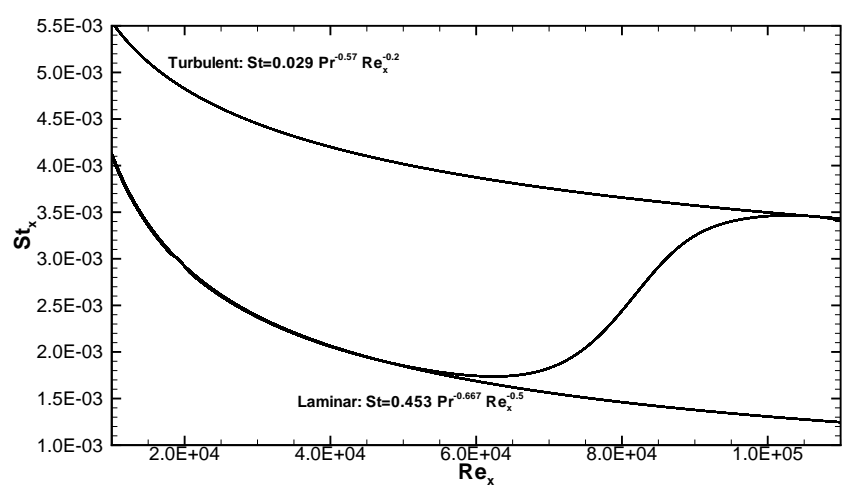

Figura 6.21: Evolução na direção longitudinal da média do número de Stanton na direção transversal para $\lambda_{z}=0,20$.

\section{Resultados para $\lambda_{z}=0,25$}

A figura 6.22 mostra a distribuição de energia, dando origem aos vórtices longitudinais, que são conhecidos como os vórtices de Görtler. Na direção longitudinal para os modos estáveis de 1 a 10. A região de saturação inicia-se na posição $R e_{x} \sim 5,0 \times 10^{4}$.

Os contornos de isovelocidade e isotemperatura em $R e_{x}=3,32 \times 10^{5}$ são mostrados na figura 6.23 .

A figura 6.24 mostra a evolução longitudinal do número de Stanton para $\lambda_{z}=0,25$. No presente caso em $R e_{x}=1,09 \times 10^{5}$, o número de Stanton com o escoamento de Görtler é $238 \%$ e $23 \%$ maior que o escoamento laminar e que o escoamento turbulento, respectivamente. Neste caso, temos o segundo melhor resultado para o aumento da transferência de calor.

\section{Resultados para $\lambda_{z}=0,30$}

A figura 6.25 mostra a distribuição de energia na direção longitudinal para os modos estáveis de 1 a 10, e também a distribuição do escoamento médio, modo (0). A região de saturação inicia-se na posição $R e_{x}=6,0 \times 10^{4}$. 


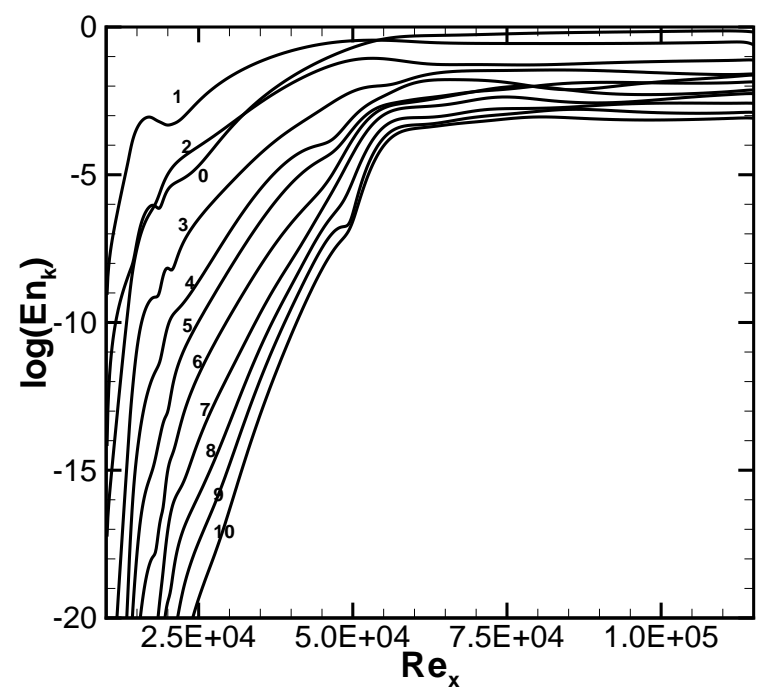

Figura 6.22: Distribuição de energia na direção longitudinal para cada modo de Fourier transversal. Comprimento de onda transversal fundamental de $\lambda_{z}=0,25$.

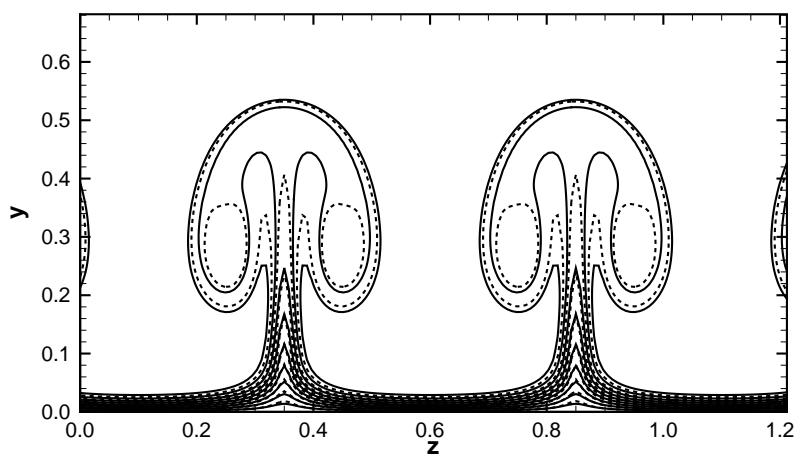

Figura 6.23: Contornos de isovelocidade (linhas tracejadas) e isotemperatura (linhas sólidas) no plano $z y \mathrm{em} R e_{x}=3,32 \times 10^{5}$ para $\lambda_{z}=0,25$.

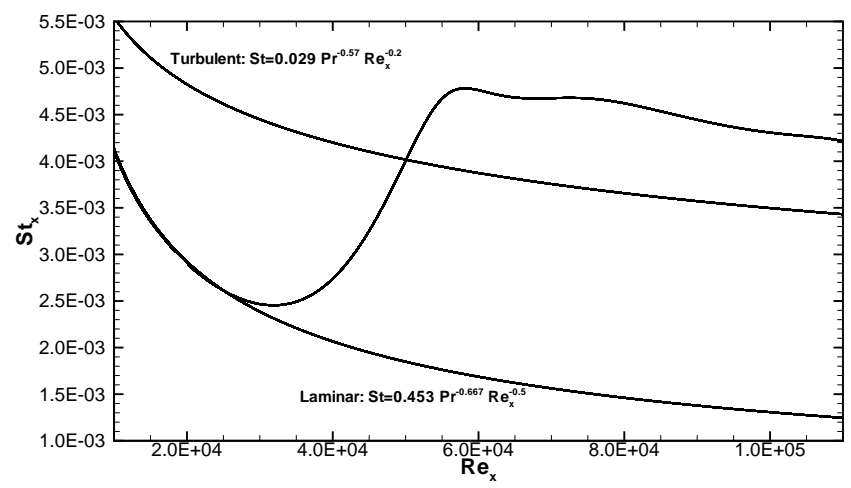

Figura 6.24: Evolução na direção longitudinal da média do número de Stanton na direção transversal para $\lambda_{z}=0,25$.

Os contornos de isovelocidade e isotemperatura em $R e_{x}=3,32 \times 10^{5}$ são mostrados na figura 6.26 . 


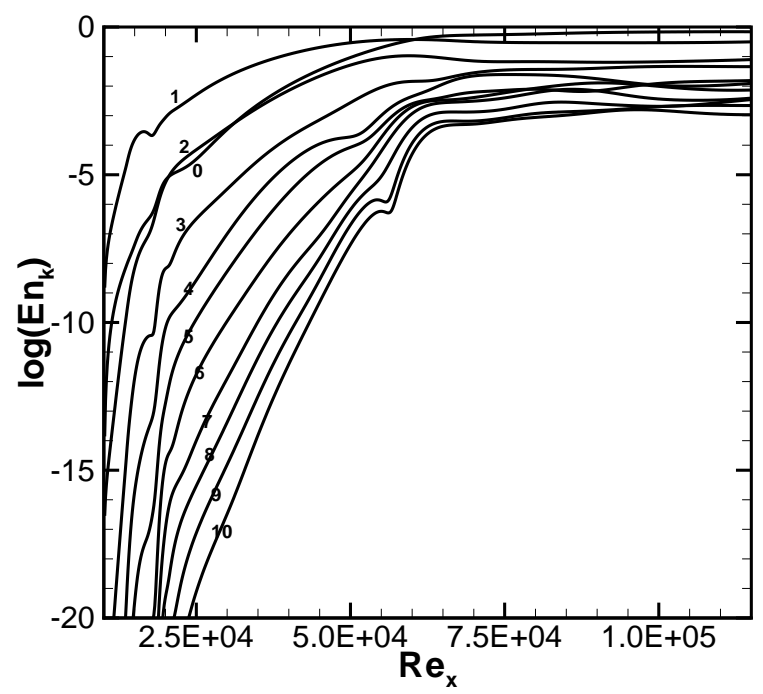

Figura 6.25: Distribuição de energia na direção longitudinal para cada modo de Fourier transversal. Comprimento de onda transversal fundamental de $\lambda_{z}=0,30$.

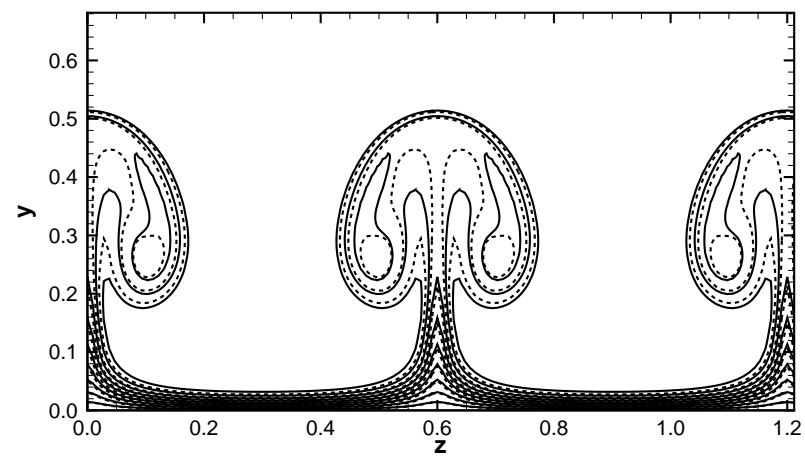

Figura 6.26: Contornos de isovelocidade (linhas tracejadas) e isotemperatura (linhas sólidas) no plano $z y$ em $R e_{x}=3,32 \times 10^{5}$ para $\lambda_{z}=0,30$.

A figura 6.27 mostra a evolução longitudinal do número de Stanton para $\lambda_{z}=0,30$. No presente caso em $R e_{x}=1,09 \times 10^{5}$, o número de Stanton com o escoamento de Görtler é $207 \%$ e $22 \%$ maior que o escoamento laminar e que o escoamento turbulento, respectivamente. O resultados mostram que o crescimento dos vórtices não é monotônico.

\subsubsection{Análise da transferência de calor adotando os parâmetros experimentais de Mitsudharmadi et al. [2004, 2005a,b]}

No capítulo 5, já foi analisado o escoamento de Görtler para a validação do presente código com os parâmetros de Mitsudharmadi et al. [2004, 2005a,b]. No presente caso foi analisada a evolução na direção longitudinal da média do número de Stanton na direção transversal, sem a presença da instabilidade secundária, a qual será o foco da próxima 


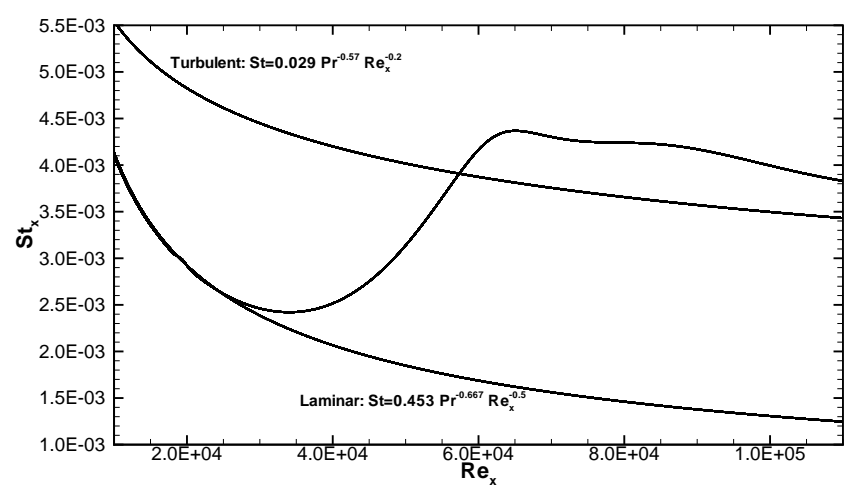

Figura 6.27: Evolução na direção longitudinal da média do número de Stanton na direção transversal para $\lambda_{z}=0,30$.

seção. Para isto os parâmetros adotados foram: o raio de curvatura da parede foi de $R=2$ m e a velocidade de corrente livre $U_{\infty}=3 \mathrm{~m} / \mathrm{s}$. A distância entre dois pontos consecutivos em $x$ foi de $d x=0,0035$, e na direção $y$ o primeiro espaçamento foi de $d y=0,0004$ com estiramento de $1 \%$ a cada ponto da malha. O número de Prandtl adotado $\operatorname{Pr}=0,72$, o número de pontos na direção $x$ e $y$ foram 1177 , e 201, respectivamente. O número de modos de Fourier foi $k=21$ com 64 pontos no espaço físico.

A figura 6.28 mostra a evolução longitudinal do número de Stanton para o número de onda $\lambda_{z}=0.02$. De acordo com Floryan [1982] este é o número de onda o qual apresenta a máxima taxa de amplificação para a teoria linear de instabilidade. No presente caso em $R e_{x}=1,8 \times 10^{5}$, o número de Stanton com o escoamento de Görtler é $392 \%$ e $122 \%$ maior que o escoamento laminar e que o escoamento turbulento, respectivamente.

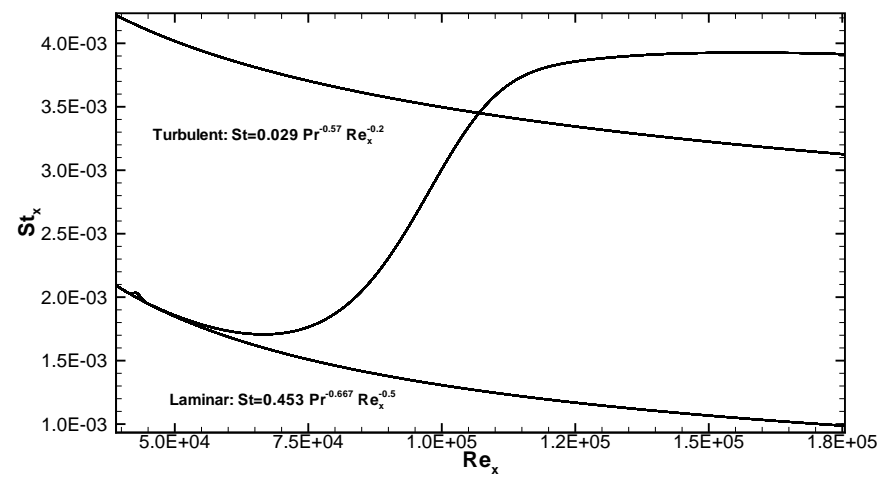

Figura 6.28: Evolução na direção longitudinal da média do número de Stanton na direção transversal para o número de onda $\lambda_{z}=0,02$.

\subsection{Instabilidade secundária e transferência de calor em escoamentos contendo vórtices de Görtler}

As perturbações estacionárias dão origem a vórtices longitudinais, que são conhecidos como os vórtices de Görtler. Estes vórtices causam inflexões no perfil de velocidade 
longitudinal $u$ nas direções normal a parede $y$ e transversal $z$. Na região não-linear do desenvolvimento dos mesmos, pode ocorre a instabilidade secundária no escoamento. Nesta seção, é apresentado o desenvolvimento da instabilidade secundária dos modos varicoso e sinuoso, à partir dos vórtices de Görtler e a transferência de calor, com base nos parâmetros analisados por Mitsudharmadi et al. [2004, 2005b,a].

Os parâmetros adotados na simulação foram: o número de Reynolds, $R e=36230$; o número de Görtler, $G o=2,385$; a distância entre dois pontos consecutivos na direção $x$ e na direção $y$ foram $d x=0,015$ e $d y=0,00069$, com incremento de $1 \%$ nesta direção, o número de Prandtl foi $\operatorname{Pr}=0,72$, o número de pontos na direção $x$ e $y$ foram respectivamente 1177 e 201, o passo utilizado no integrador temporal foi de $d t=0,003$; a perturbação estacionária introduzida na posição $1,735 \leq x \leq 2,185$ com uma amplitude de $A=6,0 \times 10^{-3}$. As perturbações não estacionárias foram introduzidas pelo mecanismo de sucção e injeção de massa na parede, em três diferentes posições: $R e_{x} \sim 7,5 \times 10^{4}$, $R e_{x} \sim 9,5 \times 10^{4}$ e $R e_{x} \sim 1,15 \times 10^{5}$, com frequências de $18,75 \mathrm{~Hz}$ a $300 \mathrm{~Hz}$ com passos de $18,75 \mathrm{~Hz}$.

\subsubsection{Modo varicoso}

Na figura 6.29 é mostrada a amplitude máxima da distribuição de velocidade na direção longitudinal para cada cada frequência sobre o plano $(z, y)$. Inicialmente todos os modos são forçados a exibir uma estabilidade até a posição de $R e_{x} \sim 1,25 \times 10^{5}$, depois desta posição, todos os modos crescem a partir do mecanismo da instabilidade secundária. As frequências com os maiores valores de taxa de amplificação na região da instabilidade secundária são: 18,75 Hz, 112, $50 \mathrm{~Hz}, 130,25 \mathrm{~Hz}$ e 141, $00 \mathrm{~Hz}$, estas frequências estão destacadas na figura 6.29.

$\mathrm{Na}$ figura 6.30 são mostradas isocontornos das quatro frequências dominantes em planos $z \times y$ na região da instabilidade secundária $18,75 \mathrm{~Hz}, 112,50 \mathrm{~Hz}, 130,25 \mathrm{~Hz}$ e 141, $00 \mathrm{~Hz}$ para a posição: $R e_{x}=1,4 \times 10^{5}$.

A distribuição de tempeturatura é mostrada nos cortes sobre o plano (z,y) e as estruturas obtidas na simulação são mostradas através dos isocontornos $Q$, mostrados nas figuras 6.31 e 6.32 em oito instantes diferentes. Observa-se nestas a formação dos vórtices do tipo ferradura.

A figura 6.33 mostra a evolução longitudinal do número de Stanton. No início os vórtices estão no desenvolvimento linear e o escoamento de Görtler é o mesmo que a curva linear. Na região não-linear, depois de $R e_{x} \sim 1,05 \times 10^{5}$ os vórtices de Görtler intensificam a transferência de calor, atigindo valores mais elevados que o escoamento turbulento. Na região a jusante $R e_{x} \sim 1,7 \times 10^{5}$, todos os modos apresentam alta amplitude, e inicía-se uma perda na taxa transfência de calor. 


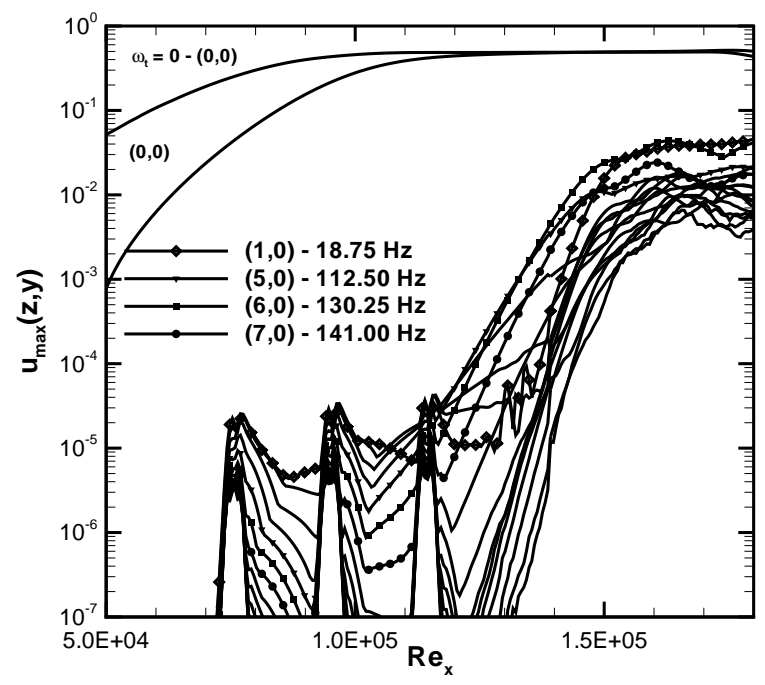

Figura 6.29: Amplitude máxima de cada velocidade $u$ na direção longitudinal para cada frequência sobre o plano $(x, y)$.

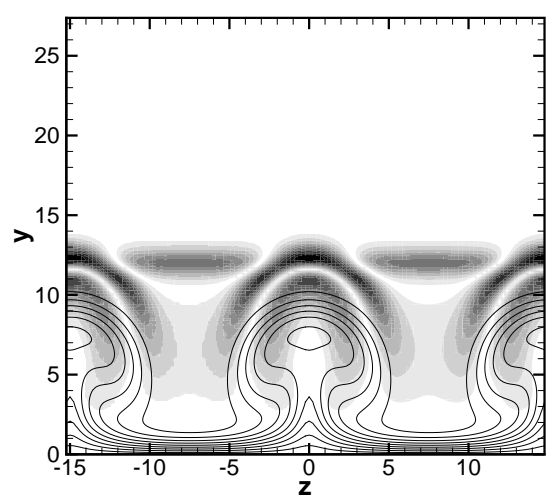

$\mathrm{a}-18,75 \mathrm{~Hz}$

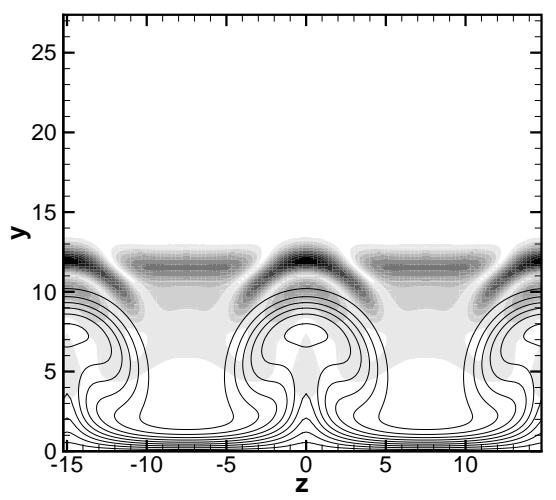

c $-130,25 \mathrm{~Hz}$

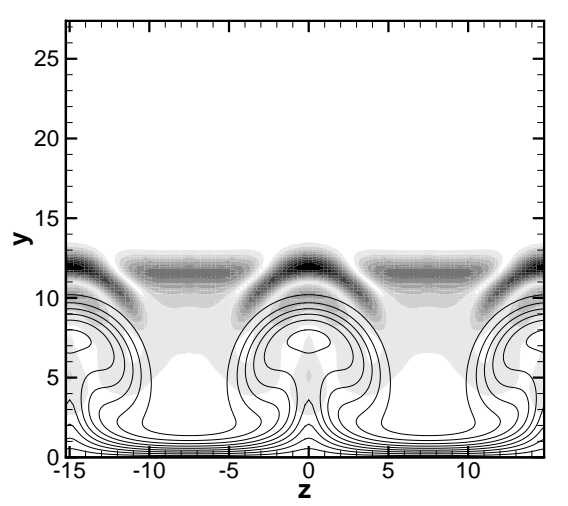

$\mathrm{b}-112,50 \mathrm{~Hz}$

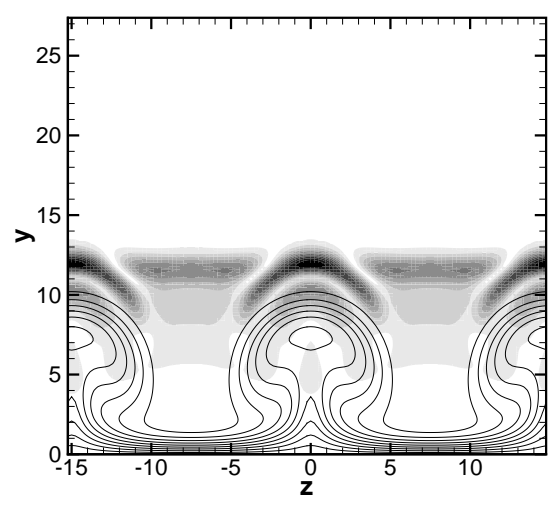

$\mathrm{d}-141,00 \mathrm{~Hz}$

Figura 6.30: Isocontorno da perturbação da velocidade longitudinal não estacionária e as isolinhas do escoamento de Görtler no plano zy em $R e_{x}=1,4 \times 10^{5}$. 

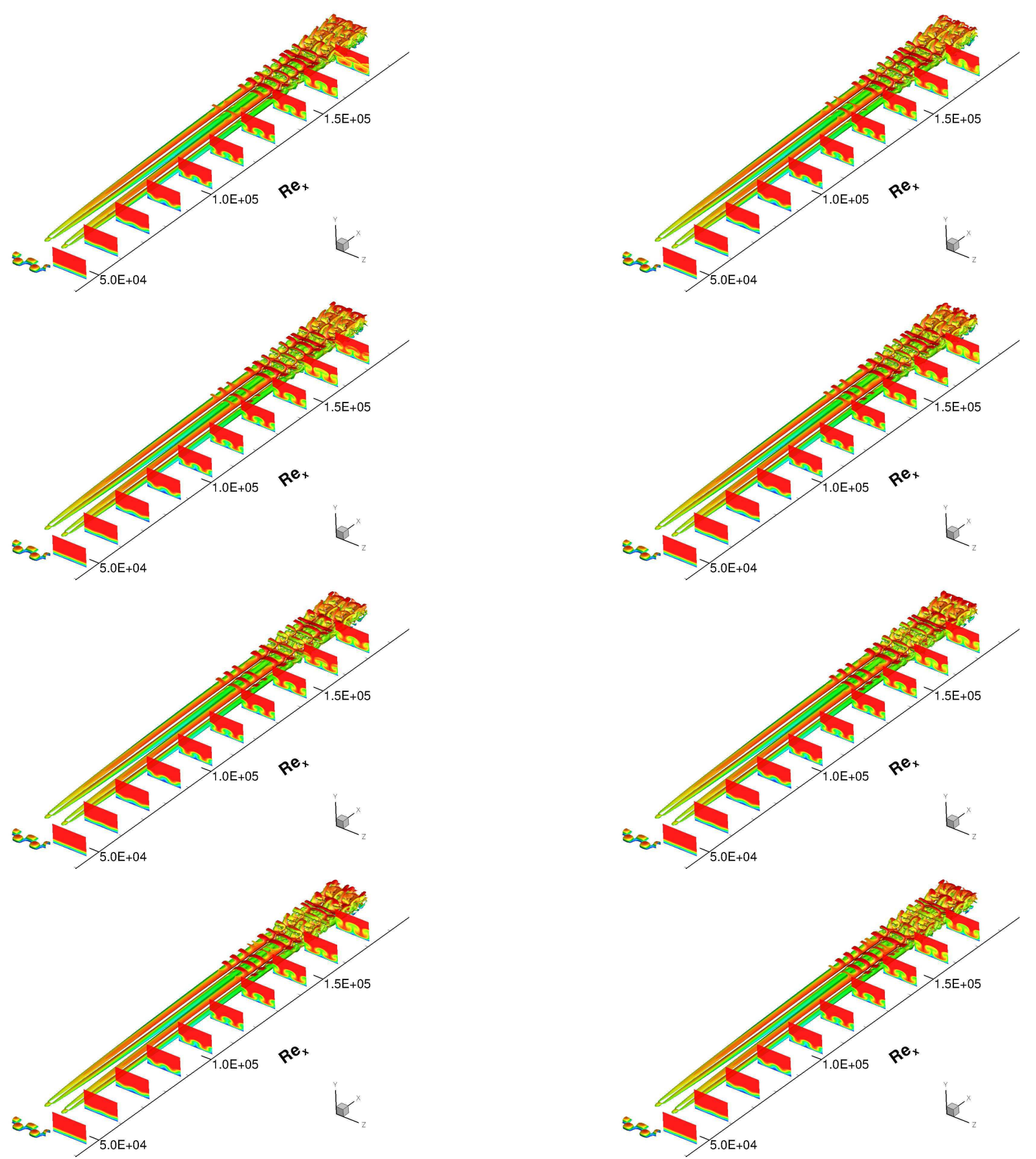

Figura 6.31: Isocontornos obtidos $\operatorname{com} Q=0.5$ colorida pela temperatura $(\theta)$ e a distribuição de temperatura no corte $z \times y$.

\subsubsection{Modo sinuoso}

Na figura 6.34 é mostrado a amplitude máxima da distribuição de velocidade na direção longitudinal para cada cada frequência sobre o plano $(z, y)$. Inicialmente todos os modos são forçados a exibir uma estabilidade até a posição de $R e_{x} \sim 1,25 \times 10^{5}$, depois desta posição todos os modos crescem a partir do mecanismo da instabilidade secundária. As frequências com os maiores valores de taxa de amplificação na região da instabilidade 

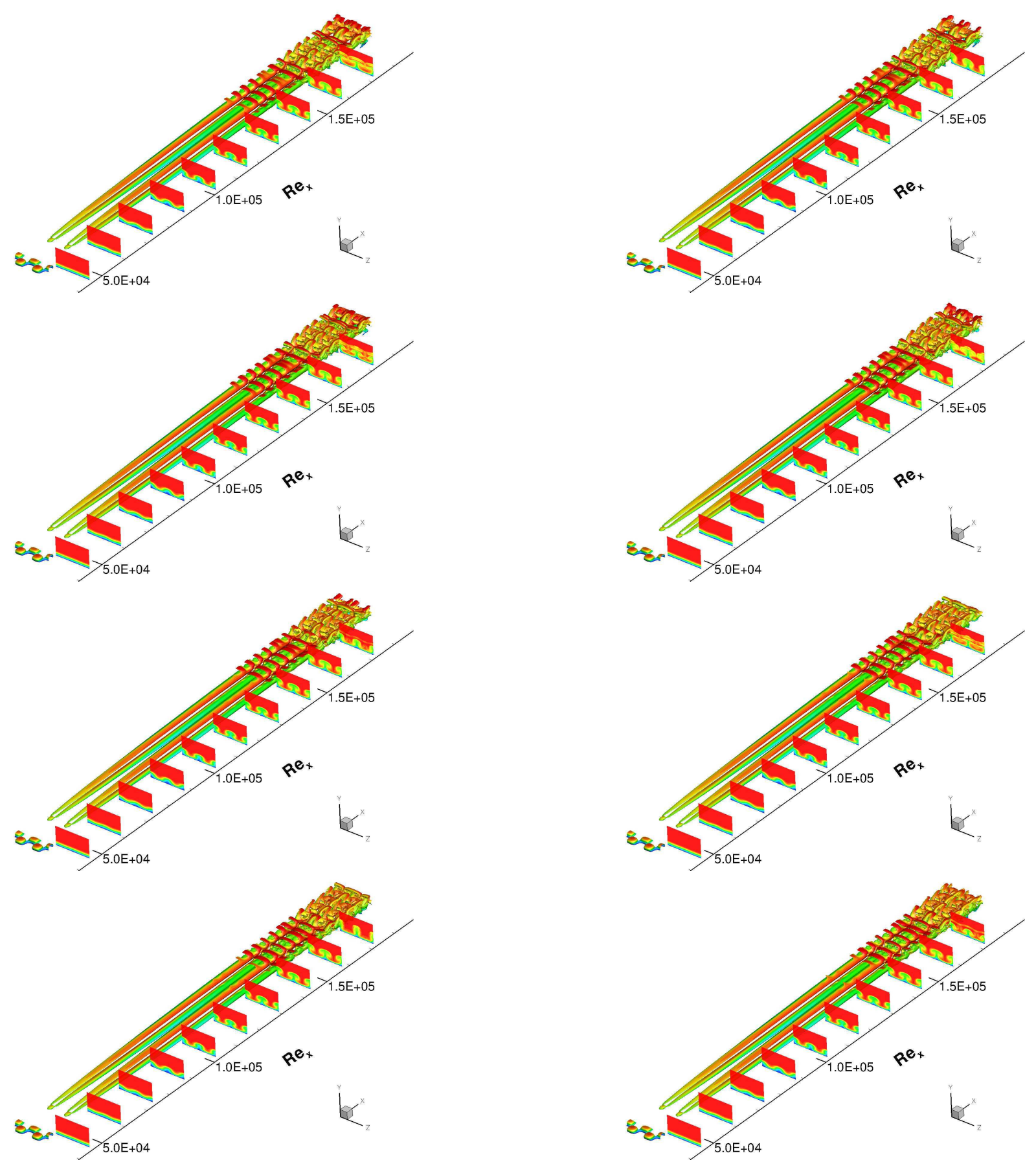

Figura 6.32: Isocontornos obtidos $\operatorname{com} Q=0.5$ colorida pela temperatura $(\theta)$ e a distribuição de temperatura no corte $z \times y$.

secundária são: 18,75 Hz, 130, $25 \mathrm{~Hz}, 141,00 \mathrm{~Hz}$ e 159,75 Hz, estas frequências estão destacadas na figura 6.34 .

Na figura ?? são mostradas os isocontornos das quatro frequências dominantes em planos (z,y), na região da instabilidade secundária 18, $75 \mathrm{~Hz}, 130,25 \mathrm{~Hz}, 141,00 \mathrm{~Hz}$ e $159,75 \mathrm{~Hz}$ para a posição $R e_{x}=1,5 \times 10^{5}$. Na introdução das perturbações não estacionárias em relação as perturbações que geraram os vórtices de Görtler, pode-se perceber que os valores mais elevados das frequências 18, 75; 130.25; 141 e 159, 75 Hz encontra-se 


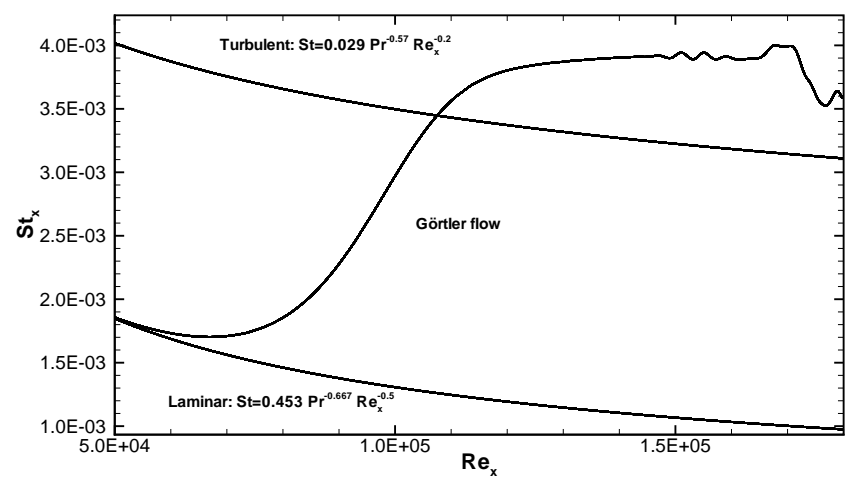

Figura 6.33: Evolução na direção longitudinal da média do número de Stanton na direção transversal.

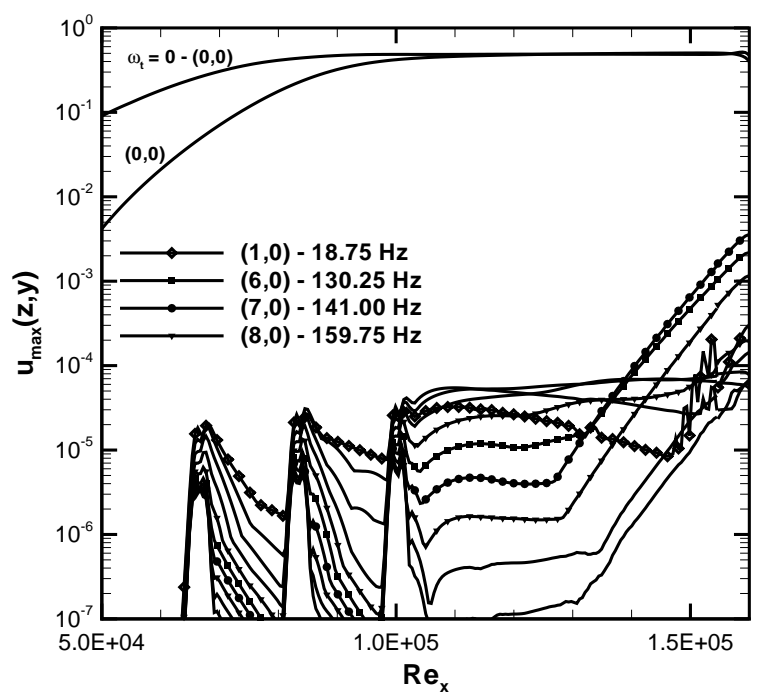

Figura 6.34: Amplitude máxima de cada velocidade $u$ na direção longitudinal para cada frequência sobre o plano $(x, y)$.

na parte superior da região upwash, o que é característico do modo varicoso.

A distribuição de tempeturatura é mostrada nos cortes sobre o plano (z,y) e as estruturas obtidas na simulação são mostradas através dos isocontornos $Q$ mostrados nas figuras 6.36 e 6.37 em oito instantes de tempo diferentes. Observa-se nas figuras 6.36 e 6.37 a formação dos vórtices do tipo ferradura. 


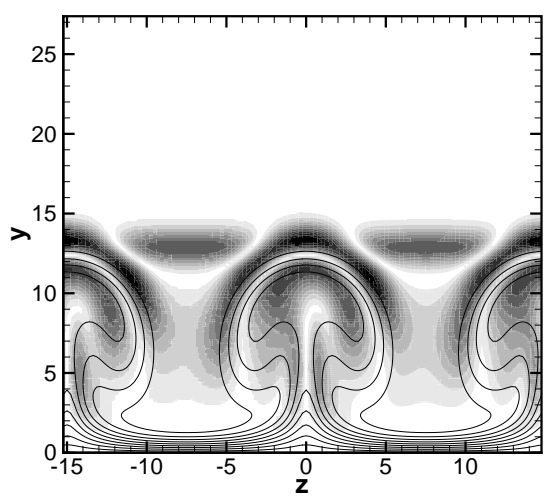

$\mathrm{a}-18,75 \mathrm{~Hz}$

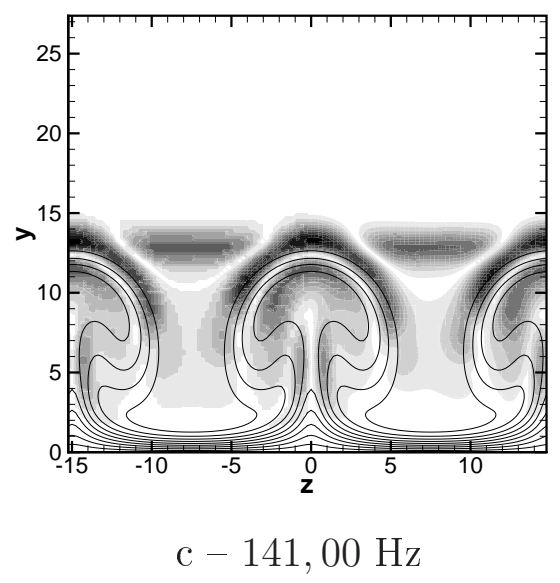

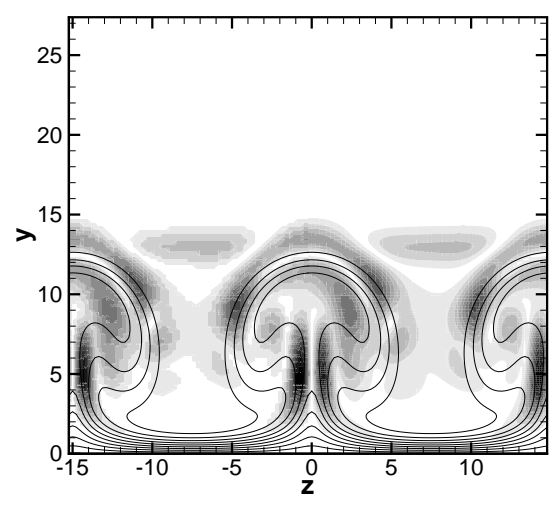

b $-130,25 \mathrm{~Hz}$

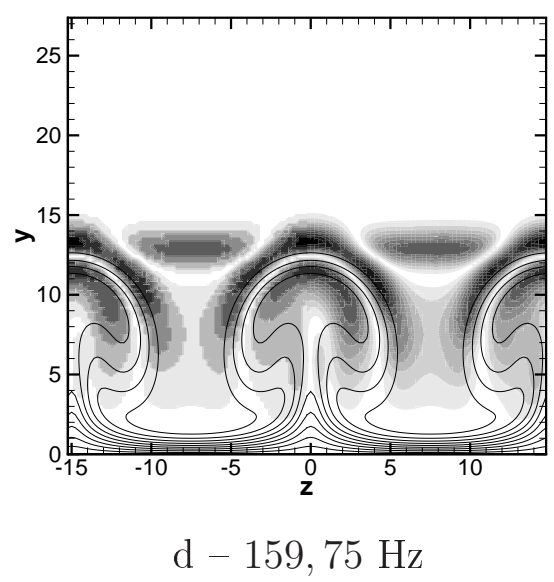

Figura 6.35: Isocontorno da perturbação da velocidade longitudinal não estacionária e as isolinhas do escoamento de Görtler no plano $z y$ em $R e_{x}=1,5 \times 10^{5}$. 

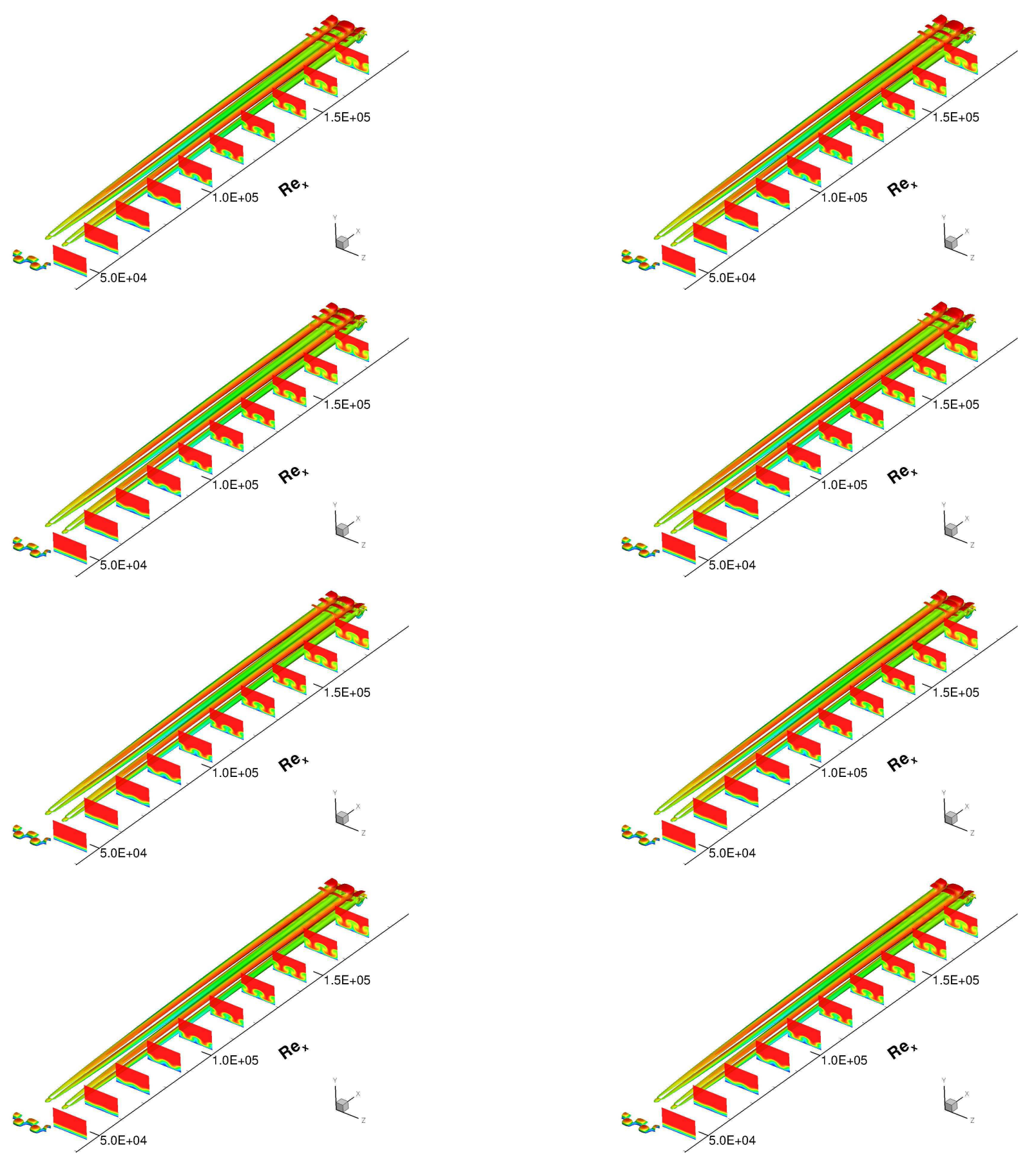

Figura 6.36: Isocontornos obtidos $\operatorname{com} Q=0.5$ colorida pela temperatura $(\theta)$ e a distribuição de temperatura no corte $z \times y$. 

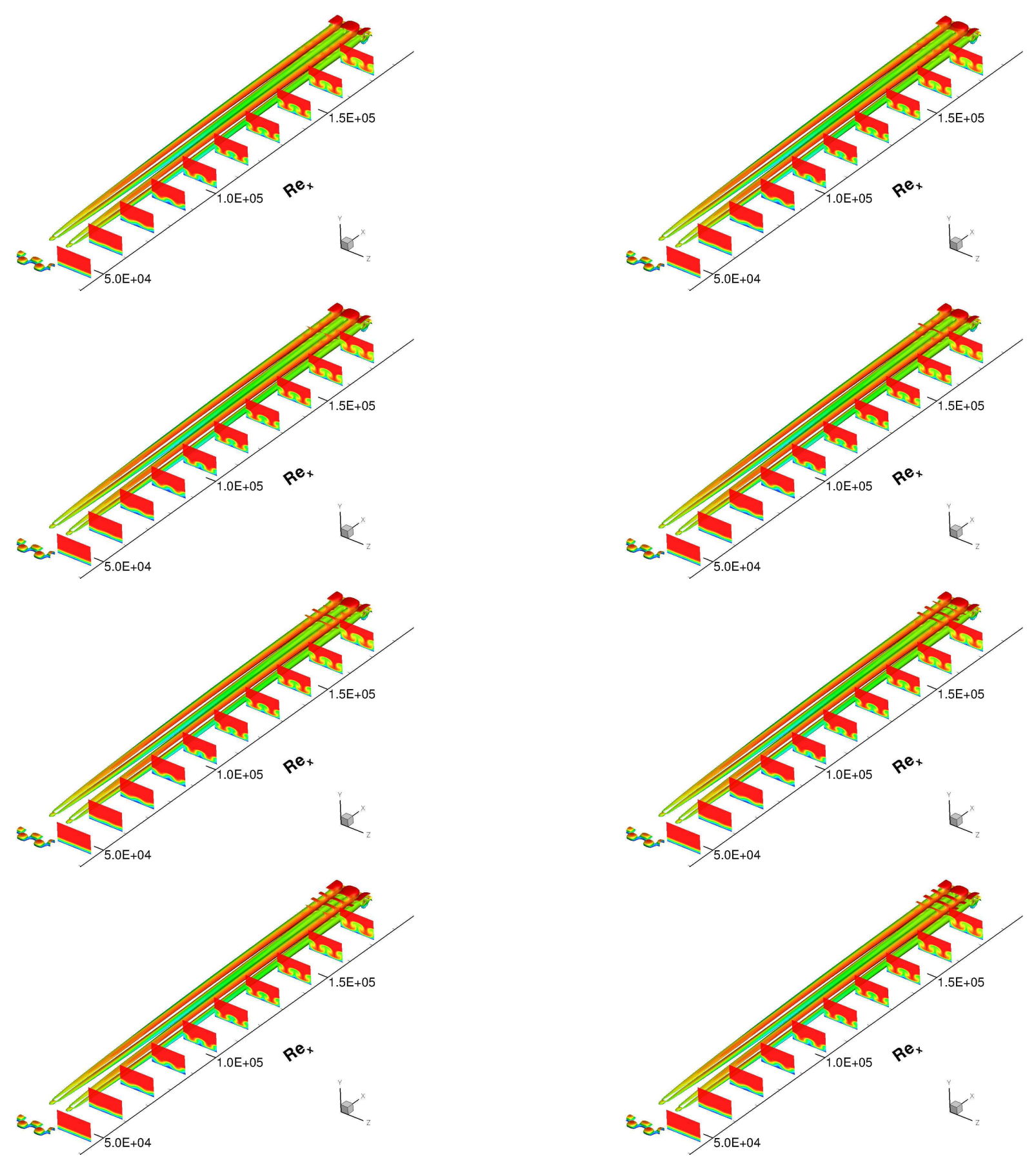

Figura 6.37: Isocontornos obtidos com $Q=0.5$ colorida pela temperatura $(\theta)$ e a distribuição de temperatura no corte $z \times y$. 



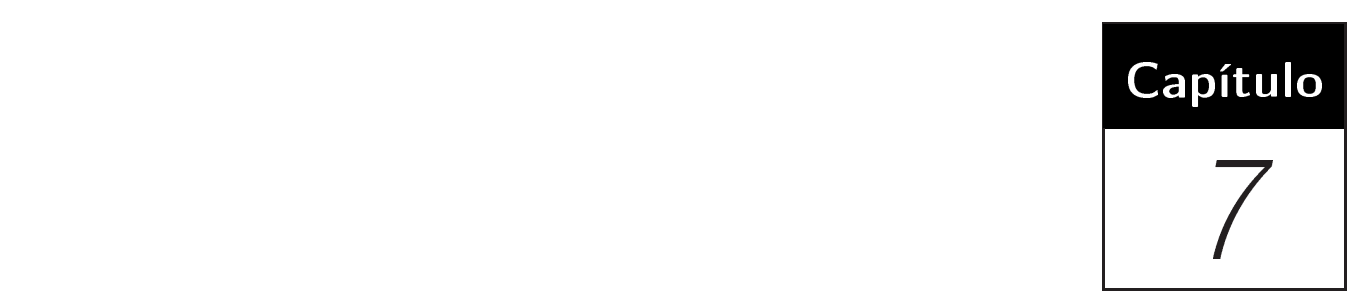

Conclusões e Trabalhos Futuros

O objetivo principal desta tese foi estudar a instabilidade centrífuga que pode ocorrer sobre superfícies côncavas e a intensificação da transferência de calor causada por vórtices longitudinais, conhecidos como os vórtices de Görtler. A investigação deste fenômeno pode levar a um melhor conhecimento do fenômeno de transição do escoamento laminar para o estado turbulento, além de determinar na região de transição, a máxima transferência de calor envolvida, e também pode servir para antecipar ou aumentar esta região para uma maior eficiência da transferência de calor.

Para este propósito, foi verificado e validado um código computacional, de alta ordem de resolução espacial e temporal, que permite o estudo da propagação de instabilidades em camada limite incompressível. O modelo matemático utilizado para estudo de movimento de fluidos é dado pelas equações de Navier-Stokes em coordenadas curvilíneas ortogonais e a formulação perturbação foi adotada para o escoamento ser decomposto em um escoamento base e uma perturbação. Baseado em evidências experimentais, assumiu-se que o escoamento é periódico na direção transversal ao experimento $(z)$.

Primeiramente, foi realizado um estudo da evolução da instabilidade hidrodinâmica; em seguida foi analisado o desenvolvimento linear e não-linear dos vórtices de Görtler e a transferência de calor para três diferentes comprimentos de onda: $\lambda_{z}=0,09,0,18$, e 0,36. A máxima transferência de calor encontrada para este primeiro caso foi para $\lambda_{z}=$ 0,09. Em relação ao escoamento laminar, a intensificação foi $247 \%$ maior, e em relação ao escoamento turbulento foi $14 \%$ menor.

Para a segunda análise foram introduzidos seis diferentes comprimentos de onda: $\lambda_{z}=$ $0,05,0,10,0,15,0,20,0,25$ e 0,30. O único comprimento de onda a não atingir a curva do escoamento turbulento para a intensificação da transferência de calor foi $\lambda_{z}=0,05$, tal fenômeno é devido a taxa de amplificação dos vórtices de Görtler não ter sido suficiente. 
Já a maior intensificação ocorreu para $\lambda=0,10$, onde a taxa de transferência de calor com o escoamento de Görtler foi de $299 \%$ e $45 \%$ maior que o escoamento laminar e turbulento, respectivamente.

Em seguida, foi analisado o desenvolvimento da instabilidade secundária dos modos varicoso e sinuoso, a partir dos vórtices de Görtler e a transferência de calor envolvida para os parâmetros experimentais de Mitsudharmadi et al. [2004, 2005a,b]. O modo varicoso, caracterizado pelo surgimento dos vórtices de ferradura foi verificado, e a transferência de calor para este modo continuou sendo maior, tanto para escoamento laminar, quanto para escoamento turbulento. No final do domínio computacional a transferência de calor diminuiu pelo fato da instabilidade secundária transicionar para o caso turbulento, assim a taxa de transferência de calor cai até a curva turbulenta.

Ao introduzir o modo sinuoso da instabilidade secundária no escoamento, verificou-se, para os parâmetros adotados, que o modo varicoso foi predominante, assim no final do domínio computacional os vórtices do tipo ferradura se amplificaram. Tal fato é devido ao comprimento de onda perturbado, confirmando assim os dados experimentais de Mitsudharmadi et al. [2004, 2005a,b]. Como a amplificação dos vórtices do tipo ferradura foi pequena, não foi relatada a transferência de calor envolvida no fenômeno para este caso.

Como sugestões para estudos futuros ficam:

- Estudo de instabilidade centrífuga em conjunto com perturbações não estacionárias em escoamentos com gradiente de pressão;

- Alteração do programa para inclusão de escoamento base-tridimensional, permitindo estudo de outras instabilidades, como por exemplo o vórtice cruzado;

- Estudo de escoamentos sobre superfícies côncavas com raio de curvatura variável para aplicações em pás de turbinas.

- Utilização dos dados de simulação numérica direta do processo de calibração de modelos para transição;

- Análise de métodos de controle de escoamento para retardar a transição para a turbulência; 
- Alteração do programa para o escoamento compressível para aplicação na engenharia aeronáutica. 



\section{Referências}

Y. Adam. Highly accurate compact methods and boundary conditions. Journal of Computational Physics, 24:10-22, 1977.

A. Benmalek e W. S. Saric. Effects of curvature variation on the nonlinear evolution of goertler vortices. Physics of Fluids, 6:3353-3367, 1994.

R. Bethov e W. O. Criminale. Stability of parallel ows. Academic Press, 1967.

H. Bippes. Experimental study of the laminar-turbulent transition of a concave wall in a parallel flow. Technical Report NASA TM 75243, National Aeronautics and Space Administration - NASA, 1978.

A. Bottaro e B. B. Klingmann. On the linear breakdown of Görtler vortices. European Journal of Mechanics B / Fluids, 15:301-330, 1996.

A. Bottaro e A. Zebib. Görtler vortices promoted by wall roughness. Fluid Dynamics Research, 19:343-362, 1997.

R. J. Briggs. Electron-Stream interaction with plasmas. M.I.T. Press, 1964.

W. Briggs. A Multigrid Tutorial. Lancaster Press, 1987.

S. Chandrasekhar. Hydrodynamic and hydromagnetic stability. Dover Publications, 1961.

M. Clauser e F. Clauser. The effect of curvature on the transition from laminar to turbulent boundary layer. Technical Report NACA TN-613, National Advisory Commitee for Aeronautics - NACA, 1937.

L. Collatz. The Numerical Treatment od Differential Equations. Springer Verlag, 1966.

R. Crane. Boundary layers and transition on concave surfaces. Boundary Layer in Turbomachines, 6, 1991.

P. G. Drazin e W. H. Reid. Hydrodynamic stability. Cambridge, 1981. 
P. A. Eibeck e J. K. Eaton. The effects of longitudinal vortices embedded in a turbulent boundary layer on momentum and thermal transport. Heat Transfer, 3:1115-1120, 1986.

P. A. Eibeck e J. K. Eaton. Heat transfer effects on a longitudinal vortex embedded in a turbulent boundary layer. ASME Journal of Heat Transfer, 33:166-173, 1987.

J. H. Ferziger e M. Peric. Computational methods for fluid dynamics. Springer-Verlag Berlin Heidelberg New York, 1997.

M. Fiebig. Vortices and heat transfer. Zeitschrift für Angewandte Mathematik und Mechanik, 366:2699-2716, 1996.

J. M. Floryan. Stability of Görtler vortices in boundary layers. The American Institute of Aeronautics and Astronautics, 20(3):316-324, 1982.

J. M. Floryan e W. S. Saric. Effects of suction on the Görtler instability of boundary layers. The American Institute of Aeronautics and Astronautics, 21(12):1635-1639, 1983.

I. G. Girgis e J. T. C. Liu. Mixing enhancement via the release of strongly nonlinear longitudinal Görtler vortices and their secondary instabilities into the mixing region. Journal of Fluid Mechanics, 468:29-75, 2002.

I. G. Girgis e J. T. C. Liu. Nonlinear mechanics of wavy instability of steady longitudinal vortices and its effect on skin friction rise in boundary layer flow. Physics of Fluids, 18:024102-1-024102-12, 2006.

H. Görtler. On the three-dimensional instability of laminar boundary layers on concave walls. Technical Report NACA TM-1375, National Advisory Commitee for Aeronautics - NACA, 1940.

Y. Guo e W. H. Finlay. Wavenumber selection and irregularity of spatially developing nonlinear Dean and Görtler vortices. Journal of Fluid Mechanics, 264:1-40, 1994.

M. M. Gupta, J. Kouatchou, e J. Zhang. Comparison of second- and fourth-order discretizations for multigrid poisson solvers. Journal of Computational Physics, 132:226$232,1997$.

R. S. Hirsh. High order accurate difference solutions of fluid mechanics problem by a compact differencing technique. Journal of Computational Physics, 19:90-109, 1975.

H. G. Homero, L. F. Souza, e M. A. F. Medeiros. Verification of a mixed high-ordem accurate dns code for laminar turbulent transition by the method of manufactured solutions. International Journal for Numerical Methods in Fluids, 64:336-354, 2010. 
P. Huerre e P. A. Monkewitz. Local and global instabilities in spatially developing flows. Annual Review of Fluid Mechanics, 22:473-537, 1990.

K. Inagaki e Y. Aihara. An experimental study of transition region of boundary-layer along a concave wall. Europe Journal of Mechanics - B/Fluids, 14:143-168, 1995.

A. Ito. Breakdown structure of longitudinal vortices along a concave wall. Journal of Japan Society for Aeronautical and Space Sciences, 33:166-173, 1985.

P. S. Klebanoff, K. D. Tidstrom, e L. M. Sargent. The three-dimensional nature of boundary layer instability. Journal of Fluid Mechanics, 12:1-34, 1962.

M. Kloker, U. Konzelmann, e H. F. Fasel. Outflow boundary conditions for spatial navierstokes simulations of transition boundary layers. The American Institute of Aeronautics and Astronautics, 31:620-628, 1993.

Z. Kopal. Numerical Analisys. Chapman e Hall, 1961.

V. Kottke. Taylor-Görtler vortices and their effect on heat and mass transfer. In 8th International conference on Heat Transfer, pages 1139-1144, Washington DC, 1986.

L. D. Landau e E. M. Lifshitz. Fluid mechanics. Pergamon, 1987.

K. Lee e J. T. C. Liu. On the growth of the mushroomlike structures in nonlinear spatially developing goertler vortex flow. Physics of Fluids, A4:95-103, 1992.

S. Lele. Compact finite difference schemes with spectral-like resolution. Journal of Computational Physics, 103:16-42, 1992.

F. Li e M. R. Malik. Fundamental and subharmonic secondary instability of Görtler vortices. Journal of Fluid Mechanics, 297:77-100, 1995a.

F. Li and M. R. Malik. Fundamental and subharmonic secondary instability of Görtler vortices. Journal of Fluid Mechanics, 297:77-100, 1995b.

C. C. Lin. The theory of hydrodynamic stability. Cambridge University Press, 1955.

J. T. C. Liu. Nonlinear instability of developing streamwise vortices with applications to boundary layer heat transfer instensification through an extended reynolds analogy. Philolsofical Transactions of the Royal Society, 366:2699-2716, 2008.

J. T. C. Liu e K. Lee. Heat transfer in a strongly spatially developing longitudinal vorticity system. Physics of Fluids, 7:559-599, 1995.

W. Liu e J. A. Domaradzki. Direct numerical simulation of transition to turbulence in Görtler flow. Journal of Fluid Mechanics, 246:267-299, 1993. 
P. MacCormack, H. Welker, e M. Kellerher. Taylor-Görtler vortices and their effect on heat transfer. ASME Journal of Heat Transfer, 92:101-112, 1970.

K. Mahesh. A family of high order finite difference schemes with good spectral resolution. Journal of Computational Physics, 145:332-358, 1998.

V. Malatesta, L. F. Souza, e J. T. C. Liu. Influence of goertler vortices spanwise wavelength on the heat transfer rates. Computational Thermal Sciences, 5:389-400, 2013.

H. L. Meitz. Numerical investigation of suction in a trasitional flat-plate boundary layer. PhD thesis, The University of Arizona, 1996.

H. L. Meitz e H. F. Fasel. A compact-difference scheme for the navier-stokes equations in vorticity-velocity formulation. Journal of Computational Physics, 157:371-403, 2000.

H. Mitsudharmadi, S. H. Winoto, e D. A. Shah. Development of boundary layer flow in the presence of forced wavelength Görtler vortices. Physics of Fluids, 16:3983-3996, 2004.

H. Mitsudharmadi, S. H. Winoto, e D. A. Shah. Splitting and merging of Görtler vortices. Physics of Fluids, 17(12):1-12, 2005a. art. no. 124102.

H. Mitsudharmadi, S. H. Winoto, e D. A. Shah. Secondary instability in forced wavelength Görtler vortices. Physics of Fluids, 17(7):1-8, 2005b.

L. Momayez, P. Dupont, e H. Peerhossaini. Some unexpected effects of wavelenght and perturbations strenght on heat transfer enhancement by Görtler instability. International Journal of Heat and Mass Transfer, 47:3783-3795, 2004a.

L. Momayez, P. Dupont, e H. Peershossaini. Effects of vortex organization on heat transfer enhancement by goertler instability. International Journal of Thermal Sciences, 43: 753-760, 2004b.

L. Momayez, P. Dupont, O. Lottin, e H. Peerhossaini. Genetic algotithm based correlations for heat transfer calculation on concave surfaces. Applied Thermal Engineering, 29:3476-3481, 2009.

W. L. Oberkampf e T. G. Trucano. Verification and validation in computational fluid dynamics. Progress in Aerospace Sciences, 38:209-272, 2002.

W. R. Pauley e J. K. Eaton. An experimental study of the development of longitudinal vortex pairs embedded in a turbulent boundary layer. American Institute of Aeronautics and Astronautics, 87, 1987a. 
W. R. Pauley e J. K. Eaton. Experimental study of the development of longitudinal vortex pairs embedded in a turbulent boundary layer. American Institute of Aeronautics and Astronautics, 87, 1987b.

H. Peerhossaini. L'Instabilite d'une couche limite sur une paroi concave (les tourbilons de Görtler). PhD thesis, Université Pierre et Marie Curie, Paris, 1987.

H. Peerhossaini e J. E. Wesfreid. Experimental study of the Görtler instability. In J. Wesfreid, H. Brand, P. Mannville, G. Albinet, and N. Boccara, editors, Propagation in systems for from equilibrium, pages 399-412. Springer, 1988.

W. H. Press, B. P. Flannery, S. A. Teukolsky, e W. T. Vetterling. Numerical recipes in fortran r\%: the art of scientific computing. Cambridge University Press, 1987.

H. L. Reed, T. S. Haynes, e W. S. Saric. Computational fluid dynamics validation issues in transition modeling. The American Institute of Aeronautics and Astronautics, 36: 742-751, 1998.

P. J. Roache. Quantification of uncertainty in computational fluid dynamics. Annual Review of Fluid Mechanics, 29:123-160, 1997.

A. S. Sabry e J. C. T. Liu. Longitudinal vorticity elements in boundary layers: nonlinear development from initial Görtler vortices as a prototype problem. Journal of Fluid Mechanics, 231:615-663, 1991.

A. S. Sabry, X. Yu, e J. C. T. Liu. Secondary instabilities of three-dimensional infleccional velocity profiles resulting from longitudinal vorticity elements in boundary layers. In The IUTAM 89 Symposium on Laminar-Turbulent Transition, Toulouse, France, 1989.

W. S. Saric. Görtler vortices. Annual Review of Fluid Mechanics, 26:379-409, 1994.

P. J. Schmid e D. S. Henningson. Stability and transition in shear flows. Springer-Verlag, 2001.

L. F. Souza. Instabilidade centrífuga e transição para turbulência em escoamentos laminares sobre superfícies côncavas. PhD thesis, Instituto Tecnológico de Aeronáutica, 2003.

L. F. Souza, M. T. Mendonça, e M. A. F. Medeiros. The advantages of using high-order finite differences schemes in laminar-turbulent transition studies. International Journal for Numerical Methods in Fluids, 48:565-592, 2005.

L. F. Souza, C. M. Oishi, J. A. Cuminato, e A. S. Neto. Comparison of poisson solvers in a transient $2 \mathrm{~d}$ fluid flow problem with dirichlet boundary conditions. In Proceedings of the 11 Brazilian Congress of Thermal Engineering and Sciences, 2006. 
R. M. Spitaleri. Full-fas multigrid grid generation algorithms. Applied Numerical Mathematics, 32:483-494, 2000.

K. Stüben e U. Trottenberg. Nonlinear multigrid methods, the full approximation scheme, chapter 5, pages 58-71. Köln-Porz, 1981.

J. D. Swearingen e R. F. Blackwelder. The growth and breakdown of streamwise vortices in the presence of a wall. Journal of Fluid Mechanics, 182:255-290, 1987.

G. L. Swinney e J. P. Gollub. Hydrodynamic instabilities and the transition to turbulence. Springer-Verlag, 1981.

Tandiono, S. H. Winoto, e D. A. Shah. Visualizing shear stress in Görtler vortex flow. Journal of Visualization, 12(3):195-202, 2009.

R. Toe, A. Ajakh, e H. Peerhossaini. Heat transfer enhancement by Görtler instability. International Journal of Heat and Fluid Flow, 23:194-204, 2002.

K. Torii e J. I. Yanagihara. The effects of longitudinal vortices on heat transfer of laminar boundary layers. The Japan Society of Mechaninal Engineers, 32:395-402, 1989.

K. Torii e J. I. Yanagihara. A review on heat transer enhancement by longitudinal vortices. Journal of the Heat Transfer Society of Japan, 36:73-86, 1997.

J. I. Yanagihara e K. Torii. Enhancement of laminar boudary layer heat transfer by a vortex generator. JSME International Journal, Series 2: Fluids Engineering, Heat Transfer, Power, Combustion, Thermophysical Properties, 35:400-405, 1992.

X. Yu e J. T. C. Liu. The secondary instability in goertler flow. Physics of Fluids, A3: 1845-1847, 1991.

X. Yu e J. T. C. Liu. On the mechanism of sinuous and varicose modes in three-dimensional viscous secondary instability of nonlinear Görtler rolls. Physics of Fluids, 6:736-750, 1994.

D. H. Zhang, S. H. Winoto, e Y. T. Chew. Measurements in laminar and transitional boundary-layer flows on concave surface. International Journal of Heat and Fluid Flow, 16:88-98, 1995.

J. Zhang. Acceleration of five-point red-black gauss-seidel in multigrid for poisson equation. Applied Mathematics and Computation., 80:73-93, 1996.

J. Zhang. Residual scaling techniques in multigrid, i: Equivalence proof. Applied Mathematics and Computation, 80:283-303, 1997. 